UNIVERSIDADE DE BRASÍLIA INSTITUTO DE CIÊNCIAS BIOLÓGICAS DEPARTAMENTO DE BIOLOGIA CELULAR PÓS-GRADUAÇÃO EM BIOLOGIA MOLECULAR

NEUROPROTEÔMICA DE ABELHAS E RATOS PARA DESCOBERTA DE PROTEÍNAS RELACIONADAS À APRENDIZAGEM

Jaques Miranda Ferreira de Souza

Orientador: Marcelo Valle de Sousa

Brasília, 2017 
Jaques Miranda Ferreira de Souza

\title{
NEUROPROTEÔMICA DE ABELHAS E RATOS PARA DESCOBERTA DE PROTEÍNAS RELACIONADAS À APRENDIZAGEM
}

\begin{abstract}
Tese apresentada ao Programa de PósGraduação em Ciências Biológicas Biologia Molecular, do Departamento de Biologia Celular, do Instituto de Ciências Biológicas da Universidade de Brasília como parte dos requisitos para obtenção do título de Doutor em Biologia Molecular.
\end{abstract}

Orientador: Marcelo Valle de Sousa

Brasília, 2017 


\section{Dedicatória}

Aos meus pais, José do Carmo e Marli a quem devo grande parte das minhas conquistas 
"Ver e sentir a vida é preciso, em toda a sua dimensão. É necessário ter paciência e persistência, recursos da esperança que devemos renovar todos os dias."

Lauro Morhy 


\section{AGRADECIMENTOS}

Ao meu orientador Prof. Marcelo, por ter me aceitado no seu grupo de pesquisa. Agradeço o exemplo, a paciência despendida comigo e a oportunidade de crescimento pessoal e profissional.

À todos os professores, colegas e colaboradores do Laboratório de Bioquímica e Química de Proteínas (LBQP), agradeço com carinho a todos pelas trocas de experiência, e pela convivência. Em especial, aos queridos amigos Simone, Marina e Alan por toda ajuda e companheirismo.

À professora Consuelo, agradeço por teu apoio em todos os momentos em que precisei, desde o fornecimento de livros didáticos até as burocracias da minha transferência para o LBQP.

À professora Deisy das Graças de Souza e ao Antônio Maurício Moreno Moreno, sem a colaboração de vocês não teria sido possível o treinamento das abelhas e por consequência, a realização dessa parte do trabalho.

À professora Elenice Seixas Hanna por toda a colaboração e suporte com o treinamento dos ratos.

Ao veterinário do biotério José Jivago e à funcionária Adriana por abrigarem e cuidarem dos nossos ratos.

À minha namorada Aline, agradeço por toda a ajuda e compreensão.

Aos meus pais, Marli e José do Carmo, que jamais mediram esforços para me darem aquilo que jamais alguém conseguirá me roubar: meus estudos! Aos meus irmãos Arthur e Júnior: obrigada por me apoiarem e por acreditarem que um dia eu chegaria lá!

Aos meus familiares e amigos por sempre acreditarem em mim.

A CAPES pela bolsa concedida e ao CNPq, FINEP e FAPDF pelo apoio financeiro. 


\section{APRESENTAÇÃO}

Esta tese está organizada em tópicos, a saber: Introdução, Justificativa Objetivos, Capítulos (1 - referente a análise proteômica quantitativa de ratos submetidos a aprendizagem operante, 2 - referente a proteômica quantitativa de proteínas cerebrais de abelhas submetidas a treinamento operante, Discussão, Conclusões e Bibliografia. Em Anexo, encontra-se manuscrito em processo de revisão no periódico Scientific Reports. A Introdução apresenta o embasamento teórico que nos levou a formular a proposta de trabalho. Os Objetivos - geral e específicos - estão dispostos no corpo da tese e em maiores detalhes inseridos dentro de cada trabalho científico. Os Capítulos contêm materiais e métodos, resultados e discussão e o manuscrito submetido, realizados durante o período do doutorado. $O$ tópico Discussão apresenta uma interpretação geral dos resultados obtidos nos diferentes trabalhos. Nas seções Conclusões há uma abordagem geral das conclusões da tese e a partir dos resultados obtidos na presente tese. As tabelas suplementares deste trabalho poderão ser obtidas mediante pedido via e-mail ao seguinte correio eletrônico: jaquess@unb.br 


\section{RESUMO}

O condicionamento operante é uma forma de aprendizagem associativa, através da qual o indivíduo aprende a antecipar eventos futuros em decorrência das consequências de seus atos. Essa forma de aprendizagem encontra-se compartilhada entre o homem e outros animais. O uso de ratos e abelhas no estudo de aprendizagens associativas têm gerado informações a respeito dos mecanismos moleculares envolvidos nessas aprendizagens. No entanto, existem poucos relatos a respeito de alterações proteômicas envolvidas na aprendizagem por condicionamento operante utilizando modelos biológicos como ratos e abelhas. $O$ presente trabalho teve como objetivo identificar proteínas com abundâncias alteradas em indivíduos treinados no paradigma operante utilizando uma abordagem de cromatografia líquida acoplada a espectrometria de massas. Ratos foram submetidos a sessões de treinamento operante em caixa de Skinner e tiveram seus perfis proteicos hipocampais comparados com os seus controles. Seguindo essa abordagem foi possível identificar 6.082 proteínas das quais 39 apresentaram diferenças de abundância entre os grupos. Tais proteínas estão envolvidas em processos de regulação da organização do citoesqueleto, tráfico de vesículas, transdução de sinais e controle pós-transcricional da expressão gênica. Uma segunda vertente da tese utilizou abelhas da espécie Mellipona quadrifasciata submetidas a aprendizagem por condicionamento operante de pressão a barra. Um total de 3.291 proteínas foram identificadas, até então a maior cobertura para o proteoma cerebral dessa espécie. Conseguimos identificar 850 proteínas com diferença de abundância entre os grupos treinados e controle. 


\begin{abstract}
Operant conditioning is a form of associative learning in which the subject learns to anticipate future events coming as consequence of its behavior. This learning process occurs in humans and other animals. Rats and bees have been used in behavior and learning research for the generation of molecular information related to such processes. However, little proteomic data related to operant conditioning is available. The present thesis aimed at using LC-MS/MS to identify proteins with differential abundance in subjects trained under the operant paradigm. Rats were submitted to operant conditioning in Skinner boxes, followed by analyses of their hippocampal proteomes. A total of 6,082 proteins were identified, from which 39 were differentially abundant between trained and control rats. Such proteins are involved in regulation of cytoskeleton organization, vesicle traffic, signal transduction and gene expression control. A second work in this thesis used Mellipona quadrifasciata bees submitted to operant conditioning for bar pressing learning. A total of 3,291 brain proteins were identified, the widest coverage for this species to date, from which 850 presented differential abundance between trained and control groups. A third work was the determination of 120 proteins from Apis mellifera brain that interact with MRJP1 (major royal jelly protein 1). Many of them are involved in processes related to synaptic plasticity.
\end{abstract}




\section{LISTA DE ABREVIATURAS E SIGLAS}

CID. Collision-induced dissociation, dissociação induzida por colisão.

Da. Dalton.

DDA. Data-dependent acquisition, aquisição dependente de dados.

DTT. Ditioltreitol.

ESI. Electrospray ionization, ionização por eletronebulização.

FDR. False discovery rate, taxa de descoberta de falsos positivos

IAM. lodoacetamida.

HPLC High performance liquid chromatography; cromatografia líquida de alto desempenho.

LC. Liquid chromatography; cromatografia líquida.

LTM. Long-term memory, memória de longa duração.

LTP. Long-term potentiation, potenciação de longa duração.

LTQ. Linear trap quadrupole, armadilha linear de íons.

MS. Mass spectrometry, espectrometria de massas.

MS/MS. Tandem mass spectrometry, espectrometria de massas em tandem.

STM. Short term memomy, memória de curta duração.

SDS. Sodium dodecyl sulfate, dodecil sulfato de sódio.

PSD. Postsynaptic density, densidade pós-sináptica.

SDS-PAGE. Sodium dodecyl sulfate polyacrylamide gel electrophoresis, eletroforese em gel de poliacrilamida com dodecil sulfato de sódio.

TEAB. Bicarbonato de trietilamônio.

TFA. Ácido trifluorácetico. 


\section{LISTA DE FIGURAS}

Figura 1. Rato em uma caixa de condicionamento operante (caixa de Skinner).

Figura 2. Inter-relação das funções biológicas relacionadas à aprendizagem e memória.

Figura 3. Organização neuroanatômica da formação hipocampal em ratos. ....25

Figura 4. Fluxograma de uma abordagem proteômica shotgun/ bottom up.....28

Figura 5. Etapas do treinamento operante discriminativo de ratos. 43

Figura 6. Número de sessões de treinamento por condicionamento operante discriminativo em função do tempo (minutos) de cada sessão.

Figura 7. Número de sessões de treinamento por condicionamento operante discriminativo em função do tempo (minutos) de cada sessão..

Figura 8. Curva de aprendizagem de ratos submetidos a treinamento por condicionamento operante discriminativo em função do índice discriminativo em cada sessão com 50 pressões de barra.

Figura 9. Número de identificação de proteínas de hipocampo de ratos submetidos a treinamento operante discriminativo e seu grupo controle. 47

Figura 10. Classificação das proteínas de hipocampo de rato, com abundância reduzida, de acordo com os processos biológicos.

Figura 11. Classificação das proteínas de hipocampo de rato, com abundância aumentada, de acordo com os processos biológicos. 56

Figura 12. Classificação das proteínas de hipocampo de rato, com abundância reduzida, de acordo com a função molecular.

Figura 13. Classificação das proteínas de hipocampo de rato, com abundância aumentada, de acordo com a função molecular. .58

Figura 14. Classificação das proteínas de hipocampo de rato, com abundância reduzida, de acordo com o componente celular. 59

Figura 15. Classificação das proteínas de hipocampo de rato, com abundância aumentada, de acordo com o componente celular.

Figura 16. Via de regulação do citoesqueleto de actina.

Figura 17 Via de fagocitose mediada por receptor Fc gama.

Figura 18. Via de sinalização de cAMP.

Figura 19. Representação esquemática do cérebro de uma abelha operária....77 
Figura 20. Caixa de condicionamento operante para abelhas.

Figura 21. Diferentes etapas de modelagem de resposta instrumental (operante) com abelhas.

Figura 22. Número de proteínas cerebrais de abelhas $M$. quadrifasciata identificadas por cromatografia líquida acoplada a espectrometria de massas. 


\section{LISTA DE TABELAS}

Tabela 1. Proteínas de hipocampo de ratos submetidos ao treinamento operante discriminativo com abundância diminuída em relação ao grupo controle.

Tabela 2. Proteínas de hipocampo de ratos submetidos ao treinamento operante discriminativo com abundância aumentada em relação ao grupo controle. 51

Tabela 3. Tabela de vias KEGG enriquecidas. .65

Tabela 4. Proteínas com abundância reduzida nas abelhas treinadas e diferentes entre os três grupos analisados. .89

Tabela 5. Lista de proteínas com aumento de abundância entre abelhas do grupo E224 e que apresentaram menores níveis em abelhas do grupo E2-8. 90 Tabela 6. Lista de proteínas que tiveram maiores níveis de abundância em abelhas do grupo E2-8 e uma diminuição de abundância em abelhas do grupo E2-24. 


\section{SÚMARIO}

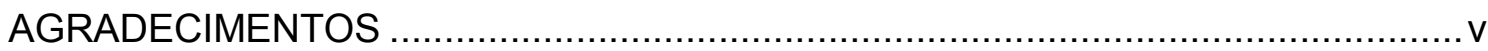

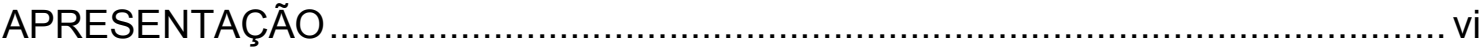

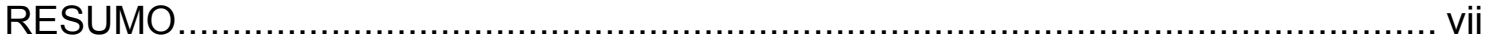

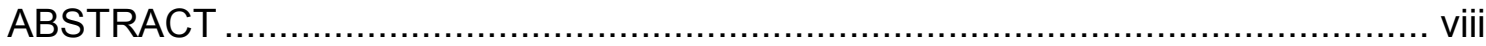

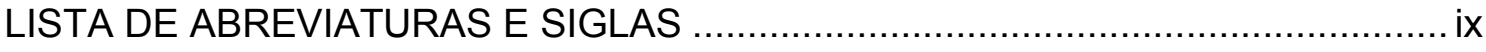

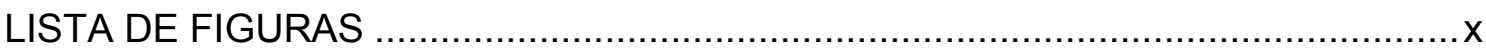

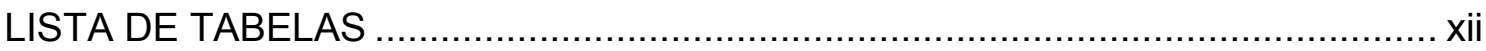

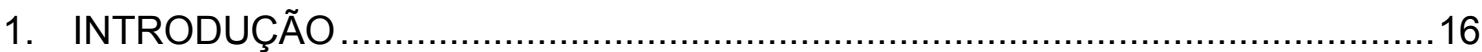

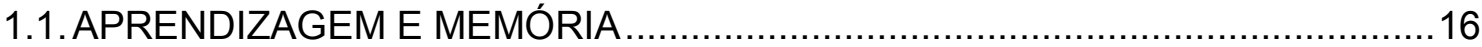

1.1.1. Aprendizagem por condicionamento clássico ........................................17

1.1.2. Aprendizagem por condicionamento operante ....................................17

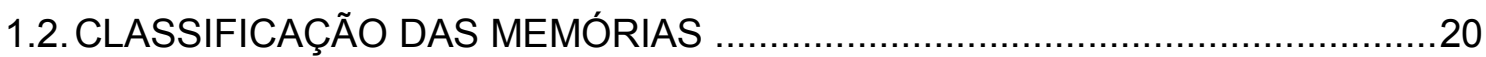

1.3. MECANISMOS ENVOLVIDOS NO ARMAZENAMENTO E CONSOLIDAÇÃO

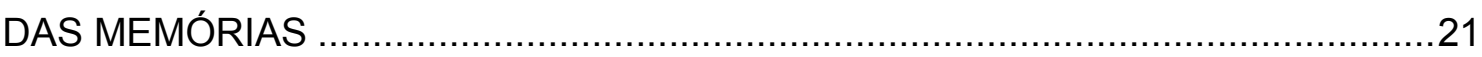

1.4.ESTRUTURAS ENCEFÁLICAS RELACIONADAS À APRENDIZAGEM E

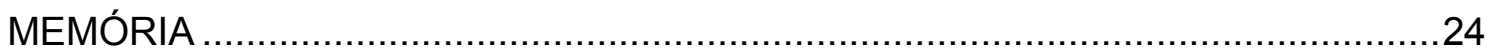

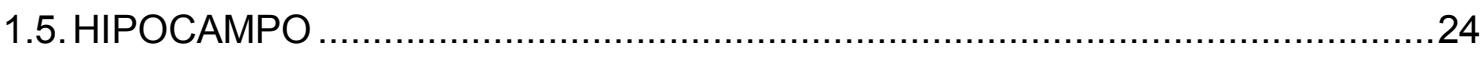

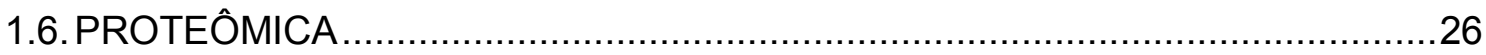

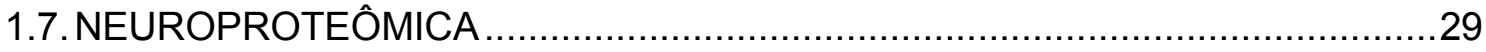

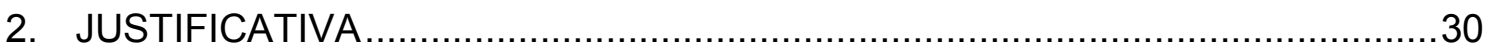

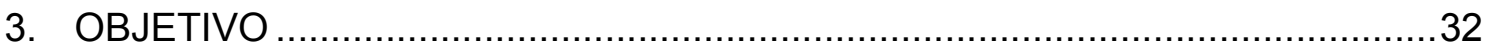

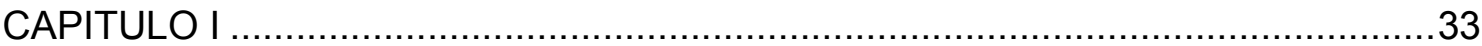

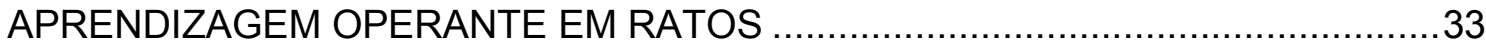

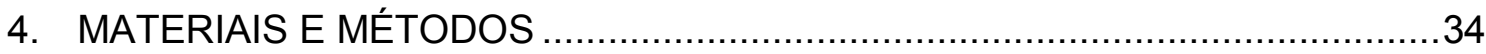

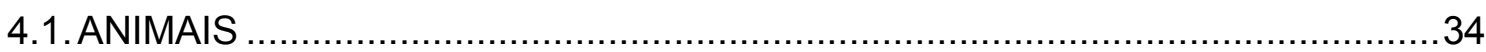

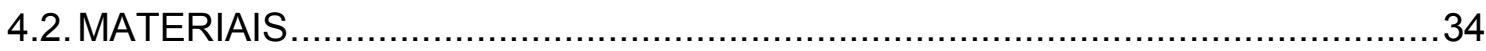




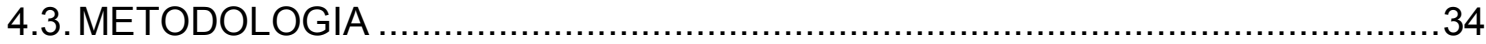

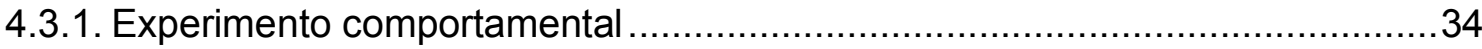

4.3.2. Habituação à caixa de condicionamento operante ……………………….......35

4.3.3. Modelagem de pressão à barra e esquema de reforço contínuo (CRF) ...........35

4.3.4. Treinamento Operante Discriminativo …………….......................................

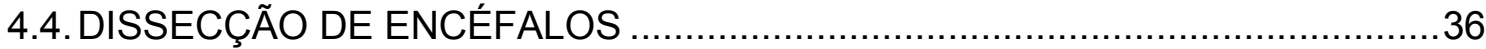

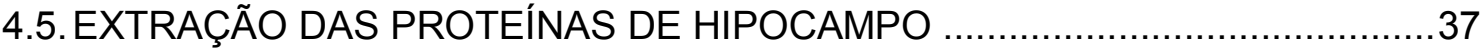

4.6. DIGESTÃO TRÍPTICA DE PROTEÍNAS DO HIPOCAMPO DE RATOS .............37

4.7. CROMATOGRAFIA LÍQUIDA ACOPLADA À ESPECTROMETRIA DE MASSAS

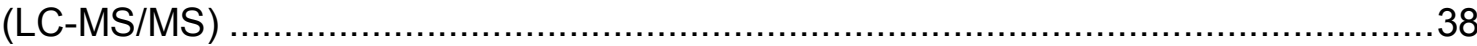

4.8. IDENTIFICAÇÃO DE PROTEÍNAS DE HIPOCAMPO DE RATOS .....................40

4.9. QUANTIFICAÇÃO LABEL-FREE DE PROTEÍNAS ….......................................

4.10. CLASSIFICAÇÃO POR ONTOLOGIA GÊNICA. .......................................41

4.11. ANOTAÇÃO DAS PROTEÍNAS EM VIAS METABÓLICAS ............................41

4.12. ANÁLISE DE ENRIQUECIMENTO DE VIAS E TERMOS GO …....................42

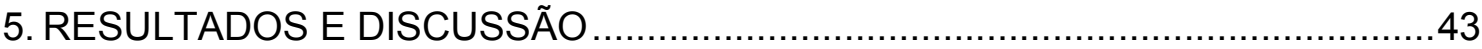

5.1. EXPERIMENTOS DE APRENDIZAGEM OPERANTE DISCRIMINATIVA .........43

5.2. PROTEOMA DO HIPOCAMPO DE RATOS E ANÁLISE DIFERENCIAL ...........47

5.3. ANÁLISE DE PROTEÍNAS COM DIFERENÇA NO PERFIL DE ABUNDÂNCIA 47

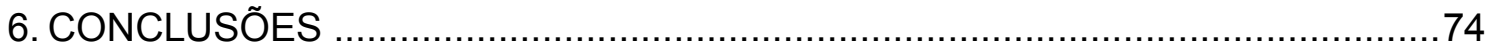

CAPITULO II - APRENDIZAGEM OPERANTE EM ABELHAS ...............................75

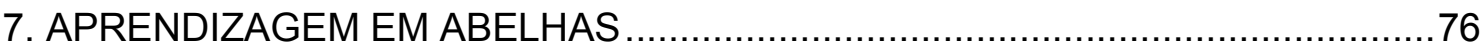

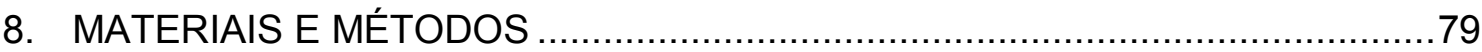

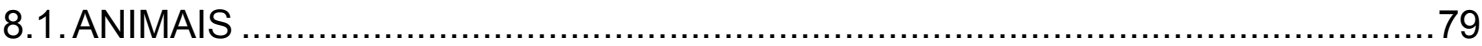

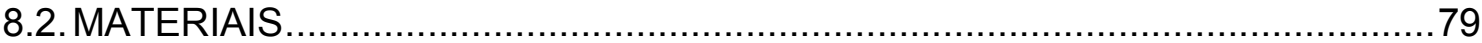

8.2.1. Caixa de condicionamento operante para abelhas ........................................79

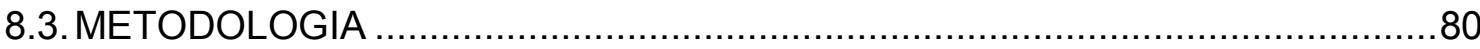




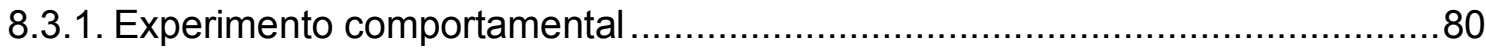

8.3.2. Identificação do sujeito e modelagem de pouso sobre a caixa.........................81

8.3.3. Modelagem da resposta de pressão à barra ………..................................... 81

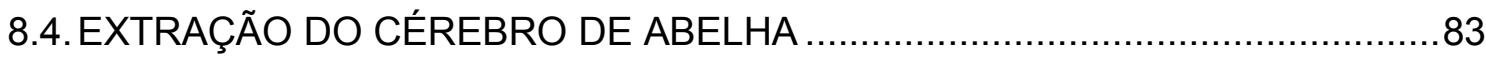

8.5. DIGESTÃO DE PROTEÍNAS E ANÁLISE VIA LC MS/MS …...........................83

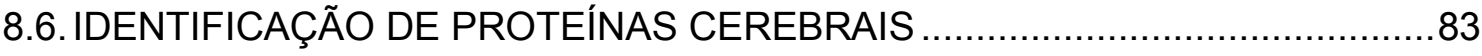

8.7. ANÁLISE DE PROTEÍNAS COM DIFERENÇA NO PERFIL DE ABUNDÂNCIA 84

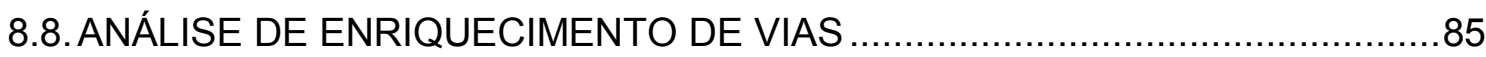

8.9. ANÁLISE DOS CLUSTERS DOS PADRÕES DE ABUNDÂNCIAS ....................85

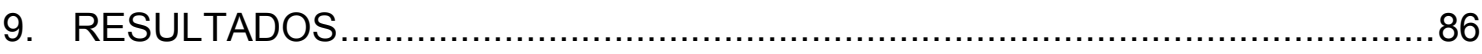

9.1. PROTEOMA CEREBRAL DE Melipona quadrifasciata. .................................. 86

9.2. ANÁLISE DE PROTEÍNAS COM DIFERENÇA NO PERFIL DE ABUNDÂNCIA 87

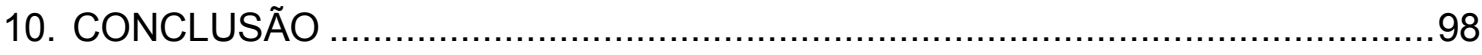

CAPÍTULO III - ANÁLISE DO INTERATOMA ENTRE MRJP1 E PROTEÍNAS

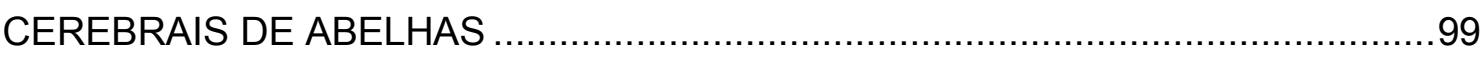

11. CONCLUSÃO GERAL DA TESE E PERSPECTIVAS ….............................126

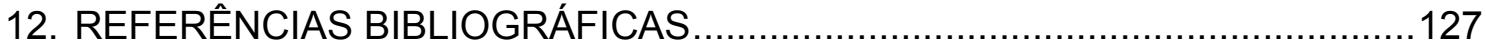




\section{INTRODUÇÃO}

Os elementos envolvidos nos processos de aprendizagem e memória são alguns dos mistérios envolvidos no funcionamento do cérebro que inquietam a humanidade há séculos. A construção de memórias, uma das principais funções do cérebro, é um processo de extrema importância, que possibilita o organismo a se adaptar e responder de forma mais eficiente a eventos similares que possam ocorrer no futuro (Reul, 2009). Com isso, a busca por elucidar tais mecanismos e seus desdobramentos constitui um grande desafio que abrange diversas áreas, como a psicologia, a neurobiologia e a ecologia comportamental.

\subsection{APRENDIZAGEM E MEMÓRIA}

De acordo com Squire (2004), a aprendizagem e a memória são processos intimamente relacionados. A aprendizagem pode ser definida como todo processo de aquisição de novas informações, resultante da interação do indivíduo com o meio ou de representações internas, que possibilitam a aquisição de novas informações/ habilidades que se manifestam como um novo comportamento ou a modificação de um comportamento pré-existente, enquanto memória é a capacidade geral para adquirir, formar, conservar e evocar informações adquiridas através das experiências (Izquierdo, Ivan, 2011).

No processamento da memória estão envolvidos os seguintes estágios: aquisição, consolidação e evocação. A aquisição da memória refere-se à aprendizagem, à codificação de uma informação após uma experiência. A evocação de uma memória, também definida como recuperação, pode ser resumida a uma lembrança de uma experiência que pode ser mensurada por intermédio de uma adaptação comportamental. Entre a aquisição e a evocação de memórias está a consolidação, fase de estabelecimento da memória de longa duração, que pode ocorrer em dias, semanas ou anos após a sua aquisição (Estevez e Abel, 2011). Tratase de um processo complexo e lento envolvendo diversas etapas, que convertem traços de memórias ainda lábeis em formas mais estáveis e fortalecidas (Dudai, 2004). 
No presente trabalho, serão abordados dois tipos de aprendizagem associativa: o condicionamento clássico e o condicionamento operante, ambos dependentes do hipocampo (Andersen 2007). Estes processos retratam as duas principais formas de aprendizagem associativa e são exibidas por todos os animais, inclusive pelos humanos (Jeanne, Sharpee et al. 2013).

\subsubsection{Aprendizagem por condicionamento clássico}

O condicionamento clássico foi um termo concebido por Ivan Pavlov (18491936), através da realização de experimentos comportamentais com cães. Ele observou que os animais associavam alguns estímulos neutros aleatório (NS) a um estímulo incondicionado (US). Nessas condições, após o emparelhamento dos estímulos o estímulo neutro, que antes não gerava nenhuma resposta, passou a eliciar a mesma resposta que o estímulo incondicionado. Com o isso o estímulo neutro passou a retratar um estímulo condicionado. Como por exemplo, ao apresentar um alimento (US) para um cão, o mesmo apresentava a resposta de salivar. Ao tocar um sino (NS), o animal não apresentava nenhuma resposta fisiológica, mas ao se parear o sino com a apresentação do alimento, o animal passava a associar o som do sino com a comida, a ponto de eliciar a resposta de salivação mesmo quando apenas o som do sino é apresentado (Millenson 1975, Clark, Manns et al. 2002).

\subsubsection{Aprendizagem por condicionamento operante}

Diversas memórias são adquiridas por meio da associação de um estímulo particular a outro ou a uma resposta. Em resposta a esse estímulo, o organismo se modifica e exibe esta modificação através de uma mudança no seu comportamento (Izquierdo, 2011).

O condicionamento operante envolve a associação entre um comportamento e sua consequência, sendo a aprendizagem baseada nas consequências de suas ações (Lorenzetti et al., 2008). Denomina-se condicionamento operante quando um organismo age com a finalidade de produzir uma alteração no meio em que se encontra. 
O pesquisador Edward Thorndike (1874-1949) foi o primeiro a estudar o condicionamento operante. Ele avaliou o comportamento de gatos com a utilização de caixas do tipo puzzles box, estruturas contendo uma abertura para a saída do animal, que era mediada pela pressão de uma barra fixada dentro da caixa. Thorndike constatou que os animais passaram a conseguir sair cada vez mais rápido, conforme eram colocados na caixa, inferindo assim, que eles aprenderam.

Com base nessas observações, Thorndike concluiu que os comportamentos são alterados pelas consequências dos mesmos, postulando então o conceito da "lei de efeito". De acordo com esse postulado as respostas que produzem um efeito satisfatório são reforçadas no sujeito e aumentam a sua probabilidade de ocorrer novamente em uma dada situação, enquanto que respostas que produzem desconforto, como uma punição, tornam-se menos prováveis de ocorrerem novamente na mesma situação. Em 1938, Skinner reformulou alguns conceitos desenvolvidos por Thorndike, substituindo os termos "satisfatório" e "desconforto" para o indivíduo pelos termos "reforço" e "punição" respectivamente, além de cunhar o termo comportamento operante (Jozefowiez e Staddon, 2008).

Skinner realizou alguns estudos com ratos e pombos, e seu método experimental acabou se tornando uma referência para outros pesquisadores. Em seus experimentos, animais eram privados de comida ou água e eram submetidos a um treinamento dentro de uma caixa para realizar à pressão de uma barra para receber o reforço. Toda vez que o animal emitia uma resposta desejada pelo experimentador ele recebia o reforço (Figura 1). 


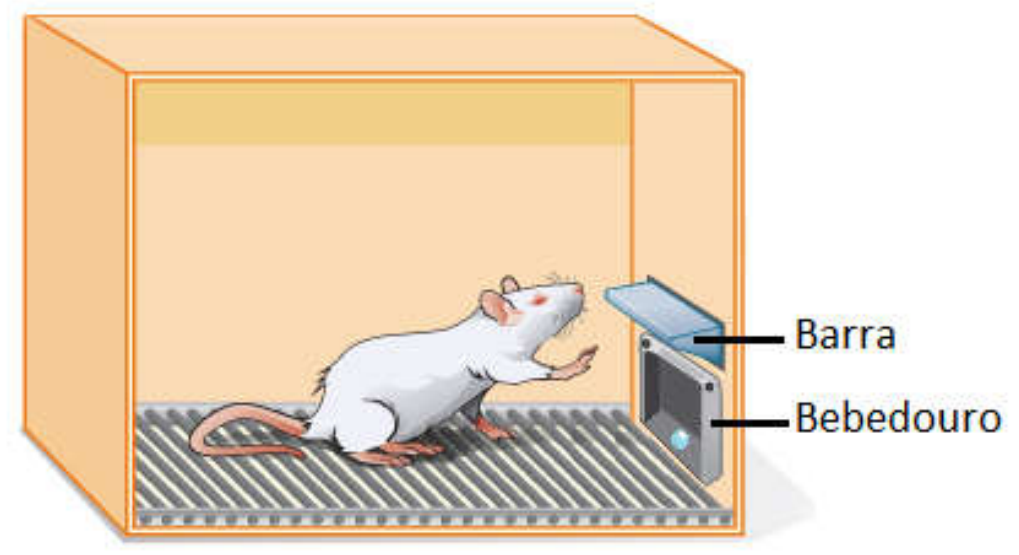

Figura 1. Rato em uma caixa de condicionamento operante (caixa de Skinner). Nesse aparato, ao pressionar uma barra o animal recebe um reforço, que pode ser água ou comida (Modificado de https://courses.lumenlearning.com).

Dessa forma, o condicionamento operante explica como as consequências levam à mudanças no comportamento voluntário. Assim, existem dois componentes básicos no condicionamento operante: os reforços, que tornam um comportamento mais provável e a punição, que tornaria menos provável a frequência de um determinado comportamento Os reforços ainda podem ser divididos em duas categorias: reforços positivos, por meio da apresentação de uma recompensa, e reforços negativos, que funcionam a partir da remoção de uma consequência indesejada.

Assim, as respostas que produzem reforços, por exemplo, alimentos, são reforçadas e passam a ocorrer com maior frequência em relação aquelas que não apresentam nenhum efeito, ao passo que respostas que provocam alguma punição do sujeito tendem a diminuir a sua frequência (Swiergiel et al., 2007).

Alguns estudos, com abordagem neurobiológica, realizados com roedores sujeitos ao paradigma de condicionamento operante apresentam aumento hipocampal nos níveis de expressão de determinados mRNAs, como por exemplo, BDNF, CREB, Synapsin I, CamKII, Arc, c-Jun e c-Fos (Gomez-Pinilla et al., 2007; Rapanelli et al., 2009; Rapanelli, M. et al., 2010). A exposição à tarefa induziu a neurogênese e a gliogênese, além de promover a sobrevivência e a maturação dessas novas células no hipocampo e no córtex medial pré-frontal (Rapanelli et al., 2011). 
Com base no exposto, sabe-se que a síntese proteica e as alterações no conjunto de proteínas envolvidas na plasticidade sináptica estão intimamente relacionadas ao processo de formação de memória de longa duração. Mais precisamente, a análise do condicionamento operante parece apresentar um conjunto de sinalizações específicas, ainda não totalmente elucidadas, que parecem acarretar no comportamento exibido pelo animal.

\subsection{CLASSIFICAÇÃO DAS MEMÓRIAS}

De acordo com Squire (2004), as memórias não são faculdades unitárias da mente, sendo compostas de múltiplos sistemas com diferentes princípios de funcionamento e distintas neuroanatomias. Didaticamente, as memórias podem ser classificadas de acordo com o tempo de duração e com o seu conteúdo (Izquierdo, Ivan, 2011; Quillfeldt, 2016).

Com base no conteúdo, as memórias podem ser classificadas em dois grupos, conforme a natureza do mesmo: implícitas (não declarativas) e explícitas (declarativas). As memórias implícitas são relacionadas às habilidades perceptuais e motoras, também conhecidas como memórias do "saber como". Nos vertebrados, essas memórias encontram-se associadas à regiões encefálicas do cerebelo, corpo estriado e amígdalas (Squire, 1992; Quillfeldt et al., 1996). As memórias explícitas são relacionadas a fatos, eventos, lugares e objetos, também conhecidas como memórias do "saber que" e estão associadas à região do hipocampo e o córtex adjacente (Kandel et al., 2014). Segundo Dudai (2004), os mecanismos que suportam esses tipos de sistemas de memórias parecem estar parcialmente dissociados, mas é importante ressaltar que eles podem interagir.

Em relação ao tempo que duram, as memórias podem ser classificadas em: memória de curta duração (STM - do inglês Short Term Memory), memória de longa duração (LTM - do inglês Long Term Memory) e memória remota.

As STM podem durar alguns minutos ou horas (tipicamente entre $1 \mathrm{e} 6 \mathrm{~h}$ ), sendo as modificações pós-traducionais um forte componente envolvido na sua formação; por sua vez, as LTM podem durar dias ou meses e envolvem um intenso processo de síntese proteica (Barron et al.; Krug et al., 1984; Montarolo et al., 1986; Frey et al., 
1988; Malenka e Nicoll, 1999; Abel e Lattal, 2001; Reymann e Frey, 2007). EM virtude dessa dependência de síntese de novas proteínas, a LTM não fica estabelecida em sua forma estável ou permanente imediatamente depois da aquisição, sendo lábeis e suscetíveis a numerosos agentes externos e internos (Lechner et al., 1999; Mcgaugh, 2000). É importante ressaltar que a STM não é uma fase inicial da memória como um todo; tanto a STM quanto a LTM requerem as mesmas estruturas nervosas, mas envolvem mecanismos próprios e distintos (Alonso et al., 2002). Por último, as memórias remotas são aquelas que sobrevivem por anos ou décadas e são responsáveis por fazer o ser humano na fase adulta lembrar-se de momentos da infância (Rossato et al., 2009; Izquierdo, Ivan, 2011).

\subsection{MECANISMOS ENVOLVIDOS NO ARMAZENAMENTO E CONSOLIDAÇÃO DAS MEMÓRIAS}

Antigamente, acreditava-se que as memórias eram armazenadas nas conexões sinápticas, hipótese levantada pelo neurocientista Santiago Ramo y Cajal em 1894. Cajal imaginava que as memórias eram armazenadas através de mudanças anatômicas na força entre as conexões sinápticas. Com o passar do tempo, essa hipótese foi sendo reformulada e, em 1948, Konorski introduziu o conceito de plasticidade sináptica, como sendo a habilidade dos neurônios de modular a força das conexões sinápticas como resultado da atividade intensa dos neurônios (Kandel et al., 2014). No ano seguinte, Donald Hebb propôs que mudanças na conectividade entre os neurônios mediava a aquisição de novas mudanças comportamentais: "Quando um axônio de uma célula $A$ está próximo o suficiente de excitar uma célula $B$ e repetidamente ou persistentemente participa da ativação desta, algum processo de crescimento ou mudança metabólica ocorre em uma ou ambas as células, de tal forma que a eficiência de A ativar B é aumentada".(Hebb, 1949 in Sweatt, 2016).

A plasticidade sináptica é o processo biológico pelo qual padrões específicos de atividade sináptica, tanto no terminal pré- quanto pós-sináptico, resultam em mudanças na força entre as sinapses. Isso inclui tanto o fortalecimento das sinapses já existentes através do aumento persistente da resposta de neurônios à breve estimulação repetitiva de um axônio ou conjunto de axônios que fazem sinapses com elas, processo conhecido como potenciação de longa duração (LTP); o 
enfraquecimento de algumas sinapses existentes, conhecido como depressão de longa duração (LTD), a formação de novas sinapses (sinaptogênese), modulação da excitabilidade intrínseca do neurônio e neurogênese em adultos (Giese e Mizuno, 2013) (Figura 2).

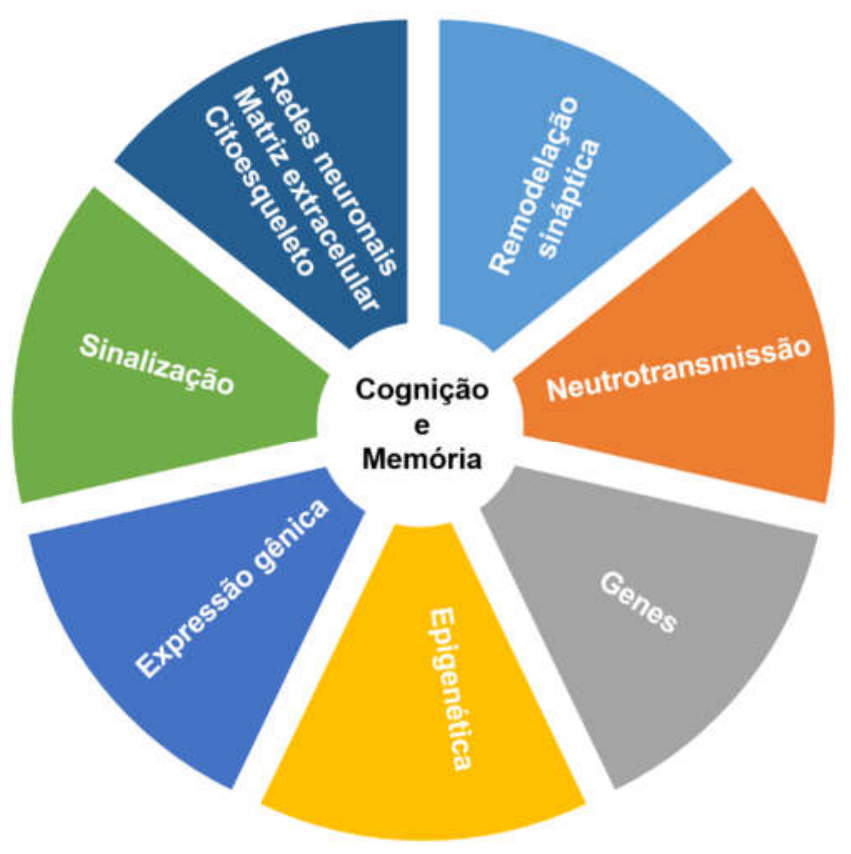

Figura 2. Inter-relação das funções biológicas relacionadas à aprendizagem e memória. Adaptado de Khan et al (2014).

Com relação aos mecanismos de formação da memória de longa duração no hipocampo, os processos metabólicos ativados na consolidação da memória são essencialmente os mesmos descritos para a LTP na região CA1 (Ardenghi et al., 1997; Izquierdo et al., 2006; Whitlock et al., 2006). Um dos componentes moleculares mais estudados no processo de consolidação da memória é a estimulação repetida de receptores glutamatérgicos NMDA, AMPA e metabotrópicos com concomitante ativação de receptores colinérgicos muscarínicos e noradrenérgicos do tipo $\beta$. $O$ influxo de cálcio pelo receptor NMDA modula sinalizações intracelulares que têm como resultado a ativação de proteínas cinases, como a proteína cinase dependente de GMPc (PKG) que ativa, por sua vez, a óxido nítrico sintase (produzindo óxido nítrico), a heme oxigenase (produzindo monóxido de carbono) e a enzima PAF acetilhidrolase que produz o fator de ativação plaquetário (PAF) (Ota et al., 2010). O óxido 
nítrico, o monóxido de carbono e o PAF retornam para o terminal pré-sináptico aumentando a eficiência da sinapse. O aumento do cálcio intracelular estimula direta ou indiretamente uma série de outras cinases como a proteína cinase dependente de cálcio (PKC) (Abel et al., 1997; Rosenegger e Lukowiak, 2010), proteína cinase dependente de AMPc (PKA) (Abel et al., 1997; Locatelli e Romano, 2005), proteína cinase dependente de cálcio/calmodulina (CaMKI, II, III e IV) (Wayman et al., 2011) e as proteínas cinases ativáveis extracelularmente (ERKs) (Schafe et al., 2000; Szapiro et al., 2003). Essas proteínas, entretanto, participam em momentos diferentes no processo de aquisição e consolidação da memória. Enquanto a via de sinalização ativada pela ERK parece atuar 3h ou mais depois da aquisição da informação, a PKA possui 2 picos distintos de intervenção. Nos primeiros minutos após a aquisição, o pico de atividade da PKA ocorre simultaneamente ao aumento do fator de transcrição nuclear CREB (do inglês cAMP response element-binding protein). Uma vez ativado, o CREB estimula a produção de moléculas de RNAs mensageiros favorecendo a síntese proteica, especialmente das proteínas de adesão celular que migram para os locais de sinapses da célula, alterando a sua superfície e, portanto, a sua função. Em um segundo pico, entre 2 e $6 \mathrm{~h}$ após a aquisição, a atividade da PKA passa a ser regulada pelos receptores dopaminérgicos tipo D1/D5 e noradrenérgicos do tipo $\beta$, que estimulam indiretamente a atividade da cinase, enquanto que receptores serotoninérgicos tipo IA a inibem, causando uma facilitação ou depressão da consolidação da memória, respectivamente (Kandel et al., 2000).

A cascata de sinalização iniciada pela sinapse glutamatérgica é seguida de uma sequência de eventos metabólicos em diferentes estruturas encefálicas, que envolvem desde a síntese de novo de mRNA e proteínas até mudanças estruturais a nível sináptico (Kandel, 2001; Nader e Hardt, 2009). Após esses eventos, a memória passa do estado lábil, sensível a interferências, para um estado estável, onde não pode mais ser enfraquecida ou fortalecida (Ji e Wilson, 2007). 


\subsection{ESTRUTURAS ENCEFÁLICAS RELACIONADAS À APRENDIZAGEM E MEMÓRIA}

Os diferentes tipos de memórias são processados fundamentalmente por áreas distintas do sistema nervoso, entretanto, a variedade de memórias possíveis é tão grande que é evidente que a capacidade de adquirir, armazenar e evocar informações é inerente a muitas áreas ou subsistemas cerebrais, e não é função exclusiva de nenhuma delas (Izquierdo, I., 2011).

Entretanto, há determinadas estruturas e vias que são centrais no armazenamento e na evocação da maioria das memórias: o hipocampo, a amígdala, e suas conexões com o hipotálamo e o tálamo. Este conjunto de estruturas integra um sistema modulador (circuito neural) que influencia na decisão, pelo sistema nervoso, ante cada experiência, do que deve ser gravado e do que deve ou pode ser evocado. O hipocampo e a amígdala estão interligados entre si e recebem informação de todos os sistemas sensoriais: em parte provenientes do córtex e, em parte, de forma inespecífica quanto à modalidade sensorial, desde a formação reticular mesencefálica. O hipocampo e a amígdala projetam ao hipotálamo e, através deste, ao tálamo e, finalmente, ao córtex. Estas estruturas e suas conexões estão, portanto, estrategicamente localizadas para modular o processamento de informações baseadas na experiência (Izquierdo, 2011). Na presente tese, vamos enfatizar o papel do hipocampo no processo de aprendizagem operante.

\subsection{HIPOCAMPO}

O hipocampo (ou formação hipocampal) é uma estrutura subcortical, localizada bilateralmente no corno inferior do ventrículo lateral, que desempenha um papel chave nas funções cognitivas do cérebro (Hasselmo e Eichenbaum, 2005; Weitzdorfer et al., 2008). Em conjunto com o giro denteado, complexo subicular e o cortéx entorrinal, compõe a formação hipocampal (Figura 3) (David e Pierre, 2009; Hagihara et al., 2009). O hipocampo é essencial para a formação de memórias, sua reorganização e consolidação durante longos períodos após a aprendizagem (Hales et al., 2015). O hipocampo propriamente dito pode ser divido em três camadas: CA1, CA2, CA3 (CA de Cornu Ammonis) (David e Lavenex, 2009). 


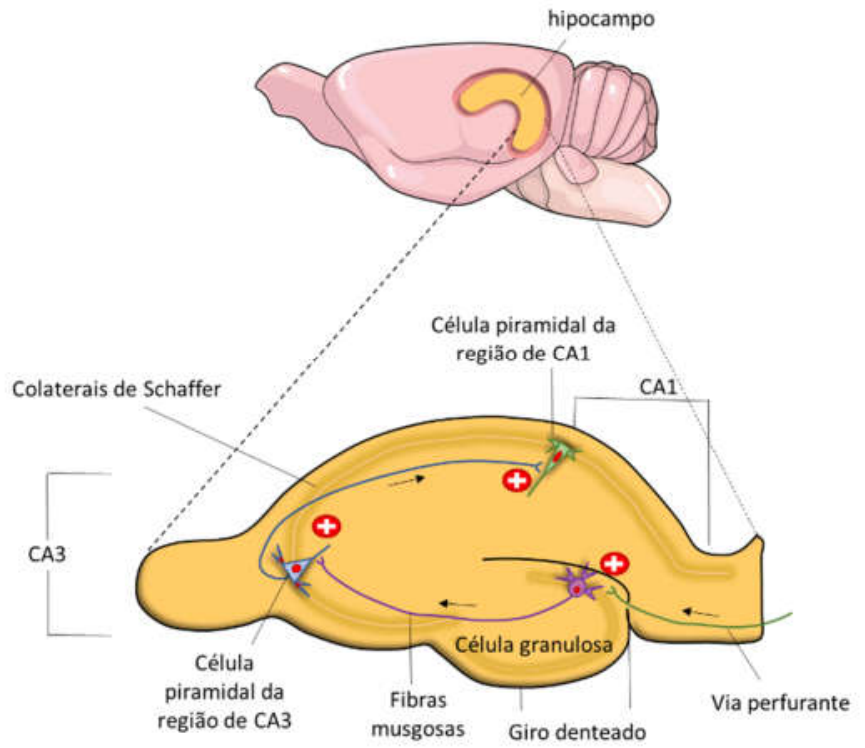

Figura 3. Organização neuroanatômica da formação hipocampal em ratos. Modificado de Rudy, (2008).

O giro denteado recebe projeções aferentes do córtex entorrinal através de uma via unidirecional que recebe o nome de via perforante (ou via perfurante) (David e Pierre, 2009). As células granulosas do giro denteado enviam projeções de axônios, denominadas fibras Mossy (ou fibras musgosas), até a camada de neurônios piramidais da região CA3 do hipocampo. Por conseguinte, as células piramidais CA3, enviam projeções para a camada CA1 através das colaterais de Schaffer. Esse circuito neural, que começa no giro denteado e vai até CA1, recebe o nome de circuito trisináptico. Por fim, os neurônios piramidais de CA1 enviam projeções para o subículo e para o córtex entorrinal (David e Pierre, 2009).

O hipocampo está relacionado a diversos processos neurofisiológicos como a plasticidade sináptica, a resposta ao estresse e a integração de informações provenientes de diferentes órgãos sensoriais (Squire et al., 2004). Esta estrutura cerebral está associada a várias doenças psiquiátricas, neurodegenerativas e neurológicas (Fountoulakis et al., 2005; Leuner e Gould, 2010).

Evidências sugerem que a plasticidade nessa região é essencial para formação de algumas formas de memórias explícitas em mamíferos (Stepan et al., 2015). Tal plasticidade pode ser tanto em nível estrutural como em nível sináptico. Até o 
momento, esta é uma das poucas regiões encefálicas de mamíferos adultos em que pode ser observada a neurogênese (Altman e Das, 1965; Gould e Gross, 2002), fenômeno associado à aprendizagem e memória (Schmidt-Hieber et al., 2004). Estima-se que, diariamente, milhares de novos neurônios são gerados no giro denteado, chegando a alterar a população em aproximadamente $6 \%$ por mês (Cameron e Mckay, 2001).

Além disso, sabe-se que rápidas mudanças estruturais nos espinhos dendríticos, pequenas protusões na superfície dos dendritos, ocorrem no hipocampo estando associadas a eventos sinápticos tais como a LTP e a LTD (Murakoshi e Yasuda, 2012). Espinhos dendriticos são estruturas especializadas para a transmissão sináptica e geralmente são elementos pós-sinápticos (Ethell e Pasquale, 2005; Sheng, 2006). Restritos à superfície dos espinhos dendriticos encontram-se os receptores para os neurotransmissores, em aposição ao elemento pré-sináptico (Nusser, 1999; Popov et al., 2005). A estrutura morfológica e o tamanho dos espinhos são altamente dependentes dos microfilamentos de actina, presentes na cabeça do espinho, e mudanças, tanto na estrutura quanto no tamanho, estão relacionadas à alterações na força da conexão sináptica (Hotulainen e Hoogenraad, 2010).

\subsection{PROTEÔMICA}

O proteoma, termo cunhado por Wilkins (1994) como sendo um complemento ao genoma, reflete o conjunto de todas as proteínas expressas em uma célula, tecido ou órgão em um determinado momento/condição.

A proteômica, área da ciência que estuda os proteomas de determinadas condições, promove uma abordagem complementar as tecnologias genômicas e trasncriptômicas, ao interrogar fenômenos biológicos a nível de proteínas (Mallick e Kuster, 2010). As análises proteômicas diferenciais podem ser qualitativas ou quantitativas. O foco da proteômica diferencial qualitativa é identificar peptídeos ou proteínas específicos de cada amostra sob análise. Por outro lado, o foco da proteômica diferencial quantitativa busca mensurar diferenças na abundância de proteínas ou modificações pós-traducionais de forma relativa ou absoluta entre condições (Craft et al., 2013; Yılmaz et al., 2016). 
Tradicionalmente, a técnica de eletroforese bidimensional em gel de poliacrilamida (2D-PAGE ou 2DE) era utilizada como procedimento padrão para as pesquisas proteômicas. Nessa técnica, proteínas são separadas em uma primeira dimensão de acordo com o seus pontos isoelétricos e em seguida são separados de acordo com suas massas moleculares. A análise dos mapas proteômicos por 2DE podem permitir a detecção e identificação de modificações específicas que não possuem métodos eficientes de enriquecimento por afinidade seguidos por espectrometria de massas. Dessa maneira uma abordagem por 2DE possibilita tanto a visualização quanto a quantificação de proteínas totais e das quantidades das proteínas modificadas, permitindo acessar as variações entre as modificações das proteínas em relação a mudanças na expressão das proteínas (RogowskaWrzesinska et al., 2013). No entanto, análises baseadas em 2DE são muito laboriosas e demandam muito tempo além de não são adequadas para análises proteômicas de alto-rendimento. Em decorrência disso e somado aos avanços tecnológicos na instrumentação dos espectrômetros de massas e na miniaturização e aumento da robustez dos sistemas cromatográficos tem ocorrido um aumento de estudos proteômicos baseados em cromatografia líquida acoplada a espectrometria de massas (LC-MS/MS) (Mallick e Kuster, 2010).

Embora possam existir diferentes abordagens para análises proteômicas baseadas em espectrometria de massas, a mais comum é a abordagem bottom-up. Nesse tipo de abordagem a amostra proteica e submetida a uma digestão enzimática protease sítio específico, seguida pela separação desses peptídeos por meio de cromatografia líquida, em geral cromatografia em fase reversa, em que uma mistura de peptídeos é separada de acordo com a sua hidrofobicidade (Figura 4). Os peptídeos eluídos são ionizados na ponta da coluna e transferidos por um sistema de vácuo ao espectrômetro de massas. O espectrômetro de massas registra periodicamente o perfil das razões massa/carga e a intensidade dos peptídeos que são eluídos da coluna. A esses registros dá se o nome de scan e o conjunto de scans gerados em um único experimento pode ser visto na forma de um mapa tridimensional de picos localizados em um determinado tempo de eluição com relação a um espaço da razão massa/carga e pela intensidade dos mesmos. Normalmente, após um scan, o espectrômetro de massas pode isolar peptídeos de forma individual e submetê-los a diferentes tipos de fragmentação (a depender do modelo do equipamento), seguido 
por um novo registro do espectro dos fragmentos gerados, ao qual dá se o nome de MS2 ou MS/MS. As massas dos peptídeos e dos seus fragmentos são utilizadas para identificar o peptídeo, enquanto que a intensidade dos mesmos pode ser utilizada para a quantificação. (Meissner e Mann, 2014). Outro tipo de abordagem proteômica é denominada top-down, pela qual as proteínas intactas são diretamente analisadas por LC-MS/MS. Abordagens top-down tem potenciais vantagens para a determinação de modificações pós-traducionais e de isoformas. No entanto, ainda existem algumas limitações técnicas quando comparadas a abordagem bottom-up devido a dificuldades com o fracionamento, a ionização e fragmentação em fase gasosa das proteínas (Zhang et al., 2013).

Por essas razões, quando comparamos abordagens proteômicas por 2DE, topdown e bottom-up, esta última leva vantagem com relação ao número de proteínas identificadas sendo classificada como uma abordagem de alto rendimento (Nesvizhskii e Aebersold, 2005).

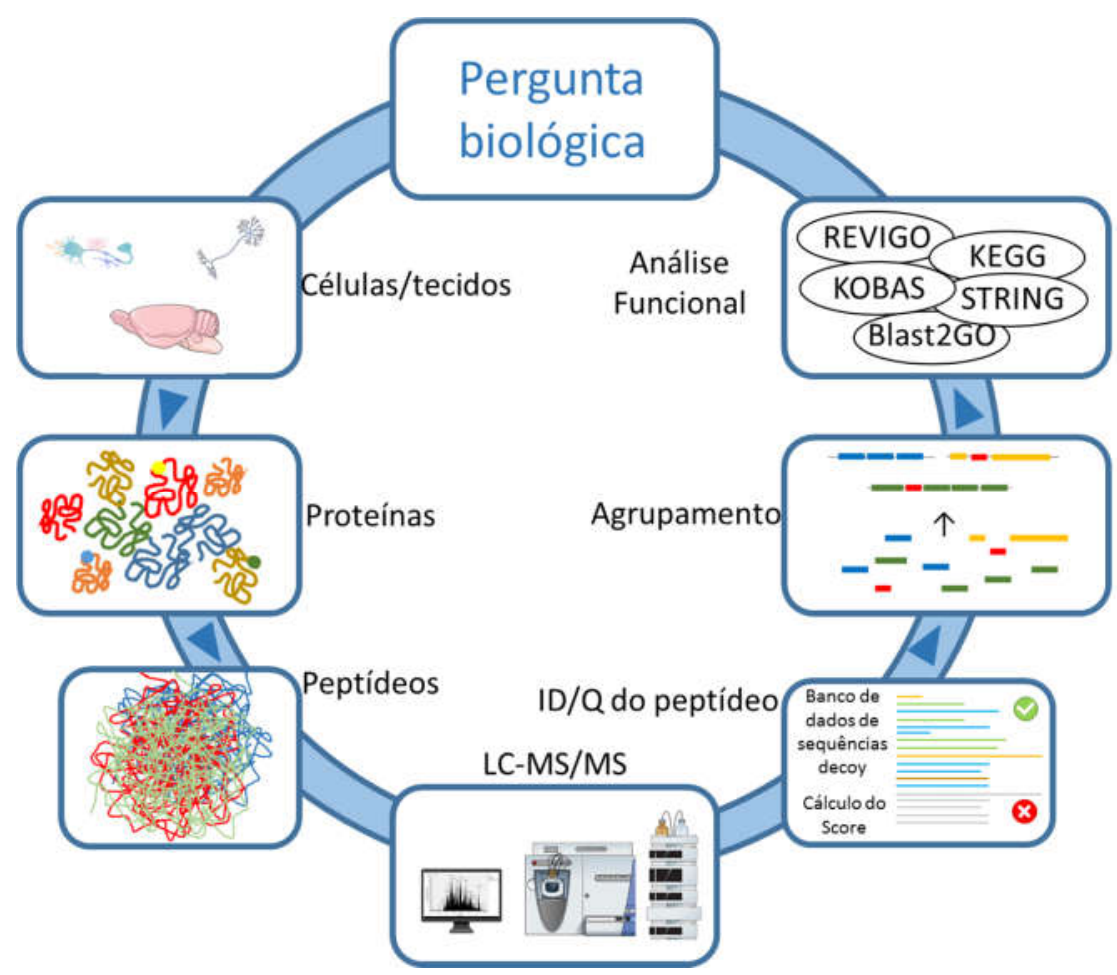

Figura 4. Fluxograma de uma abordagem proteômica shotgun/ bottom up. Amostra de interesse é sujeita a extração de proteínas e digestão enzimática. Os peptídeos gerados são separados por cromatografia e diretamente eletronebulizados em um espectrômetro de massas onde as razões massa/ carga e espectros de fragmentação são gravados. Os espectros gerados são utilizados para identificar e quantificar peptídeos e então esses são agrupados em proteínas. Em seguida podem ser realizadas análises funcionais das proteínas que apresentam diferença entre as amostras a fim de se descobrirem vias, iterações ou modificações pós-traducionais relevantes para a questão biológica de interesse. (Adaptado de Schmidt, 2014). 


\subsection{NEUROPROTEÔMICA}

Com o aprimoramento de diversas técnicas de isolamento, identificação, caracterização e quantificação de proteínas, a proteômica vem destacando-se como estratégia para a elucidação de processos biológicos, para a localização e interação de proteínas de interesse com outras moléculas, bem como para a participação de tais proteínas em vias metabólicas e regulatórias. A neuroproteômica, busca explicar como as variações nos perfis proteicos, em função do tempo do evento observado e/ou de condições externas, influenciam o funcionamento do sistema nervoso. A neuroproteômica tenta correlacionar os dados referentes às variações com as informações pertinentes fornecidas por outras análises, como sinais elétricos, potenciais de ação e plasticidade sináptica com o intuito de elucidar os eventos moleculares envolvidos na questão em estudo (Pienaar et al., 2008; Bayes et al., 2011; Craft et al., 2013; Li et al., 2013; Bayés et al., 2014).

Bayes e Grant (2009) dividem a neuroproteômica em quatro categorias: a de perfis de expressão, dedicada ao catálogo ou descrição qualitativa e/ou quantitativa de perfis proteicos; a funcional, que visa a análise e descrição de funções de proteínas individuais, bem como sua interação e organização em complexos e redes; a clínica, que trata da identificação de biomarcadores e dos mecanismos de patologias neurológicas, neurodegenerativas e psiquiátricas e, por último, a neuroproteômica informática, que se destina ao desenvolvimento de ferramentas para o manuseio e análise de banco de dados.

A investigação da constituição proteica de sinapses e vesículas sinápticas mostra que a ação coordenada de proteínas sinalizadoras constitui uma rede de eventos complexos de grande diversidade molecular que exerce um controle fundamental sobre o desenvolvimento e funcionamento cerebral (Kandel et al., 2000; Hernandez e Abel, 2008), determinando, dessa forma, como os processos neuroplasticidade, aprendizagem e a formação de memórias podem ser regulados ( $\mathrm{Li}$ et al., 2010; Klemmer et al., 2011). 


\section{JUSTIFICATIVA}

O encéfalo dos vertebrados envolve estímulos processados e interligados em diferentes etapas hierárquicas, levando a uma complexidade tal que dificulta o discernimento dos circuitos responsáveis pela geração de determinados comportamentos e os mecanismos moleculares envolvidos (Kolb e Cioe, 2004).

Dados da literatura indicam que determinadas experiências podem causar alterações em algumas estruturas cerebrais, modificações essas essenciais para o armazenamento de novas memórias ou para a alteração de memórias pré-existentes (Kolb et al., 1998; Kim e Diamond, 2002; Kim e Linden, 2007). De acordo com Izquierdo et al. (2006), no cérebro há uma rede de eventos moleculares paralelos que envolvem proteínas, funcionando como substratos e também como moduladores (Paul E, 2008).

Sabe-se que a síntese de proteínas é necessária para a consolidação e armazenamento de memórias (Kandel et al., 2000; Wang et al., 2006; Mayford et al., 2012; Kandel et al., 2014; Dunbar e Taylor, 2016; Ferreira et al., 2016; Levy et al., 2016). Entretanto, os mecanismos moleculares que envolvem as proteínas permanecem pouco elucidados (Patil et al., 2011).

A consolidação de protocolos comportamentais bem estabelecidos e o desenvolvimento de ferramentas de manipulação genética para roedores os tornam bons modelos para estudos de mecanismos bioquímicos e fisiológicos envolvendo processos de memória, comportamento e aprendizagem. Além disso, a similaridade da composição neuroproteômica com humanos pode ajudar no entendimento dos mecanismos moleculares da memória e aprendizagem em humanos (Bayes et al., 2012).

O condicionamento operante, uma forma de aprendizagem associativa, tem sido amplamente investigado em vários modelos animais, tanto em invertebrados quanto em vertebrados (Gomez-Pinilla et al., 2007; Brembs, 2008; Lorenzetti et al., 2008; Dalla e Shors, 2009; Gil et al., 2009; Jaholkowski et al., 2009; Jonkman et al., 2009; Rapanelli et al., 2009; Rapanelli, Maximiliano et al., 2010; Chen et al., 2011). Ainda assim, pouco se sabe sobre os mecanismos moleculares envolvidos nessa forma de aprendizagem. 
Embora alguns avanços venham ocorrendo com estudos de condicionamento operante apetitivo em roedores (Smith-Roe e Kelley, 2000; Baldwin et al., 2002; Takahashi et al., 2011), ainda não há uma completa elucidação das vias de sinalização, nem como essas cascatas de sinalização mediam a convergência entre o comportamento e a recompensa (Lorenzetti et al., 2008; Mozzachiodi et al., 2008). Assim, torna-se importante identificar proteínas envolvidas no processo de aquisição de aprendizagem por condicionamento operante em roedores.

Neste estudo investigamos as proteínas de hipocampo de rato e cérebros de abelhas utilizando proteômica baseada em espectrometria de massas de alto rendimento. Os resultados poderão contribuir, de forma significativa, para a elucidação dos eventos moleculares envolvidos neste complexo processo, possibilitando também a abertura de novas frentes de discussão em função do engajamento de proteínas identificadas em vias centrais. Tal entendimento é de suma importância uma vez que pode apontar proteínas similares em humanos que sejam importantes no processo de aprendizagem humana. Futuramente, tais proteínas poderão ser possíveis alvos farmacológicos de drogas potencializadoras do processo de aprendizagem em humanos. 


\section{OBJETIVO}

O presente trabalho tem como objetivo geral identificar proteínas relacionadas à aprendizagem por condicionamento operante em abelhas e ratos. Para tanto foram realizadas as etapas a seguir:

- Otimização do protocolo de extração de proteínas de hipocampo de rato e de cérebro de abelhas;

- Análise de proteínas extraídas de hipocampo de rato e de cérebro de abelhas por LC-MS/MS;

- Treinamento dos ratos por condicionamento operante discriminativo, dissecção dos encéfalos e extração das proteínas de hipocampo;

- Treinamento das abelhas por condicionamento operante, e dissecção de cérebro e extração de proteínas cerebrais;

- Identificação das proteínas diferencialmente abundantes entre as amostras de hipocampo de ratos e de cérebro de abelhas (controles e treinados) por meio de análise proteômica quantitativa label free;

- Identificação de proteínas cerebrais de abelhas ligantes de MRJP1 (major royal jelly protein 1). 
CAPITULO I

APRENDIZAGEM OPERANTE EM RATOS 


\section{MATERIAIS E MÉTODOS}

\subsection{ANIMAIS}

Ratos (Rattus novergicus, linhagem Wistar) machos, adultos (idade entre 80 e 90 dias) mantidos no biotério do Instituto de Ciências Biológicas da Universidade de Brasília - IB - (Campus Darcy Ribeiro) em caixas para criação de roedores $(41 \mathrm{~cm} \times 34 \mathrm{~cm} \times 16 \mathrm{~cm})$, forradas com serragem. Os animais foram separados em grupos de cinco por caixa, com o controle do ciclo 12 h claro e 12 h de escuro. Durante os 90 dias de idade, os ratos tiveram água e comida ad libitum. Todos os experimentos animais realizados com ratos foram aprovados no CEUA IB/ UnB de número de processo 57530/2008.

\subsection{MATERIAIS}

Caixas para condicionamento operante $(31 \mathrm{~cm} \times 26 \mathrm{~cm} \times 22,5 \mathrm{~cm})$ modelo 3, Insight, São Paulo, equipadas com uma barra (que pode ser acionada mecanicamente pelo animal), uma fonte luminosa (parte superior) e um bebedouro com uma concha de, aproximadamente, $40 \mu \mathrm{L}$, localizado abaixo da barra.

Reagentes com grau de pureza pró-análise.

\subsection{METODOLOGIA}

\subsubsection{Experimento comportamental}

Vinte ratos, entre 80 e 90 dias de idade, foram transferidos diariamente do biotério do IB para o laboratório de Bioquímica e Química de Proteínas da Universidade de Brasília (LBQP), onde os experimentos comportamentais foram realizados. Durante esse período de 10 dias, os ratos, nas suas respectivas caixas, foram deixados em repouso por 30 min na sala de experimentos, para se 
habituarem ao local e, em seguida, cada rato foi manuseado com o intuito de minimizar o estresse da manipulação ao longo dos experimentos.

Foram utilizadas duas caixas de condicionamento operante. Em repouso, o bebedouro era mantido mergulhado numa cuba com água localizada na parte externa da caixa. Quando o animal pressionava a barra, o bebedouro disponibilizava o líquido.

\subsubsection{Habituação à caixa de condicionamento operante}

Os vinte ratos foram separados em 2 grupos de 10 e, quando atingiram a idade adulta (90 dias), foram iniciados os experimentos comportamentais. No primeiro dia, foi realizada a etapa de habituação à caixa de condicionamento operante. Os animais foram colocados por $10 \mathrm{~min}$, individualmente, nas caixas de condicionamento com a luz da caixa acesa com potência de $25 \%$ de sua capacidade (intensidade luminosa de 16 lux). Decorrido este tempo, os animais foram retornados às suas caixas de biotério com os outros animais e levados ao biotério, onde foram privados de água nas 18 horas que antecederam as etapas seguintes do experimento.

\subsubsection{Modelagem de pressão à barra e esquema de reforço contínuo (CRF)}

Inicialmente, o sujeito experimental foi treinado por meio da liberação de água, pelo experimentador; isto ocorria quando ele se aproximava do bebedouro e quando pressionava a barra. Essa reposta de pressionar a barra foi modelada por meio de aproximações sucessivas da barra. A modelagem foi confirmada após a emissão de 15 pressões na barra que automaticamente acionaram o bebedouro.

No dia seguinte à modelagem, iniciou-se a etapa de esquema de reforço contínuo (CRF), na qual ocorria a liberação automática de água todas as vezes que o sujeito experimental pressionava a barra. Foram realizadas duas sessões de $\mathrm{CRF}$, sendo cada uma encerrada após 50 reforços. Nesta etapa do treino, a 
luz da caixa permanecia acesa durante toda a sessão. O propósito dessa etapa é fortalecer a resposta de pressão à barra.

\subsubsection{Treinamento Operante Discriminativo}

Esta etapa envolveu o treino discriminativo, no qual períodos de claro (luz da caixa acesa) e escuro, de 1 min cada, foram alternados e a resposta modelada (pressionar a barra) liberava água apenas quando a luz estava acesa $(\mathrm{S}+)$ na caixa de condicionamento. Sessões de $30 \mathrm{~min}$ foram conduzidas até o estabelecimento da discriminação. A discriminação foi considerada como estabelecida quando o índice discriminativo (número de respostas no claro/total de respostas) foi igual ou superior a 0,9 em três sessões consecutivas.

Em todos os experimentos, havia um animal controle para cada animal experimental. O controle recebeu a mesma quantidade de água nos mesmos intervalos do experimental, independente das respostas que foram emitidas.

Os resultados foram analisados em termos de taxas de respostas de pressão à barra, índice discriminativo e quantidade de reforços até o critério de aquisição da discriminação.

\subsection{DISSECÇÃO DE ENCÉFALOS}

Uma vez atingido o índice discriminativo nas três sessões, os respectivos pares de animais (treinados e controles) foram eutanasiados imediatamente após o término da sessão. Os animais foram decapitados e seus encéfalos removidos e dissecados, em gelo, separando-se o hipocampo, o córtex medial pré-frontal, o cerebelo e o córtex restante em tubos de microcentrífuga. Para o armazenamento, os tubos contendo as estruturas foram imersos em nitrogênio líquido e acondicionados em freezer a $-80{ }^{\circ} \mathrm{C}$ até a utilização. 


\subsection{EXTRAÇÃO DAS PROTEÍNAS DE HIPOCAMPO}

A cada microtubo contendo os hipocampos do cérebro dos ratos foi adicionado tampão de lise (dodecil sulfato de sódio 4\% (m/v), TEAB $20 \mathrm{mM} \mathrm{pH}$ 8,5 e DTT 0,1 M) contendo um coquetel de inibidores de proteases (cOmplete mini, Roche Diagnostics, Manheim, Alemanha) e inibidores de fosfatases (PhosSTOP, Roche Diagnostics, Manheim, Alemanha). Em seguida, os tecidos foram macerados, em banho de gelo, com um pistilo e os microtubos, contendo o material biológico, incubados em banho-maria a $90^{\circ} \mathrm{C}$ por $5 \mathrm{~min}$. As amostras foram acondicionadas em um banho de gelo e submetidas a 3 pulsos de $15 \mathrm{~s}$ com intervalos de $45 \mathrm{~s}$ com uma amplitude de $50 \%$ em um processador ultrassônico (MARKSON, Modelo GE 50 T $20 \mathrm{kHz}$ ), seguido de centrifugação a $16000 \times \mathrm{g}$ por $15 \mathrm{~min}$ a $24^{\circ} \mathrm{C}$. O sobrenadante foi recolhido, uma alíquota foi diluída a níveis adequados para quantificação de proteínas conforme o kit Qubit $\AA$ protein assay no equipamento Qubit $₫$ 2.0 Fluorometer.

\subsection{DIGESTÃO TRÍPTICA DE PROTEÍNAS DO HIPOCAMPO DE RATOS}

Alíquotas dos extratos proteicos de hipocampo dos ratos foram submetidas à digestão tríptica utilizando o protocolo de digestão de amostras em unidades de filtração (FASP) proposto por Wisniewski et al. (2009), com algumas modificações. Foram adicionados $200 \mu \mathrm{L}$ de uma solução $8 \mathrm{M}$ de ureia a $150 \mu \mathrm{g}$ de extrato de proteínas em uma unidade de filtração Vivacon 500 com cut-off de $30 \mathrm{kDa}$ (Sartorius Stedin) e colocados em um microtubo de 1,5 mL. Esse conteúdo foi centrifugado a $10000 \times \mathrm{g}$ por $15 \mathrm{~min}$. Foram adicionados, novamente, $200 \mu \mathrm{L}$ da solução de ureia e o filtro centrifugado a $10000 \times \mathrm{g}$ por 15 min. Essa etapa foi repetida por mais uma vez. A porção não retida pela peneira molecular foi descartada.

A seguir, as unidades de filtração foram acrescidas de $100 \mu \mathrm{L}$ de solução contendo DTT e ureia $8 \mathrm{M}$, submetidas à agitação por $1 \mathrm{~min}$ a $600 \mathrm{rpm}$ e repouso, a temperatura ambiente, por $30 \mathrm{~min}$, seguido de centrifugação a $10000 \times \mathrm{g}$ por $15 \mathrm{~min}$. Foram adicionados $100 \mu \mathrm{L}$ de solução de iodoacetamida $50 \mathrm{mM}$ em ureia $8 \mathrm{M}$ à unidade de filtração, seguida de agitação a $600 \mathrm{rpm}$ por $1 \mathrm{~min}$, a 
temperatura ambiente, em um Thermomixer (Eppendorf) e incubação, ao abrigo da luz, por $20 \mathrm{~min}$.

Decorrido o tempo de alquilação, as unidades de filtração foram submetidas à centrifugação a $10000 \times$ g por 15 min e, a seguir, a três lavagens com $100 \mu \mathrm{L}$ de solução de ureia $8 \mathrm{M}$ e centrifugação a $10000 \times$ g por 15 min. Adicionou-se $100 \mu \mathrm{L}$ de TEAB 20 mM pH 8 às unidades de filtração e centrifugouse as mesmas a $10000 \times \mathrm{g}$ por $15 \mathrm{~min}$; esse procedimento foi repetido mais uma vez. Adicionou-se $80 \mu \mathrm{L}$ de solução de TEAB $20 \mathrm{mM} \mathrm{pH} \mathrm{8,} \mathrm{contendo} \mathrm{tripsina}$ (Promega, Madison, Estados Unidos) na proporção de $1 \mu \mathrm{g}$ de tripsina para 50 $\mu \mathrm{g}$ de amostra, agitou-se a unidade filtradora em um Thermomixer comfort a 300 rpm durante 1 min, seguido pela incubação a $37^{\circ} \mathrm{C}$, por 16 horas.

Após essa etapa de digestão enzimática, as unidades de filtração foram transferidas para tubos coletores e centrifugadas a $14000 \times \mathrm{g}$ por $10 \mathrm{~min}$. Foram adicionados mais $80 \mu \mathrm{L}$ de TEAB e repetiu-se a centrifugação. Após isso, a amostra foi acidificada por adição de TFA até a concentração final de 0,1\% (v/v).

Seguiu-se então a etapa de dessalinização dos peptídeos utilizando uma ultra micro-spin column (Havard Apparatus, Estados Unidos). Primeiramente, a micro-coluna foi equilibrada com uma solução de TFA $0,1 \%$; a seguir, foi carregada com os peptídeos seguido de 3 ciclos de lavagens com solução de TFA $0,1 \%$. Após a lavagem, os peptídeos foram eluídos pela adição de $60 \mu \mathrm{L}$ de solução $0,1 \%$ de TFA contendo concentrações crescentes de ACN (20\%, 40\%, e 90\%). As frações eluídas foram reunidas em um microtubo, submetidas à secagem em um sistema concentrador/evaporador centrífugo SpeedVac SC100 (Savant) e os peptídeos ressuspendidos em $30 \mu \mathrm{L}$ de ácido fórmico 0,1\%. A quantificação dos peptídeos foi realizada utilizando o kit Qubit $®$ protein assay.

\subsection{CROMATOGRAFIA LÍQUIDA ACOPLADA À ESPECTROMETRIA DE MASSAS (LC-MS/MS)}

As amostras dos peptídeos trípticos foram analisadas em um sistema cromatográfico com colunas capilares (nano-UHPLC Dionex Ultimante 3000) acoplado on-line ao espectrômetro de massas híbrido ion trap-orbitrap, Orbitrap 
Elite $^{\mathrm{TM}}$ (Thermo Scientific, Bremen, Alemanha). Os solventes utilizados nas corridas foram: solvente $A(0,1 \%$ de ácido fórmico em água) e solvente $B(0,1 \%$ de ácido fórmico em acetonitrila). O sistema cromatográfico consistiu de dois tipos de colunas capilares, sendo uma pré-coluna (diâmetro interno de $100 \mu \mathrm{m} \times$ $20 \mathrm{~mm}$ de comprimento), empacotada no laboratório com partículas esféricas de sílica revestidas por C18 ReprosilPur de $5 \mu \mathrm{m}$ com poros de $120 \AA$ (Dr. Maich $\mathrm{GmbH}$, Ammerbuch, Alemanha). As amostras foram injetadas por injeção parcial e o carregamento nessa pré-coluna foi realizado a um fluxo de $3 \mu \mathrm{L} / \mathrm{min}$ de solução, sendo $98 \%$ de solvente A e $2 \%$ de solvente B. Essa pré-coluna tem função de reter os peptídeos e é utilizada como um filtro para remover resíduos de sais. A segunda coluna é uma coluna analítica (diâmetro interno de $75 \mu \mathrm{m} \times$ $35 \mathrm{~cm}$ de comprimento), também empacotada no laboratório com partículas C18 Reprosil de $3 \mu \mathrm{m}$ com poros de $120 \AA$ (Dr. Maich GmbH, Ammerbuch, Alemanha). Os peptídeos foram separados nesta coluna analítica e eluídos utilizando gradientes de 2 a $40 \%$ de solvente B em 170 min, de $40 \%$ - 85\% até 185 min, seguido por uma etapa isocrática de $85 \%$ até $190 \mathrm{~min}$, retornando para $2 \%$ de solvente B até 210 min para reequilibrar a coluna.

A interface entre nanoLC e o espectrômetro de massa híbrido LTQ Velos Pro Orbitrap Elite (Thermo Scientific) foi feita por meio do controle automático do equipamento, utilizando o software Xcalibur 2.2 SP 1.78 (Thermo Scientific). A fonte de ionização utilizada foi Nanospray flex ion source (Thermo Scientific,), com a voltagem do spray ajustada para $2,5 \mathrm{kV}$ e a temperatura do capilar de transferência de $275^{\circ} \mathrm{C}$. Os espectros de $M S$ foram adquiridos no modo positivo, sendo a aquisição dependente de dados [Data Dependent Acquisition (DDA)]. O ciclo de DDA consistiu em um survey scan compreendendo a faixa de $\mathrm{m} / \mathrm{z} 300$ 1800 sob a resolução de 120.000 FWHM (Full Width at Half-Maximum) para m/z 400 e com valor-alvo de controle de ganho automático de $1 \times 10^{6}$ íons para todos scans no FTMS e tempo máximo de preenchimento de $200 \mathrm{~ms}$. O survey scan foi seguido pela fragmentação MS/MS por dissociação induzida por colisão (CID) dos quinze íons precursores com cargas múltiplas mais abundantes de cada tempo. ĺons com carga +1 foram excluídos da fragmentação, independentemente de sua intensidade. A janela de isolamento para a seleção do íon precursor monoisotópico foi de 2 Th. A opção de lock mass não foi 
habilitada. Os espectros de $M S / M S$, provenientes da fragmentação, foram adquiridos no ion trap linear Velos Pro na taxa de scan, de rapid scan, sob energia de colisão de $35 \%$ e valor-alvo de íons igual a $1 \times 10^{4}$ no íon trap linear (limiar de seleção de íons de 1000 contagens). Foram aplicados parâmetro de ativação $q=0,25$ e tempo de ativação de $30 \mathrm{~ms}$. Íons precursores anteriormente fragmentados foram excluídos de forma dinâmica por $90 \mathrm{~s}$.

\subsection{IDENTIFICAÇÃO DE PROTEÍNAS DE HIPOCAMPO DE RATOS}

Os arquivos raw, provenientes de todas as corridas cromatográficas, foram submetidos ao processamento e à análise de dados no programa PEAKS Studio 7.0 (Bioinformatics Solutions Inc., Waterloo, ON, Canada). Os seguintes parâmetros foram utilizados para análise: tripsina como enzima utilizada; instrumento Orbitrap; tipo de fragmentação CID; correção do precursor apenas para massa; qualidade dos filtros de scan maior que 0,65 ; tolerância para o erro de massa do precursor monoisotópico de 10 ppm; erro de massa para os fragmentos de 0,5 Da; máximo de duas clivagens perdidas por peptídeo; uma clivagem não específica em um terminal do peptídeo; carbamidometilação dos resíduos de cisteína (alquilação com iodoacetamida) como modificação fixa; acetilação do N-terminal da proteína, oxidação da metionina como modificações variáveis; máximo de três modificações pós-traducionais por peptídeo.

Os dados foram confrontados com o banco de dados de Rattus novergicus (35.144 sequências, baixado do Uniprot em 17 de março de 2016). Uma taxa de falsos positivos foi estimada com a fusão do banco de dados com um banco decoy. A taxa de descoberta de falsos positivos (FDR) foi habilitada. Para os critérios de identificações finais, foram aplicados os filtros de FDR para peptídeos menor que $1 \%$ e, ao menos, um peptídeo único por proteína.

\subsection{QUANTIFICAÇÃO LABEL-FREE DE PROTEÍNAS}

Para determinação da abundância diferencial de proteínas entre os grupos treinados e controles foi realizada a análise quantitativa relativa no software Progenesis ${ }^{\circledR}$ QI. For proteomics (NonLinear Dynamics). Os mapas 
tridimensionais dos perfis proteicos de um animal treinado foram comparados aos de seu respectivo controle. Em seguida, os dados de quantificação de abundância relativa das proteínas foram submetidos à análise estatística no ambiente computacional R ( $R$ Core Team, 2016).

\subsection{CLASSIFICAÇÃO POR ONTOLOGIA GÊNICA.}

Os arquivos das sequências FASTA da lista de proteínas identificadas com diferença de abundância entre as amostra (hipocampos de ratos treinados e controles) foram carregados no software BLAST2GO versão 3.3 .5 (Conesa et al., 2005; Conesa e Götz, 2008; Götz et al., 2008). Foram utilizados os valores default recomendados pelo programa. A busca de similaridade de sequências foi realizada utilizando-se o algoritmo BLASTp com busca contra o banco de dados de sequências de proteínas não redundantes (nr) do programa de data 08.06.2016, e com filtro de e-value do Blast expectation de $1 \times 10^{-3}$, análise dos 20 primeiros hits, comprimento mínimo de alinhamento de 33 aminoácidos e habilitação do filtro de baixa complexidade. Posteriormente, foi realizado o mapeamento (Mapping) dos termos GO associados aos hits obtidos com 0 BLAST. Em seguida, foi realizada a etapa de anotação dos termos $\mathrm{GO}$, também utilizando os valores padrão do programa. O limiar de anotação foi igual a 55, o peso do GO de 5 e o filtro de e-value do hit de $1 \times 10^{-6}$.

\subsection{ANOTAÇÃO DAS PROTEÍNAS EM VIAS METABÓLICAS}

Vias metabólicas foram anotadas por ortologia utilizando o sistema de anotação automática BLASTKOALA (Kanehisa, Sato e Morishima, 2016) (http://www.kegg.jp/blastkoala), conforme o banco de dados de vias para Family eukaryotes do KEGG (Kanehisa e Goto, 2000; Okuda et al., 2008; Kanehisa, Sato, Kawashima, et al., 2016) ("http://www.kegg.jp). 


\subsection{ANÁLISE DE ENRIQUECIMENTO DE VIAS E TERMOS GO}

A sequência das proteínas que apresentaram diferença de abundância entre os grupos foram submetidas à análise de enriquecimento no servidor da web KOBAS 3.0 (disponível em http://kobas.cbi.pku.edu.cn/anno iden.php) (Xie et al., 2011). Foram utilizados os seguintes parâmetros: $R$. novergicus como espécie para comparação; para vias foram utilizados como banco de dados KEGG Pathway além do banco de GO. O método estatístico utilizado para o enriquecimento foi o teste hipergeométrico/ teste exato de Fisher e para a correção de falsos positivos, o método de Benjamin e Hochberg (Benjamini e Hochberg, 1995).

Os termos GO resultantes da análise de enriquecimento foram submetidos à sumarização no servidor da web REVIGO (Supek et al., 2011) (disponível em http://revigo.irb.hr/). Foram utilizados os seguintes parâmetros: similaridade média de 0,7 , similaridade associada aos valores-p de cada termo submetido, banco de dados de GO de $R$. novergicus e como semântica de similaridade SimRel. 


\section{RESULTADOS E DISCUSSÃO}

\subsection{EXPERIMENTOS DE APRENDIZAGEM OPERANTE DISCRIMINATIVA}

Os experimentos comportamentais foram realizados em 4 etapas, conforme representado na figura abaixo (Figura 5).

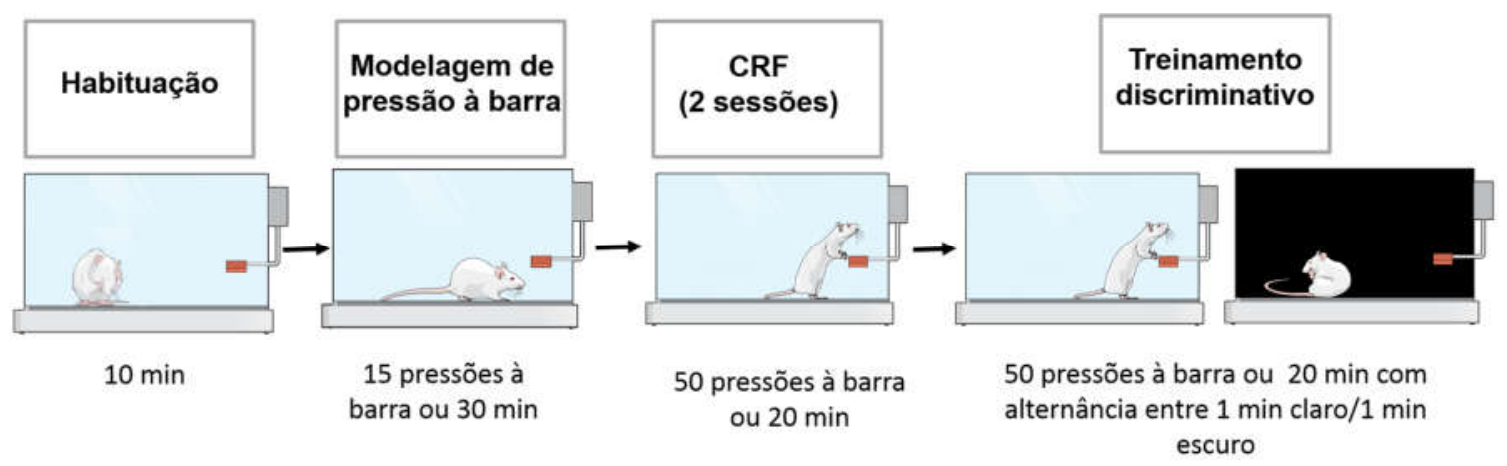

Figura 5. Etapas do treinamento operante discriminativo de ratos.

Cada sessão de treinamento discriminativo tinha uma duração máxima de 20 min, mas poderia ser terminada antes disso, desde que o animal treinado já tivesse emitido 50 pressões da barra, independentemente de ser no claro ou no escuro. Verificou-se que foram necessárias, em média, 22 sessões para a aquisição e estabelecimento da discriminação, considerando o índice discriminativo (ID, número de respostas na presença da luz/total de respostas) igual ou superior a 0,9 em 3 sessões consecutivas.

Os gráficos das Figuras 6 e 7 apresentam as curvas que descrevem a relação entre o tempo gasto por cada sujeito experimental para realizar as 50 pressões da barra por sessão. Pode-se observar que, em geral, nas primeiras sessões, o tempo que os animais passavam na caixa foi bem menor quando comparado com o das últimas sessões. Isso se deve, provavelmente, ao fato de, que nas primeiras sessões, o número de pressões na barra durante os intervalos em que a luz estava apagada superava o número de vezes que isto ocorria na presença de luz, pois quando o animal pressionava a barra na presença de luz, ele passava um determinado tempo (não medido) bebendo água no bebedouro. Quando a luz estava apagada, o animal não recebia água e, com isso, ele voltava a pressionar a barra. Como não havia recompensa no escuro, com o passar das 
sessões houve uma diminuição da frequência dessa resposta (pressão da barra), enquanto a resposta reforçada em presença de luz teve a sua frequência aumentada.

Tempo de sessão par 1

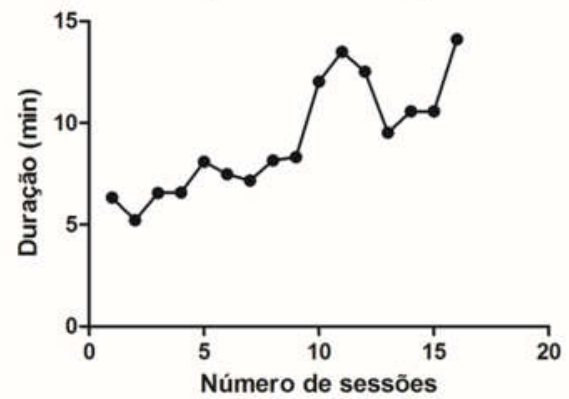

Tempo de sessão par 3

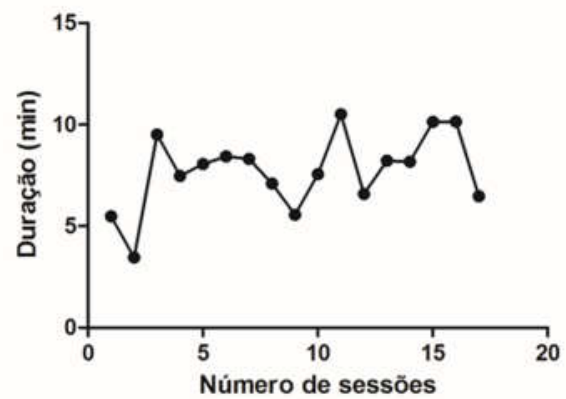

Tempo de sessão par 2

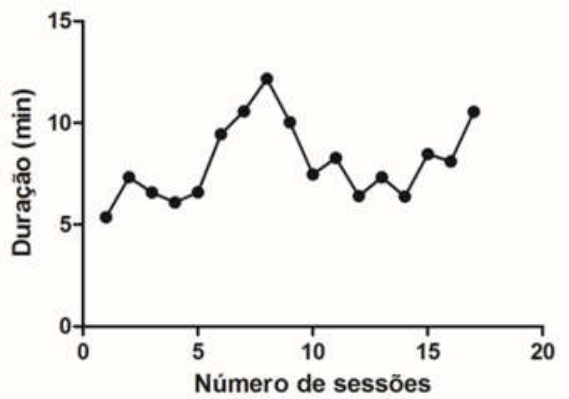

Tempo de sessão par 4

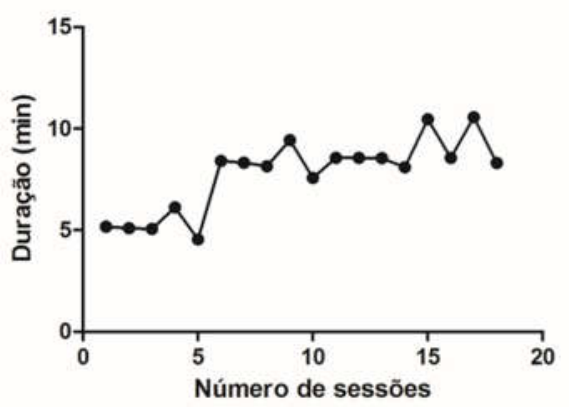

Figura 6. Número de sessões de treinamento por condicionamento operante discriminativo em função do tempo (minutos) de cada sessão. Cada gráfico representa os pares de ratos controle/treinado de 1 a 4 . Os animais controle apenas receberam a mesma quantidade de água consumida pelo seu respectivo par, não sendo submetidos ao treinamento. 
Tempo de sessão par 6

Tempo de sessão par 5
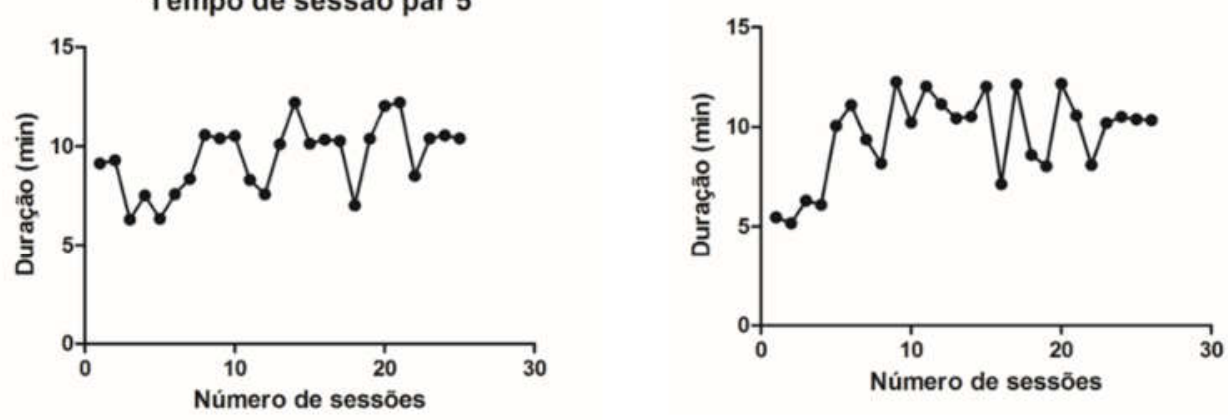

Tempo de sessão par 7

Tempo de sessão par 8
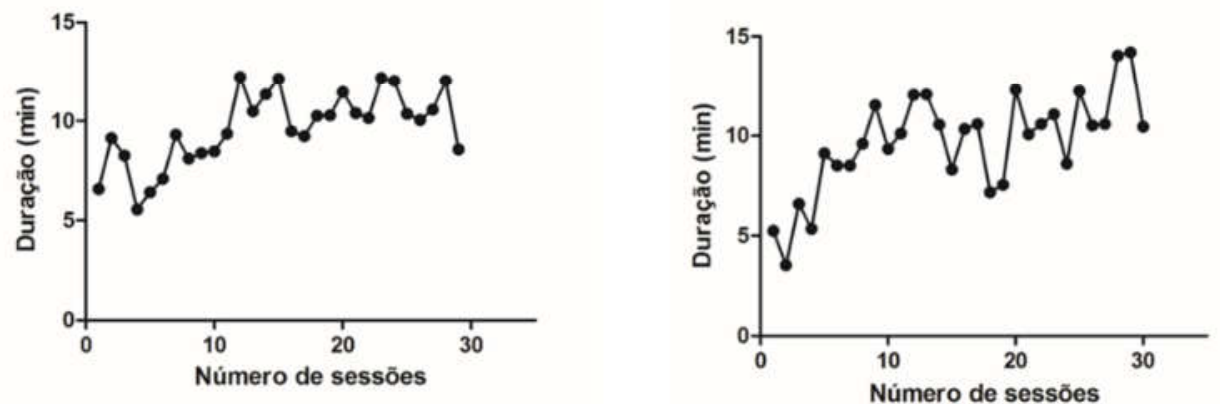

Figura 7. Número de sessões de treinamento por condicionamento operante discriminativo em função do tempo (minutos) de cada sessão. Cada gráfico representa os pares de ratos controle/treinado de 5 a 8 . Os animais controle apenas receberam a mesma quantidade de água consumida pelo seu respectivo par, não sendo submetidos ao treinamento.

Com o intuito de averiguar o progresso da aprendizagem ao longo das sessões, foram gerados gráficos relacionando o número de sessões com o índice discriminativo apresentado em cada sessão (Figura 8). Quando avaliados de forma geral, pode-se constatar que o padrão de aprendizagem dos animais tende a seguir o proposto pela curva de aprendizagem de Ebbinghaus. Nessa curva, podemos ver que há um rápido progresso na aprendizagem dos animais nas sessões iniciais e uma tendência de estabilização nas últimas sessões. 
Treinado 1

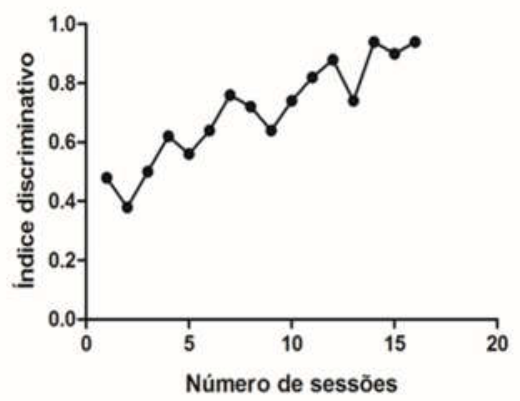

Treinado 3

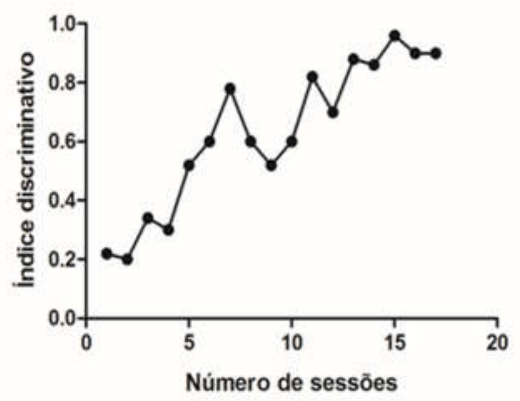

Treinado 5

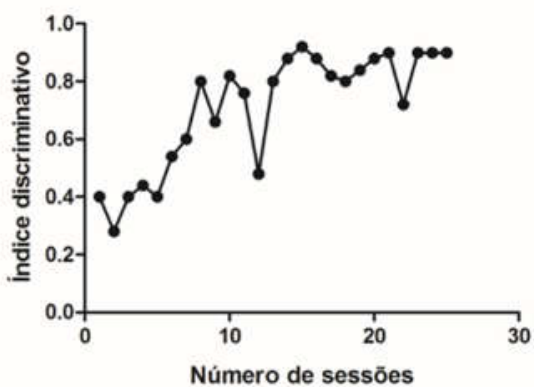

Treinado 7

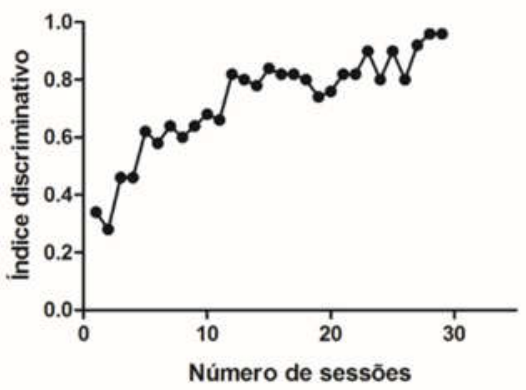

Treinado 2

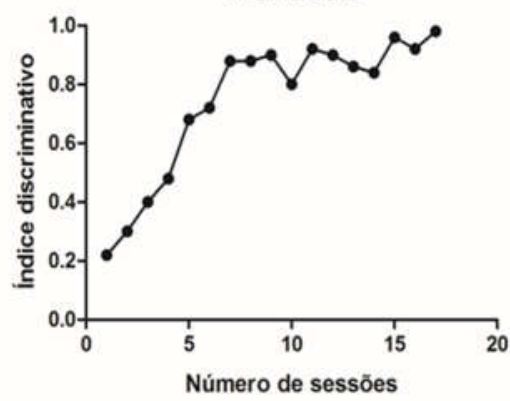

Treinado 4

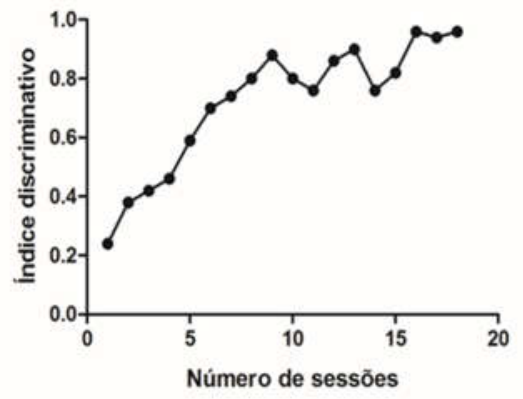

Treinado 6

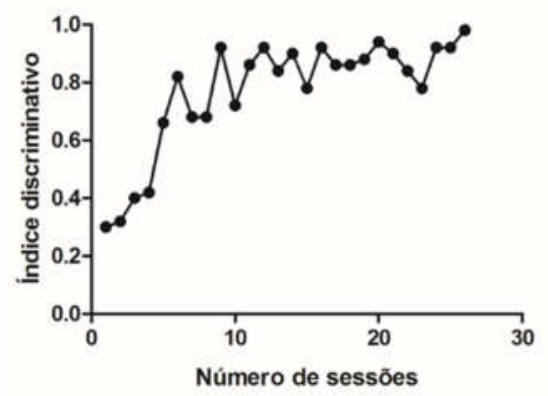

Treinado 8

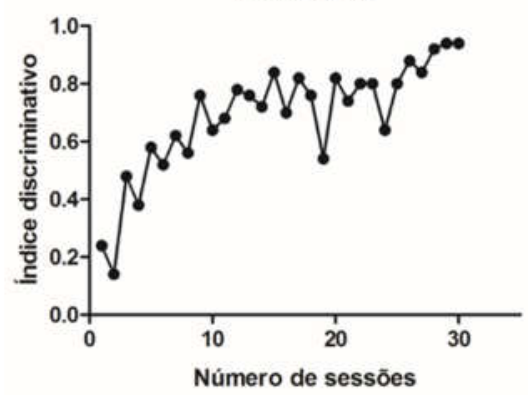

Figura 8. Curva de aprendizagem de ratos submetidos a treinamento por condicionamento operante discriminativo em função do índice discriminativo em cada sessão com 50 pressões de barra. 


\subsection{PROTEOMA DO HIPOCAMPO DE RATOS E ANÁLISE DIFERENCIAL}

A abordagem experimental realizada permitiu a identificação confiável de 6.082 proteínas. Desse total, 5.267 proteínas foram identificadas nas amostras obtidas de hipocampo de ratos submetidos ao treinamento operante discriminativo, sendo que 893 proteínas foram identificadas exclusivamente em ratos nessa condição. Foram identificadas 5.189 proteínas das amostras oriundas de ratos pertencentes ao grupo controle e, dentre essas, 815 proteínas foram identificadas exclusivamente em ratos nesta condição. (Vide Figura 9 e Tabelas suplementares 1 e 2).

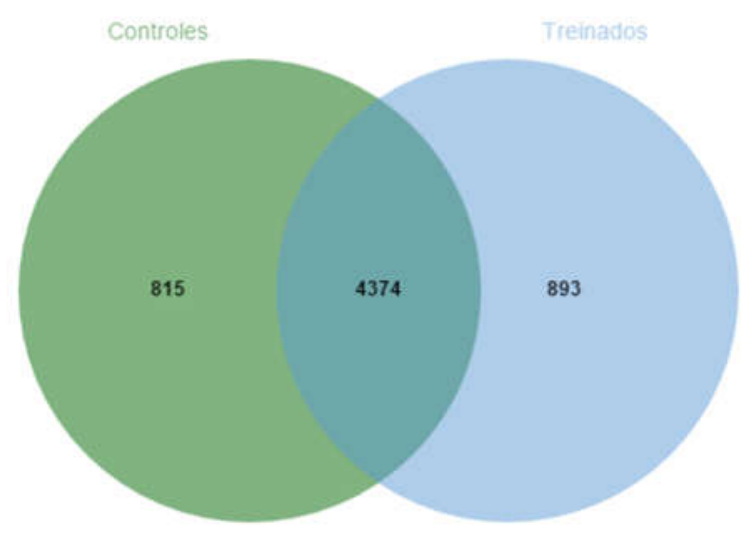

Figura 9. Número de identificação de proteínas de hipocampo de ratos submetidos a treinamento operante discriminativo e seu grupo controle. Identificação obtida a partir de análise de corridas em triplicatas de amostra de 6 ratos por grupo, separados por um gradiente de 190 min em um sistema cromatográfico Dionex Ultimate 3000 acoplado a espectrômetro de massas Obritrap Elite.

\subsection{ANÁLISE DE PROTEÍNAS COM DIFERENÇA NO PERFIL DE ABUNDÂNCIA}

Os arquivos raw referentes às corridas realizadas em triplicata dos respectivos pares de ratos 2 a 7 foram alinhados e analisados no programa Progenesis. A lista de features geradas neste programa foi submetida à busca no programa Peaks utilizando-se os parâmetros descritos na metodologia. A lista dos peptídeos/proteínas identificados nessa etapa foi exportada para o 
Progenesis e os conflitos resolvidos manualmente. Por meio dessa abordagem, label-free, foi possível determinar a quantificação relativa de 995 proteínas. Os dados da quantificação relativa de cada proteína foram exportados do Progenesis e submetidos à análise estatística utilizando o programa $\mathrm{R}$ Studio pacote estatístico versão 3.3.1.

O programa R Studio envolveu, primeiramente, a análise por teste $\mathrm{t}$ de Student considerando $p<0,05$. Em seguida os valores-p obtidos foram corrigidos por meio da aplicação do teste de hipóteses múltiplas de acordo com a função de Benjamini-Hochberg com o método para estimativa de descoberta de falsos positivos baseado no método de q-valor controlado. Após essa análise, aplicouse um filtro de $q<0,05$. Essa análise resultou em 39 proteínas com diferença significativa de abundância. Dessas 39 proteínas, 23 apresentaram um padrão de abundância diminuída nos ratos que foram submetidos ao treinamento por condicionamento operante (Tabela 1) e 16 apresentaram abundâncias aumentadas em ratos pertencentes ao grupo treinado (Tabela 2). 
Tabela 1. Proteínas de hipocampo de ratos submetidos ao treinamento operante discriminativo com abundância diminuída em relação ao grupo controle.

\begin{tabular}{ccc}
\hline Número de acesso & Proteína & Taxa de variação entre grupos \\
\hline B2RZ72 & Actin-related protein 2/3 complex subunit 4 & 1,13 \\
P85969 & Beta-soluble NSF attachment protein & 2,09 \\
Q62717 & Calcium-dependent secretion activator 1 & 1,17 \\
D3ZH00* & Calcium-transporting ATPase & 1,16 \\
P53534 & Glycogen phosphorylase, brain form (Fragment) & 1,32 \\
P30009 & Myristoylated alanine-rich C-kinase substrate & 1,77 \\
Q5PQN0 & Neurocalcin-delta & 1,16 \\
P55067 & Neurocan core protein & 1,34 \\
Q920Q0 & Paralemmin-1 & 1,27 \\
Q7TMB7 & Phospholipid phosphatase-related protein type 4 & 2,05 \\
D3ZXD2 & Protein Abca8 & 1,43 \\
D3ZCV0 & Protein Actn2 & 1,16 \\
Q5GFD9 & Protein IMPACT & 1,18 \\
E9PT22 & Protein Inf2 & 1,74 \\
F1M8Z3 & Protein Klf7 & 1,49 \\
M0R9L0 & Protein Naca & 1,19
\end{tabular}




\begin{tabular}{ccr}
\hline Número de acesso & Proteína & Taxa de variação entre grupos \\
\hline M0R907 & Protein Snrpd3 & 1,27 \\
Q4R1A4 & Protein Tfg & 1,65 \\
P06687 & Sodium/potassium-transporting ATPase subunit alpha-3 & 1,28 \\
G3V7X5 & SPARC-like 1 (Mast9, hevin), isoform CRA_a & 1,78 \\
B2RZ24 & Succinyl-CoA ligase subunit beta (Fragment) & 1,70 \\
Q00981 & Ubiquitin carboxyl-terminal hydrolase isozyme L1 & 1,26 \\
Q4KMA2 & UV excision repair protein RAD23 homolog B & 1,40 \\
\hline
\end{tabular}


Tabela 2. Proteínas de hipocampo de ratos submetidos ao treinamento operante discriminativo com abundância aumentada em relação ao grupo controle.

\begin{tabular}{lcc}
\hline Número de acesso & Proteína & Taxa de variação entre grupos \\
\hline P18418 & Calreticulin & 1,44 \\
P00173 & Cytochrome b5 & 1,37 \\
P38650 & Cytoplasmic dynein 1 heavy chain 1 & 1,27 \\
W8CEN7 & ElF2S3Y & 1,17 \\
G3V874 & Erythrocyte protein band 4.1-like 3, isoform CRA_b & 1,24 \\
D4A554 & Eukaryotic translation initiation factor 4 gamma, 3, isoform CRA_a & 1,24 \\
Q68FP1 & Gelsolin & 1,45 \\
Q5XIN6 & LETM1 and EF-hand domain-containing protein 1, mitochondrial & 1,23 \\
Q3KRE2 & Methyltransferase like 7A & 1,95 \\
P63086 & Mitogen-activated protein kinase 1 & 1,21 \\
G3V741 & Phosphate carrier protein, mitochondrial & 1,20 \\
D4A133 & Protein Atp6v1a & 1,34 \\
F1M953 & Stress-70 protein, mitochondrial & 1,32 \\
Q68FQ0 & T-complex protein 1 subunit epsilon & 1,15 \\
P62329 & Thymosin beta-4 & 1,42 \\
Q9Z269 & Vesicle-associated membrane protein-associated protein B & 1,56 \\
\hline
\end{tabular}


O processo de aprendizagem envolve diferentes vias de sinalização, como modificações pós-traducionais e síntese proteica, de acordo com o tipo de informação e tempo de duração da memória adquirida. Entretanto, até o presente momento, nenhum estudo demonstrou alterações no proteoma de hipocampo de ratos submetidos ao modelo de aprendizagem por condicionamento operante.

No presente trabalho, 39 proteínas apresentaram pequenas variações na abundância alterada no hipocampo dos animais treinados. Esse pequeno número de proteínas alteradas deve-se provavelmente tanto ao tipo de estímulo utilizado quanto ao tempo de exposição a esse estímulo. Diferentemente de um dano por trauma encefálico, uma isquemia ou mesmo um aprendizado com um componente que envolva dor ou medo (uma esquiva inibitória, por exemplo), a aprendizagem por condicionamento operante parece envolver pequenas modificações nos circuitos neurais que pode ser dependente do tempo de exposição ao modelo comportamental. Além disso, sabe-se que em sessões de aquisição longas ou repetidas há uma grande chance de detecção de diferentes fases da consolidação, ou mesmo a aquisição com a consolidação e/ou evocação da memória (Izquierdo e Medina, 1997; Izquierdo et al., 2006). Aliado a isso pode se destacar a aplicação de análise estatística estringente, com a aplicação de teste de correções de hipóteses múltiplas que aumentaram a confiabilidade das proteínas diferencialmente abundantes, mas que, ao mesmo tempo, podem ter eliminado proteínas que apresentaram algumas diferenças de abundância não significativas em tais testes.

A proteômica utilizando a abordagem shotgun, a mesma utilizada neste estudo, gera uma lista geralmente extensa de proteínas. Desta forma, utiliza-se estratégias para filtrar e classificar tais proteínas, favorecendo o processo de interpretação e a formulação de hipóteses (Schmidt et al., 2014).

Objetivando realizar a análise funcional das 39 proteínas que apresentaram variações de abundância entre os grupos, foi realizada a classificação ontológica pelo programa Blast2GO. Por meio dessa abordagem, as sequências das proteínas foram classificadas em função dos processos biológicos, função molecular e componentes celulares em que estão envolvidas. De maneira geral, as proteínas foram enquadradas em diversas categorias e muitas delas, tiveram sobreposição de categorias de processos biológicos, como regulação da sinalização celular, transdução de sinal, processos metabólicos e biossintéticos. 
Em relação aos processos biológicos, as proteínas foram classificadas em até 28 categorias, com filtro de nível igual a 6 para as proteínas com abundância diminuída e 3 para as aumentadas (Figuras 10 e 11).

A classificação ontológica das proteínas com perfil de abundância reduzida em ratos submetidos ao treinamento operante, categorizou as 23 proteínas em 28 termos GO (Figura 10). Dentre estas, 10 encontram-se relacionadas à transdução de sinal e regulação da qualidade biológica, 8 proteínas pertencem a processos celulares de regulação positiva e transporte de substâncias, 7 pertencem à regulação da sinalização, 6 proteínas encontram-se relacionadas ao processo de transcrição e regulação da expressão gênica, 7 a organização de organelas e 6 de projeções celulares e transporte mediado por vesículas. O mesmo procedimento foi realizado com as proteínas que apresentaram um aumento de abundância no grupo de ratos submetidos ao treinamento operante discriminativo. As 16 proteínas foram classificadas em 24 termos GO relacionados a processos biológicos (Figura 11). Seis das proteínas encontram-se relacionadas à organização do citoesqueleto, 5 estão relacionadas à expressão gênica, 5 encontram-se na categoria de transporte mediado por vesículas, 6 encontram-se associadas à regulação positiva de processos metabólicos.

De acordo com a função molecular que desempenham, as proteínas foram classificadas em até 20 categorias com filtro de nível igual a 2 tanto para as proteínas com abundância diminuída quanto para as aumentadas (Figuras 12 e 13). As funções moleculares com maior número de proteínas por categoria observadas foram: ligação à actina (9), proteínas que ligam-se ao ATP (9), proteínas que se ligam a íons cálcio (8), proteínas com atividade de ligação à cauda poli A do RNA (6), atividade de molécula estrutural (5), possuem função de ligação ao DNA (4), atividade ATPase transportadora de cátions e ligação a proteínas cinases (3) e ligação a receptor acoplado a proteína $\mathrm{G}(3)$.

As 23 proteínas que tiveram redução de abundância em ratos treinados foram classificadas em 20 categorias (Figura 12). As categorias que tiveram maior número de representantes foram as de ligação a íons cálcio (5), seguida pela ligação ao ATP (4), ligação ao DNA (3) e de atividade de molécula estrutural (3). As proteínas que tiveram sua abundância aumentada no grupo de ratos treinados foram classificadas em 15 categorias de GO (Figura 13). As categorias que apresentaram maior número 
de sequências foram as de ligação à cauda poli A do RNA mensageiro (5), ligação ao ATP (5), ligação à proteína desenovelada (3), ligação a íons de cálcio (3), ligação à actina (3) e atividade de transferase (3).

Com o intuito de avaliar se há uma predominância de proteínas em determinados locais da célula, as proteínas foram classificadas conforme os componentes celulares onde estão localizadas. As proteínas foram classificadas em até 25 categorias com filtro de nível igual a 2 tanto para as proteínas com abundância diminuída quanto para as aumentadas (Figuras 14 e 15). Tanto as proteínas com abundância reduzida (Figura 14) quanto as com abundância aumentada (Figura 15) tiveram maior representatividade nas mesmas categorias, a saber: exossoma (12 e 11 , respectivamente), seguida pelo citosol (7 para ambos), componente integral de membrana plasmática (5 e 6, respectivamente) e bainha de mielina (4 e 5, respectivamente). 


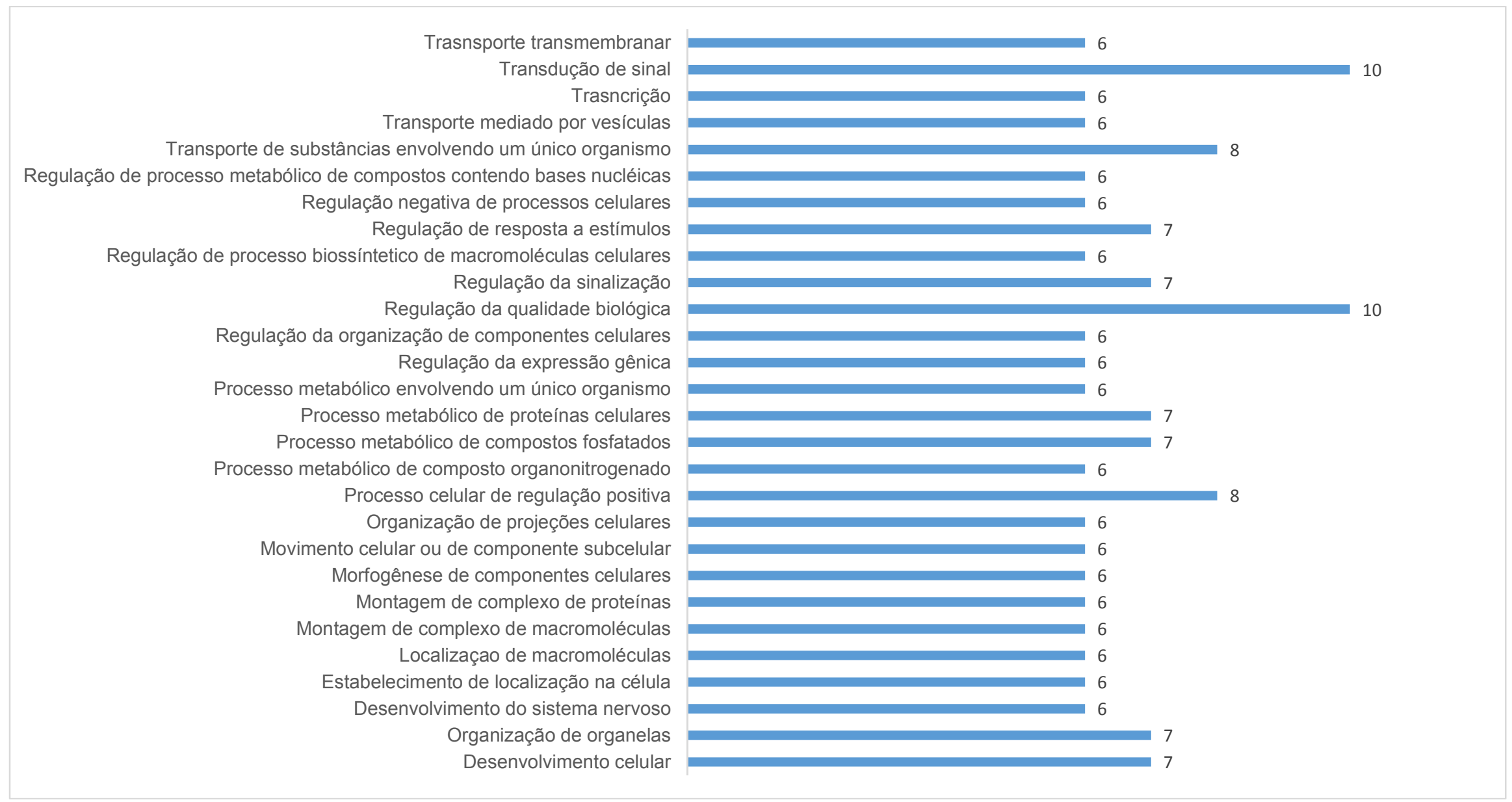

Figura 10. Classificação das proteínas de hipocampo de rato, com abundância reduzida, de acordo com os processos biológicos. 
Transporte mediado por vesículas

Transporte intracelular

Transporte de substâncias envolvendo um único organismo

Resposta a estímulos

Regulação postiva de componentes celulares

Regulação positiva de processos metabólicos de macromoléculas Regulação positiva de processo metabólico celular

Regulação de processos metabólicos de proteínas celulares Regulação de processos metabólicos de compostos nitrogenados

Regulação da qualidade biológica

Regulação da locomoção

Regulação da localização

Processo metabólico envolvendo um único organismo

Processo metabólico de compostos contendo bases nucléicas

Processo metabólico de composto organonitrogenado

Processo biossíntético de macromoléculas celulares

Processo biossíntético de compostos nitrogenados

Organização do citoesqueleto

Organização de organela que envolve um único organismo

Movimento celular ou de componente subcelular

Localização celular de proteína

Interação entre organismos

Expressão gênica
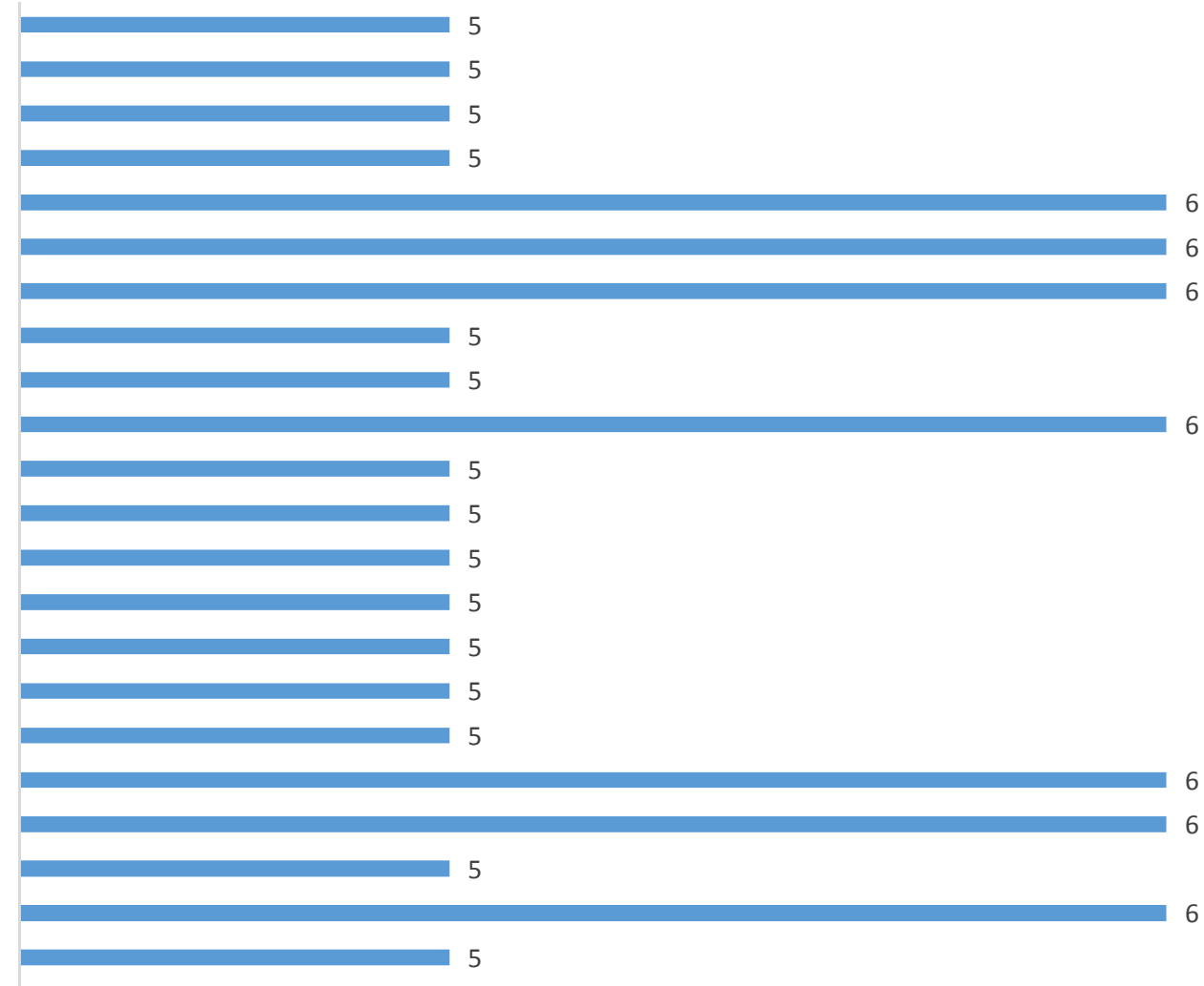
.

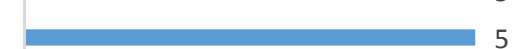

\section{Figura 11. Classificação das proteínas de hipocampo de rato, com abundância aumentada, de acordo com os processos biológicos.}




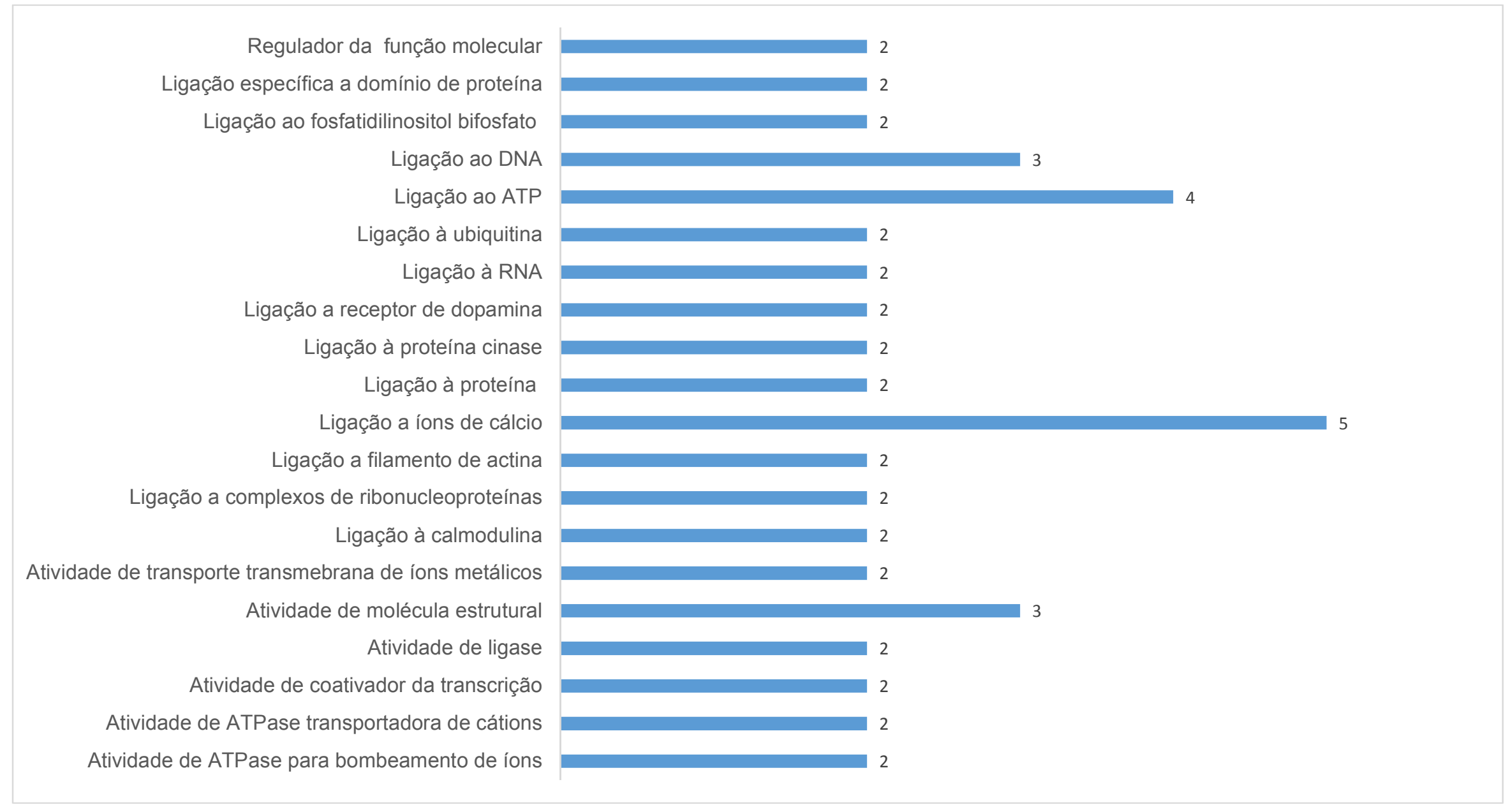

Figura 12. Classificação das proteínas de hipocampo de rato, com abundância reduzida, de acordo com a função molecular. 


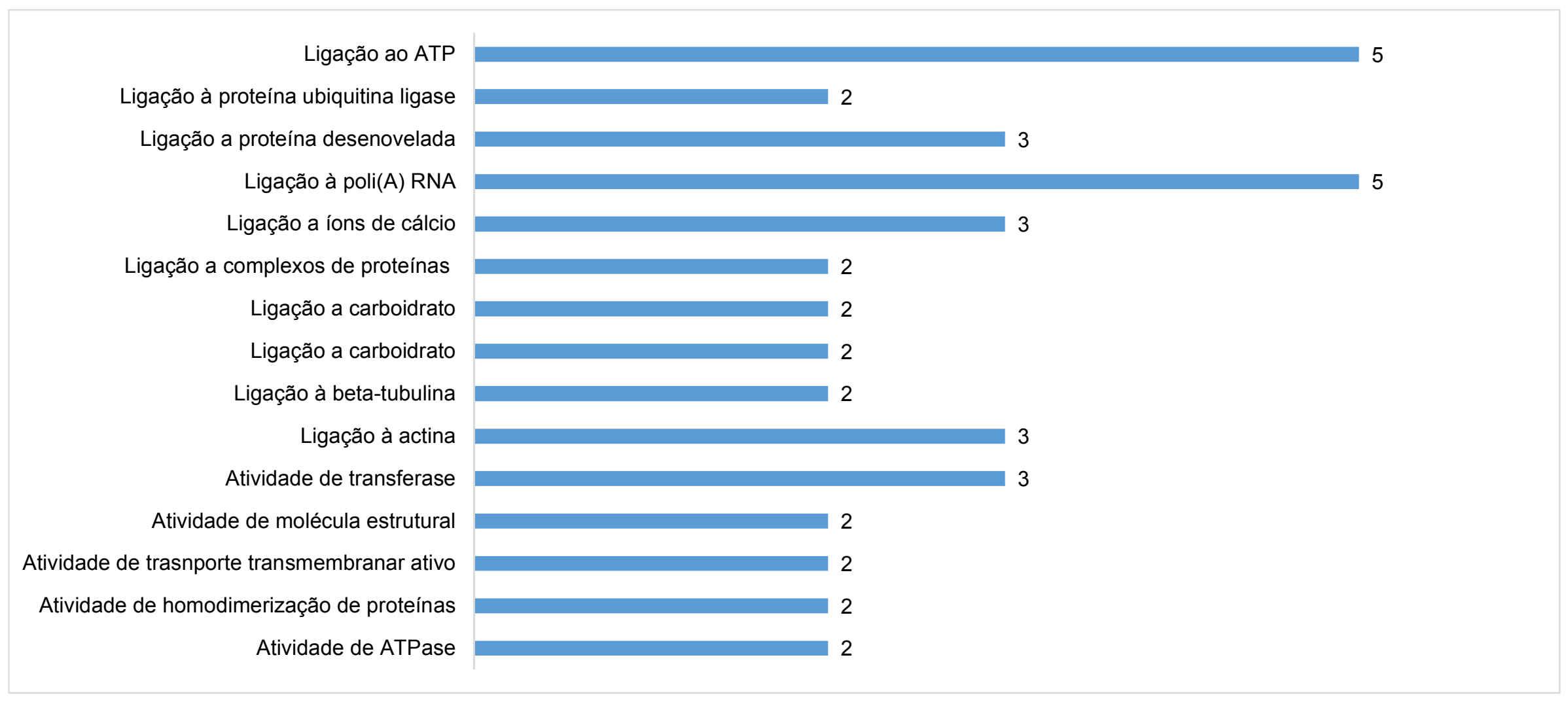

Figura 13. Classificação das proteínas de hipocampo de rato, com abundância aumentada, de acordo com a função molecular. 


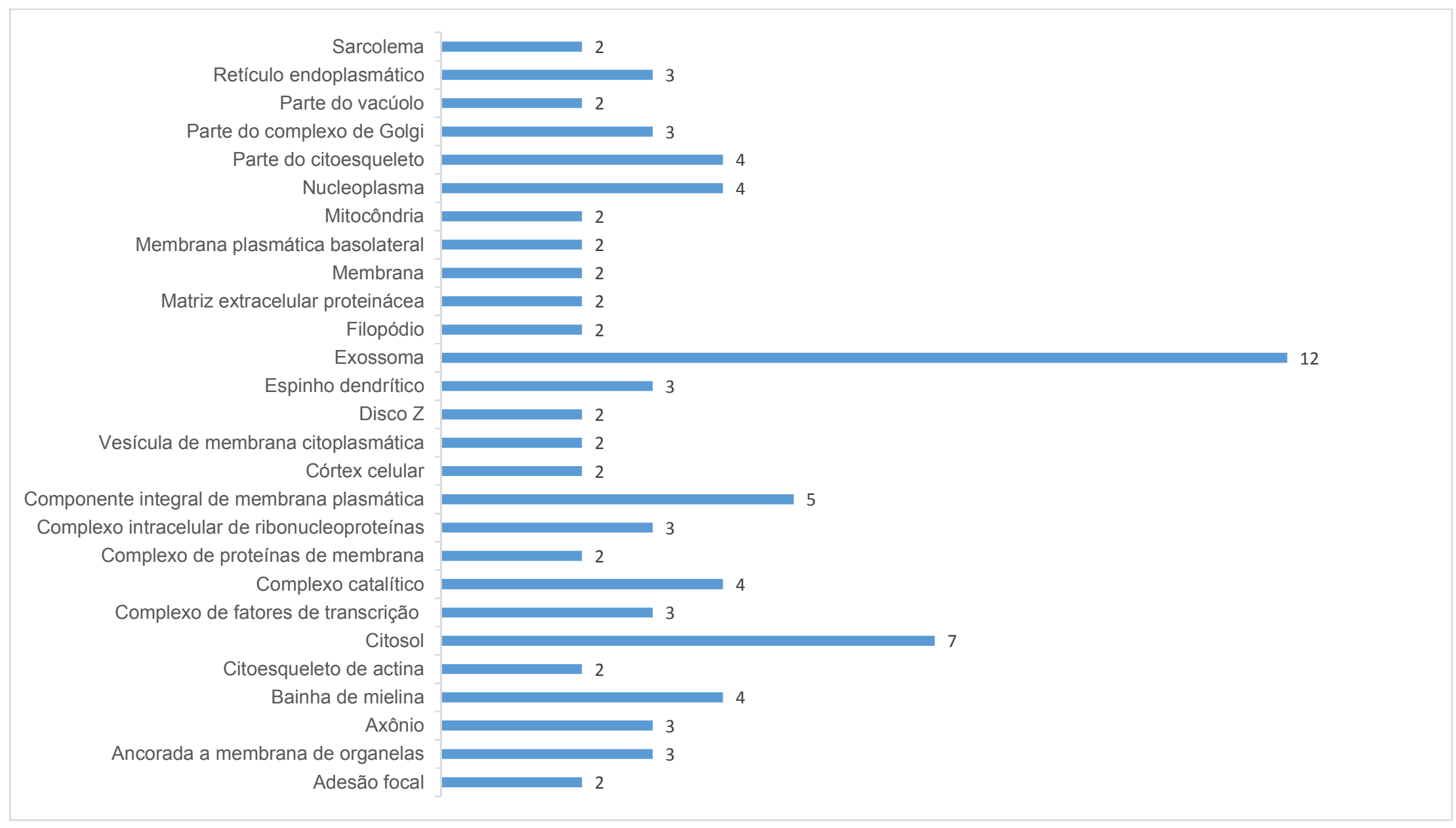

Figura 14. Classificação das proteínas de hipocampo de rato, com abundância reduzida, de acordo com o componente celular. 


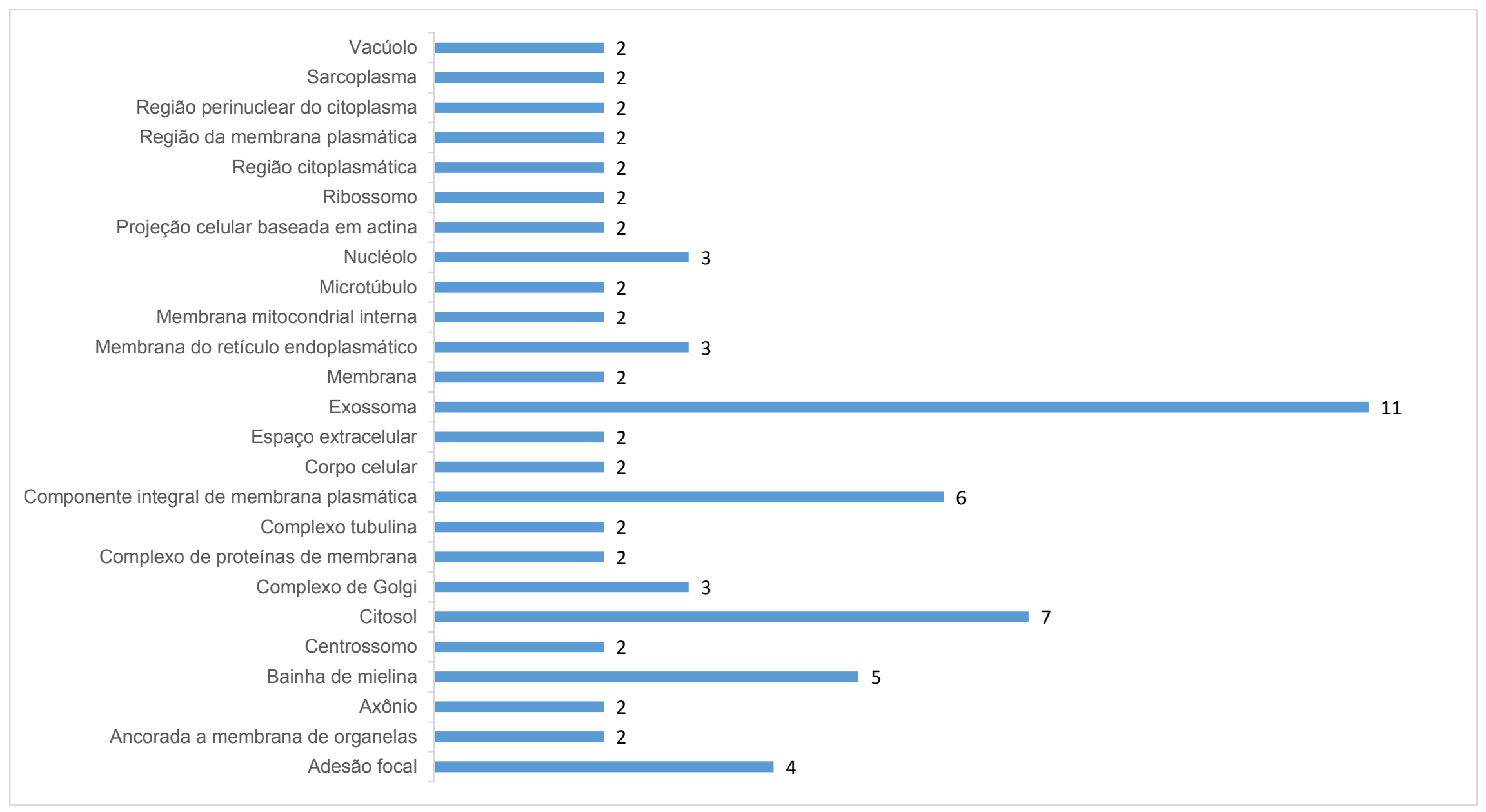

Figura 15. Classificação das proteínas de hipocampo de rato, com abundância aumentada, de acordo com o componente celular. 
Com o intuito de averiguar quais termos GO estão enriquecidos nos mecanismos moleculares envolvidos na aprendizagem por condicionamento operante em ratos foi realizada a análise de enriquecimento no servidor da web KOBAS 3.0 para anotação funcional e enriquecimento de genes/proteínas. Nesse tipo de análise a abundância do conjunto de termos GO associados a sua lista de proteínas são comparados com a abundância natural no organismo ou no conjunto de dados a ser usado como referência (Huang et al., 2009). O valor$p$ calculado reflete a super-representação da abundância de um termo GO específico (Beißbarth e Speed, 2004). Considerou-se como critério um valor-p inferior 0,05 para que um termo fosse considerado enriquecido. $\mathrm{Na}$ análise realizada os valores-p foram corrigidos conforme o método exato de Fischer/ Benjamini-Hochberg no próprio servidor.

Os dados do enriquecimento encontram-se na Tabela Suplementar 3. Em virtude do elevado número de termos $\mathrm{GO}$ associados e devido a redundância hierárquica de alguns termos, a lista foi submetida à sumarização por meio do servidor da web REVIGO. A lista de termos enriquecidos gerados encontram-se na Tabela Suplementar 4. As mesmas etapas foram realizadas para enriquecimento dos termos pertencentes a categorias de funções moleculares e de componentes celulares (Tabelas suplementares 5 e 6).

Em linhas gerais quando comparamos os termos GO enriquecidos para todas as proteínas que apresentaram diferença no perfil de abundância entre ratos treinados e controle podemos destacar que, dentro do domínio de processos biológicos, encontram-se os processos correlacionados à organização de membrana, organização de balsas membranares (membrane raft), regulação do transporte mediado por vesículas, priming de vesículas sinápticas, regulação da transdução de sinal intracelular, regulação da fosforilação de proteínas, desenvolvimento de projeções neuronais, regulação da plasticidade sináptica estrutural, organização dos filamentos de actina, regulação pós-transcricional da expressão gênica e tradução.

Com relação aos termos enriquecidos para funções moleculares temos: atividade primária de transporte transmembranar (que engloba tanto o transporte de $\mathrm{Ca}^{2+}$ como outros íons), regulação da óxido nítrico sintase, ligação do receptor 
de dopamina, ligação à subunidade beta de proteína $G$, ligação a nucleotídeos de adenina, ligação à proteína ubiquitina ligase, ligação a cauda poli(A) do RNA.

No que se refere aos componentes celulares que apresentaram enriquecimento temos: espinho neural, espinho dendrítico, projeções neuronais, sinapse, junção de ancoragem, região paranodal do axônio, terminal póssináptico, complexo de troca sódio/potássio ATPase, complexo sinaptobrevina2-SNAP-25-sintaxina-1a, citoesqueleto, núcleo e U4snRNP.

Embora extremamente útil, a categorização funcional não permite uma interpretação tão óbvia e intuitiva como a análise de vias metabólicas ou de vias de sinalização (Xie et al., 2011). Com o objetivo de averiguar quais seriam as vias envolvidas no processo de aprendizagem operante em ratos, as sequências das 39 proteínas com diferença no perfil de abundância foram classificadas no banco de vias KEGG por meio de comparação utilizando o servidor automático de anotações de sequências genômicas e metagenômicas BlastKOALA.

Dentre as 39 proteínas com diferença de abundância nos ratos, 33 apresentaram anotações em 144 vias KEGG. As vias com maior número de proteínas anotadas foram: fagocitose mediada por receptor Fc gama (4), regulação do citoesqueleto (4), fagossomo (3), via de sinalização do cAMP (3), via de sinalização do cGMP-PKG (3), sinalização adrenérgica de cardiomiócitos (3), regulação da reabsorção de sódio pela aldosterona (2), via de sinalização mTOR (2), via de secreção salivar (2), transporte de RNA (2), processamento de proteínas no retículo endoplasmático (2).

Seis proteínas das 39 que apresentaram diferenças de abundância não tinham informações depositadas no banco de dados de vias KEGG, e por isso suas informações foram buscadas individualmente através de uma revisão da literatura. São elas:

IMPACT: essa proteína encontra-se diminuída no grupo de ratos que foram submetidas ao treinamento operante. Estudos sugerem que essa proteína está envolvida na regulação da tradução em células neurais específicas (Bittencourt et al., 2008). A proteína Impact atua inibindo a proteína GCN2, uma proteína cinase que fosforila uma subunidade do fator de iniciação da tradução elF2 e que terá como efeito a diminuição da expressão de CREB-2. CREB-2 é 
um repressor de CREB, inibindo dessa forma a formação de memórias de longa duração (Trinh e Klann, 2013).

INF2: outra proteína que teve a sua abundância reduzida no grupo de ratos submetidos ao treinamento operante. É uma proteína da família das forminas, proteínas que estão envolvidas com a polimerização da actina, ou seja, estão relacionadas à organização do citoesqueleto. A INF2 possui uma função peculiar por ser a única formina conhecida que além de atuar na aceleração da polimerização do filamento de actina, age na aceleração da despolimerização desses filamentos (Chhabra et al., 2009; Gurel et al., 2015). Além disso, essa formina está envolvida na manutenção da arquitetura do complexo de golgi (Ramabhadran et al., 2011), além de estar associada ao retículo endoplasmático. Encontra-se envolvida em um passo de fissão mitocondrial mediada pelo retículo endoplasmático (Korobova et al., 2013). O balanceamento da fissão mitocondrial é essencial para o desenvolvimento do sistema nervoso.

SPARC-LIKE 1: também conhecida como Hevin ou SYNCAM1, também apresentou redução em sua abundância nos animais submetidos ao treinamento. É produzida e secretada por astrócitos na fenda sináptica, estando associada à formação de sinapses excitatórias (Kucukdereli et al., 2011). Atua na organização de proteínas tanto no terminal pré quanto no pós-sináptico. Isso ocorre devido à sua atuação como uma ponte de ligação entre neurexina-1-alpha com neuroligina-1B (Chung et al., 2015).

ATTACHMENT BETA SOLUBLE NSF: também conhecida como SNAP (NAPB) apresentou abundância reduzida em ratos submetidos ao treinamento operante. É uma chaperona molecular que desempenha um importante papel na liberação de vesículas sinápticas (via função ATPase) (Hanley, 2007). Atua no desacoplamento do complexo SNARE regenerando SNAREs livres para serem usados em reações subsequentes de fusão mediante aumento na concentração de cálcio intracelular.

CITOCROMO B5: faz parte da cadeia de transporte de elétrons e também pode fazer parta da biossíntese de colesterol

METILTRANSFERASE-LIKE 7: encontra-se com maiores níveis de abundância nos ratos treinados; estudos relatam que essa proteína pode estar 
envolvida com a degradação de proteínas via retículo endoplasmático associadas a lipid droplets.

Das 144 vias anotadas a partir do conjunto das 33 proteínas, 123 foram anotadas com apenas uma entrada, ou seja, uma única proteína do conjunto das 33. Analisado atentamente as 123 vias, a proteína MAPK1, com abundância aumentada nos animais treinados, parece ter participação central em diversas vias, uma vez que participa da transdução de sinal extracelular até o núcleo.

Com o intuito de simplificar o entendimento de quais vias podem, de fato, estar relacionadas ao processo de aprendizagem operante, já que a sobreposição de elementos de vias diferentes dificulta a interpretação biológica dos fenômenos observáveis, uma lista contendo todas as 39 proteínas foi submetida a análise de enriquecimento de vias através do servidor da web KOBAS. Para isso foram adotados os mesmos parâmetros utilizados na análise do enriquecimento de termos GO. As vias que apresentaram enriquecimento com valor-q inferior a 0,05 encontram-se representadas na Tabela 3. 
Tabela 3. Tabela de vias KEGG enriquecidas.

\begin{tabular}{lccc}
\hline \multicolumn{1}{c}{ Via } & Número de entradas & Número de proteínas na via & Valor-p corrigido \\
\hline Fc gamma R-mediated phagocytosis & 4 & 91 & 0.0001762 \\
Regulation of actin cytoskeleton & 4 & 221 & 0.0002 \\
Salmonella infection & 3 & 83 & 0.002 \\
Thyroid cancer & 2 & 29 & 0.006 \\
Adrenergic signaling in cardiomyocytes & 3 & 148 & 0.007 \\
Aldosterone-regulated Na reabsorption & 2 & 41 & 0.009 \\
cGMP-PKG signaling pathway & 3 & 171 & 0.009 \\
cAMP signaling pathway & 3 & 196 & 0.012 \\
Phagosome & 3 & 200 & 0.013 \\
Viral carcinogenesis & 3 & 239 & 0.019 \\
Adherens junction & 2 & 74 & 0.022 \\
Salivary secretion & 2 & 76 & 0.022 \\
Axon guidance & 1 & 179 & 0.23 \\
Pancreatic secretion & 2 & 97 & 0.031 \\
Chagas disease & 2 & 107 & 0.034 \\
Thyroid hormone signaling pathway & 2 & 119 & 0.037 \\
Systemic lupus erythematosus & 2 & 136 & 0.042 \\
Insulin signaling pathway & 2 & 140 & 0.042
\end{tabular}


Tight junction

mTOR signaling pathway

RNA transport

Protein processing in end. reticulum
2

2

2

2
143

160

165

165
0.043

0.047

0.048

0.048 
A via enriquecida com o maior número de proteínas anotadas foi a de regulação do citoesqueleto de actina, com quatro proteínas dentre as 33 anotadas em vias KEGG. Participam dessa via as proteínas: Thymosin beta-4, MAPK1, gelsoin, e subunidade 4 do complexo Arp2/3 sendo que apenas esta última apresenta diminuição de sua abundância (Figura 16).

As proteínas TMSB4, MAPK1(ERK), Gelsolin (GSN) encontram-se com sua abundância aumentada em ratos submetidos ao treinamento operante comparados com os ratos controle. Essas proteínas induzem à polimerização e estabilização do citoesqueleto de actina. A regulação do citoesqueleto é essencial em processos de migração celular, morfogênese, manutenção da polaridade celular, exocitose, endocitose e citocinese. Além disso, os filamentos de actina atuam como substrato para o movimento intracelular de vesículas e organelas. Embora não retratada na via, a proteína $T$ complex protein 1 (TCP-1) também apresenta abundância aumentada em ratos treinados. Essa proteína faz parte de um complexo de chaperoninas contendo TCP-1 (CCT), sendo requerida para o dobramento de proteínas presentes em grande abundância, como por exemplo actina e tubulina (Sternlicht et al., 1993) (Sternlicht, 1993). Estudo realizado por Brackley e Grantham (2010) sugere que a TCP1-epsilon participa da estabilização dos filamentos de actina. Outro estudo do mesmo grupo mostra que TCP-1 interage com Gelsolin (Brackley e Grantham, 2011) e essa interação ocorre durante a ativação da Gelsolin em presença do aumento da concentração de cálcio (Svanström e Grantham, 2016)

Estudos mostram a importância do rearranjo estrutural nas estruturas das células nervosas mediada por alterações no citoesqueleto de actina (Szabó et al., 2016). A dinâmica da montagem dos filamentos de actina em diferentes estruturas é regulada pela ação de várias proteínas, como o complexo de Arp2/3, forminas e profilinas, que atuam como sustentação de processos como a espinogênese e plasticidade dependente de experiências (Spence e Soderling, 2015). 


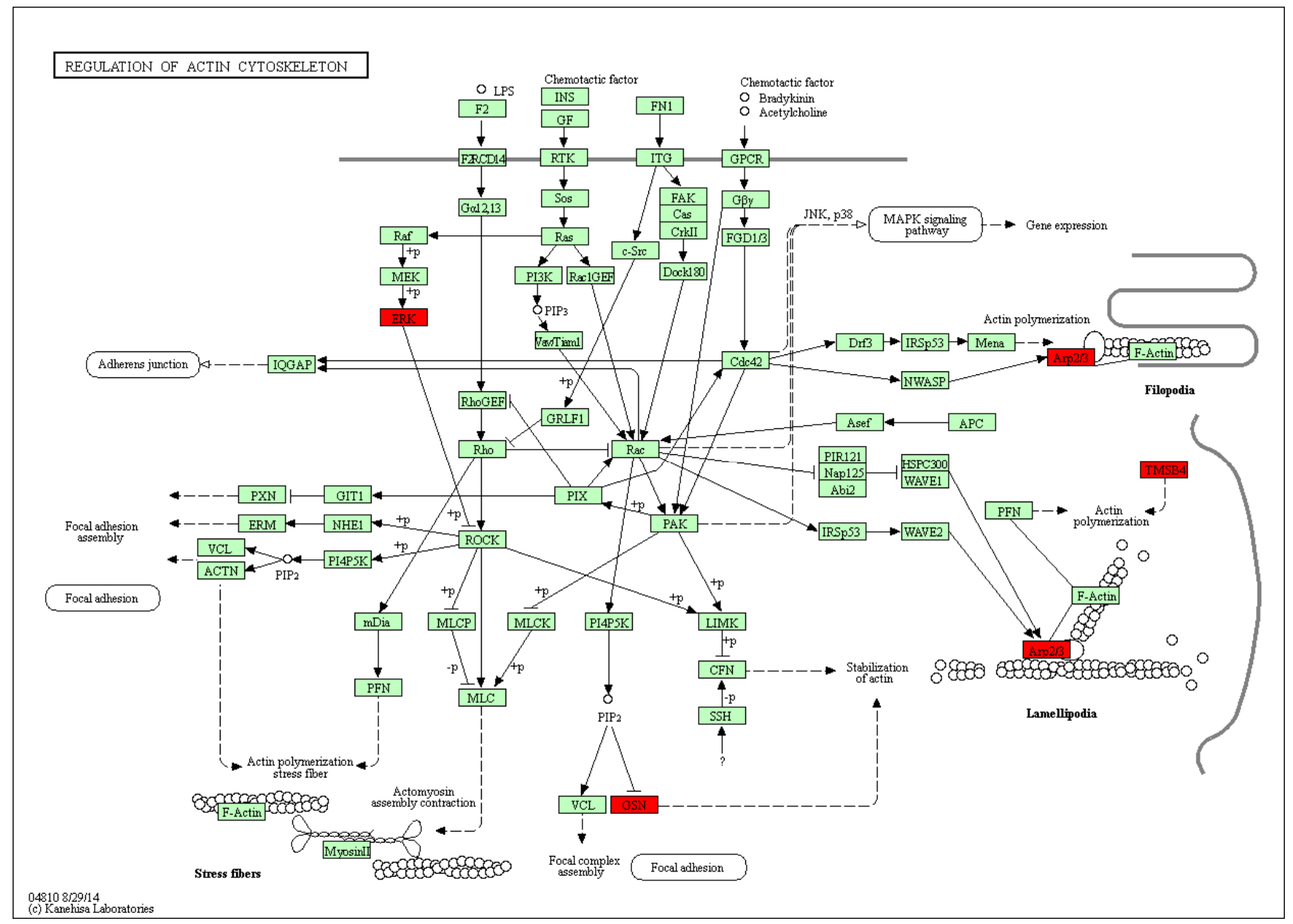

Figura 16. Via de regulação do citoesqueleto de actina. Proteínas com diferença de abundância (em vermelho) entre ratos treinados e controle envolvidas na regulação do citoesqueleto de actina. 
Arp2/3 atua na maturação morfológica de espinhos dendríticos, expandindo lateralmente sua extremidade deixando-os com formato de cogumelo, o que pode facilitar a inserção de proteínas na PSD (Spence et al., 2016). Além disso, a Arp2/3 parece ser necessária para o recrutamento de receptores AMPA. Camundongos submetidos a duas semanas de treino operante de pressão à barra apresentaram níveis menores de mRNA que codifica Arc/Arg3.1, nas regiões de CA1 e CA3, quando comparados a animais que foram submetidos apenas a uma sessão de treino (Kelly e Deadwyler, 2002). Uma diminuição na abundância dessa proteína, como encontrada nos animais treinados no presente estudo, poderia implicar na manutenção dos receptores AMPA na membrana pós-sináptica, favorecendo a sinapse glutamatérgica.

Estudos mostram que a proteína Erythrocyte protein band 4.1-like 3, que teve sua abundância aumentada em ratos que foram submetidos ao treinamento operante, apresenta níveis elevados em células granulosas do giro denteado e cerebelo (Walensky et al., 1998). Essa proteína atua como um ponto central, um eixo que auxilia na organização de proteínas de membrana, incluindo receptores acoplados a proteína $\mathrm{G}$, canais voltagem-dependentes e canais dependentes de ligantes (Baines et al., 2014). Camundongos que tiveram o gene nocauteado que para essa proteína apresentaram déficits de memória espacial (Walensky et al., 1998). Estudos mais recentes mostram uma associação entre a proteína Erythrocyte protein band 4.1-like 3 e a espectrina o que contribui na estabilização de canais de sódio voltagem-dependentes nos paranodos e justaparanodos dos axônios, um fenômeno crucial para a manutenção e rápida propagação de potenciais de ação em axônios mielinizados (Susuki et al., 2016).

Outra via enriquecida foi a de fagocitose mediada por receptor Fc gama (Figura 17). Estudos mostram a importância da dinâmica do recrutamento e endocitose de receptores AMPA e NMDA no fortalecimento e enfraquecimento de sinapses (Anggono e Huganir, 2012; Hardt et al., 2014). Esses eventos encontram-se associados a modificações estruturais do citoesqueleto. 


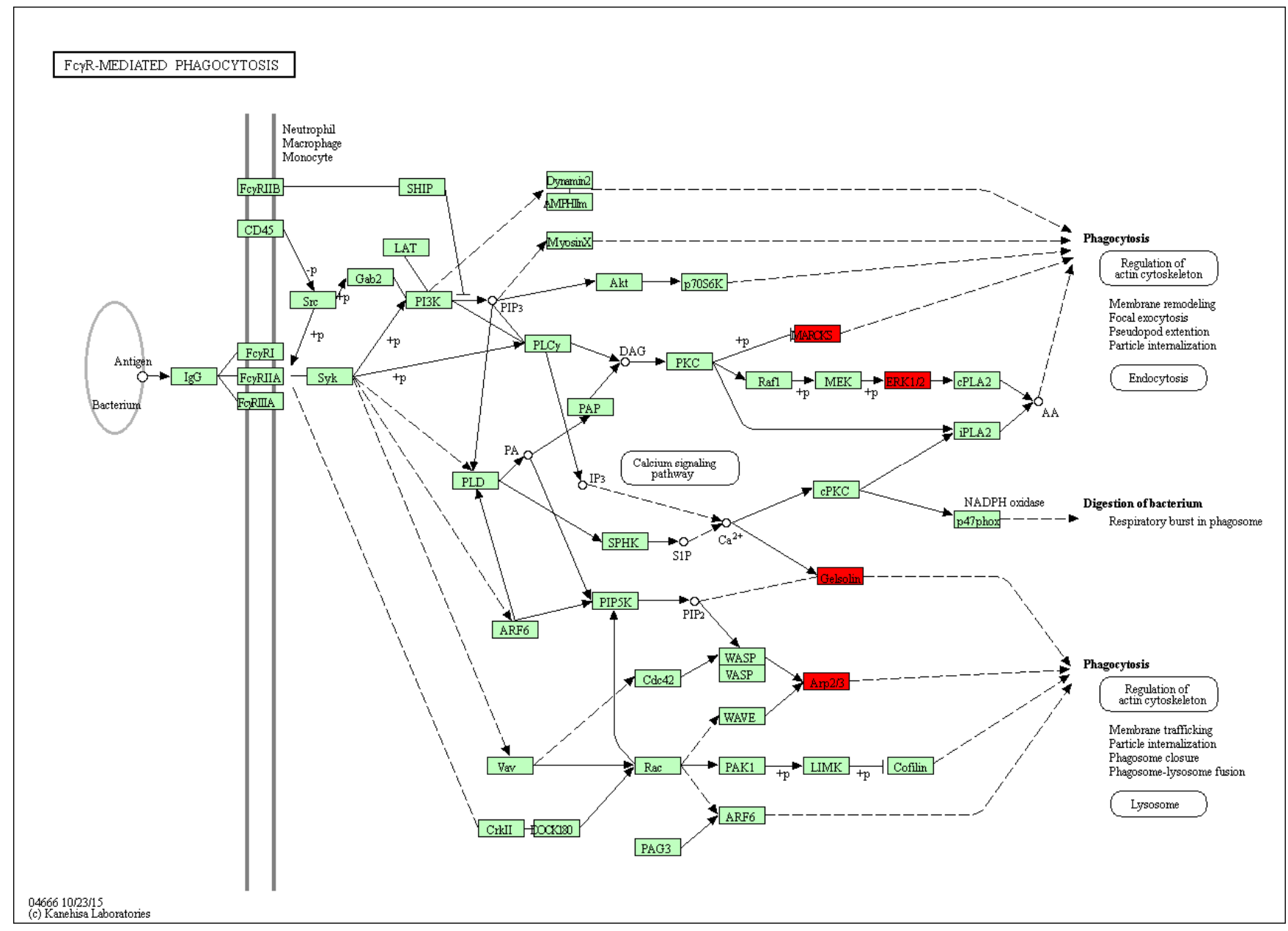

Figura 17 Via de fagocitose mediada por receptor Fc gama. Proteínas com diferença de abundância (em vermelho) entre ratos treinados e controle envolvidas na via de fagocitose. 
Das 4 proteínas que foram anotadas nessa via, o substrato de PKC miristoilado rico em alanina (MARCKS) e Arp2/3 encontram-se com suas abundâncias reduzidas nos ratos treinados. Já MAPK e gelsoin tiveram um aumento nesta condição. Cabe ressaltar que as proteínas anotadas também estão relacionadas à regulação do citoesqueleto. Alguns estudos mostram que tanto astrócitos quanto células da micróglia, de hipocampo em desenvolvimento, desempenham uma fagocitose seletiva de determinadas sinapses em um evento denominado eliminação sináptica ou sinapse pruning (Paolicelli et al., 2011). Dessa forma, sinapses com pouca atividade podem ser marcadas pela deposição de proteínas do complemento (Schafer et al., 2012). A eliminação sináptica é um processo crítico, não apenas como um dos processos moduladores dos circuitos neurais em desenvolvimento, mas também na regulação da plasticidade sináptica em resposta as experiências e memória (Chung e Barres, 2012).

Em relação a via de sinalização cAMP-PKG (Figura 18), podemos observar um aumento, em especial, na abundância da proteína MAPK1. A MAPK1 é capaz de ativar uma série de respostas celulares, desde proliferação celular a diferenciação e migração, além de apoptose (Santamaria e Nebreda; Osborne et al., 2012). Sabe-se que camundongos deficientes em MAPK1 exibem alteração no comportamento social relacionados à características comportamentais exibidas por portadores da síndrome do espectro autista (Satoh et al., 2011). Estudos realizados por Michel e colaboradores (2011) mostram que a sinalização de MAPK mediada por PKG é necessária para a memória de longa duração (LTM) em modelo de aprendizagem operante em Aplysia. Outro trabalho do mesmo grupo (Michel et al., 2010) com o mesmo modelo animal e paradigma comportamental, demonstra a importância de PKA e PKC na via de sinalização do cAMP como sendo requeridas para a formação de memórias de longa duração. 


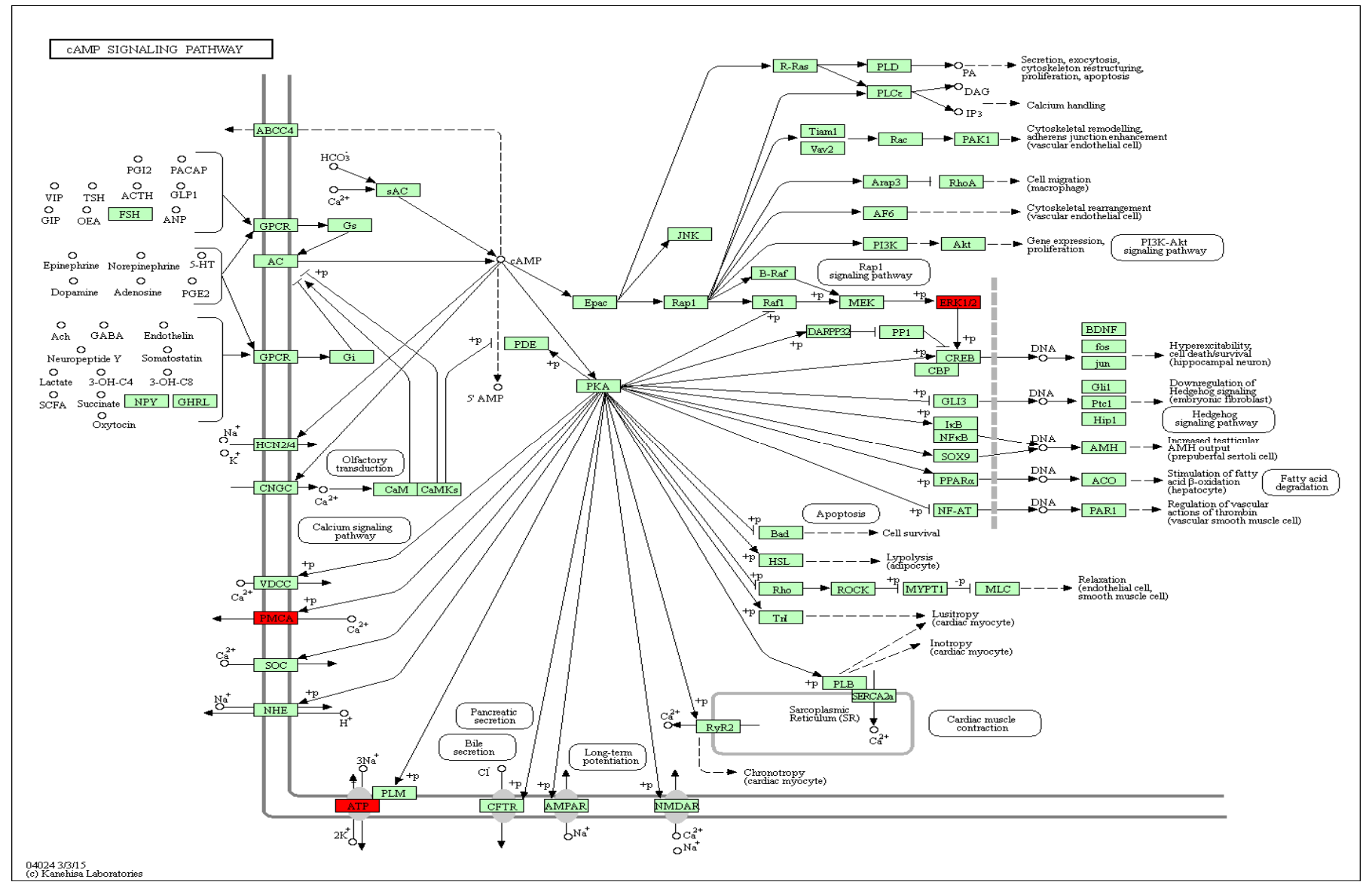

Figura 18. Via de sinalização de cAMP. Proteínas com diferença de abundância (em vermelho) entre ratos treinados por condicionamento operante. 
Duas proteínas com a função de deubiquitinação estão com abundância reduzida em ratos treinados, são elas Ubiquitina carboxi-terminal hidrolase e UV excisão proteína homologa a RAD23. É sabido que a ubiquitinação de algumas proteínas de membrana, que atuam como receptores, é uma forma de sinalizar a internalização do receptor via vesícula endossomal, que eventualmente poderá ser degradada no lisossomo. Uma diminuição da deubiquitinação entre outras coisas pode estar a favorecer a manutenção de receptores, como por exemplo o AMPA na membrana favorecendo assim a manutenção da LTP.

A diminuição da proteína Naca que interage com a proteína Histona deacetilase-2 (HDAC2) levando a repressão da expressão de alguns genes (Hekmatnejad et al., 2014). A diminuição de seus níveis de abundância em ratos treinados pode estar favorecendo a ativação da síntese do produto de alguns genes.

Por outro lado, proteínas envolvidas com o transporte de RNA/ transcrição e tradução encontram-se com abundância aumentada em ratos que foram treinados (fator de iniciação da tradução Eif2s3y e o fator 4 de iniciação da tradução em eucariotos. Sabe-se que a transcrição de genes e a tradução de proteínas são necessárias para a fase de consolidação de memórias de longa duração.

Além disso, foi observado também um aumento de duas proteínas com função de chaperona, como a Stress-70 e TCP-1, o que pode indicar um aumento da necessidade do dobramento correto de proteínas recém sintetizadas. Sabe-se que os neurônios possuem uma intrínseca rede de controle de qualidade no dobramento de proteínas, e o aumento dessas chaperonas pode ter um efeito neuroprotetivo (Smith et al., 2015)

Em conjunto, esses processos de diminuição da repressão de alguns genes, aumento da transcrição mediado pelos fatores acima citados, e aumento da síntese de chaperonas são cruciais para a regulação da proteostasia celular. 


\section{CONCLUSÕES}

Os resultados desse estudo sugerem que o treinamento de ratos no paradigma de condicionamento operante associado com discriminação entre duas condições, claro-escuro, envolve proteínas que estão relacionadas com a organização de membranas, transporte mediado por vesículas, regulação da transdução de sinal, regulação pós-transcricional da expressão gênica e regulação da plasticidade sináptica. Foram identificadas várias proteínas que interagem direta ou indiretamente com o citoesqueleto e por conseguinte podem induzir uma reorganização do mesmo. Como já relatado na literatura essa regulação é importante para a formação e fortalecimento de novas sinapses, bem como no transporte intracelular.de vesículas é organelas. Além disso proteínas encontradas que são descritas como participando de mecanismos de fagocitose sugerem que nesse processo de aprendizagem pode ocorrer eliminações de algumas sinapses intermediadas por células da glia. Os presente resultados apresentados nessa capítulo corroboram dados já descritos na literatura e fornecem informações para futuros experimentos como por exemplo o de silenciamento de determinados genes que codificam proteínas aqui identificadas e ver o seu papel que esses desempenham na performance durante tarefas de aprendizagem por condicionamento operante. 
CAPITULO II APRENDIZAGEM OPERANTE EM ABELHAS 


\section{APRENDIZAGEM EM ABELHAS}

Devido a sua relativa simplicidade, o sistema nervoso de invertebrados oferece uma vantagem significativa para investigações tanto a nível molecular, celular e genético quanto comportamental sobre os mecanismos envolvidos na aprendizagem, formação e evocação de memórias. Isso se deve ao fato dos circuitos neurais envolvidos nesse processo possuírem um menor tamanho e envolverem apenas centenas de células ao invés de milhões, como os presentes no cérebro de mamíferos. Diversos mecanismos moleculares envolvidos na aprendizagem já foram descritos, como por exemplo: o papel de segundos mensageiros como o AMP, de proteínas cinases e fosfatases e de fatores de transcrição além do envolvimento de eventos como a plasticidade neural e a plasticidade sináptica (Menzel e Benjamin, 2013).

Apesar de seus pequenos cérebros, alguns insetos podem apresentar um amplo repertório comportamental. Dentre esses insetos, as abelhas destacamse por sua habilidade em desempenhar tarefas complexas no seu ambiente natural. Abelhas formam sociedades complexas divididas em castas: rainha, operárias e zangões. Além disso, existe uma divisão de trabalho entre os indivíduos da casta operária dependente da idade dos mesmos. A rainha fica responsável pela reprodução, as operárias desempenham várias tarefas, que vão desde o cuidado com a prole, proteção contra predadores e 0 forrageamento. Dado essa gama de repertórios comportamentais, abelhas vêm sendo utilizadas como organismos modelo para estudos dos substratos neurais de aprendizagem, visual e olfatória, e memória (Behrends e Scheiner, 2009; Menzel, 2012).

Abelhas operárias possuem um cérebro contendo aproximadamente $8,2 \mathrm{x}$ $10^{5}$ neurônios e com um volume menor do que $1 \mathrm{~mm}^{3}$ (Witthöft, 1967), dividido nas seguintes estruturas lobo visual, lobos antenais, corpo central (também conhecido como lobo protocerebral), corpos cogumelares (Menzel et al., 2006) (Figura 19). 


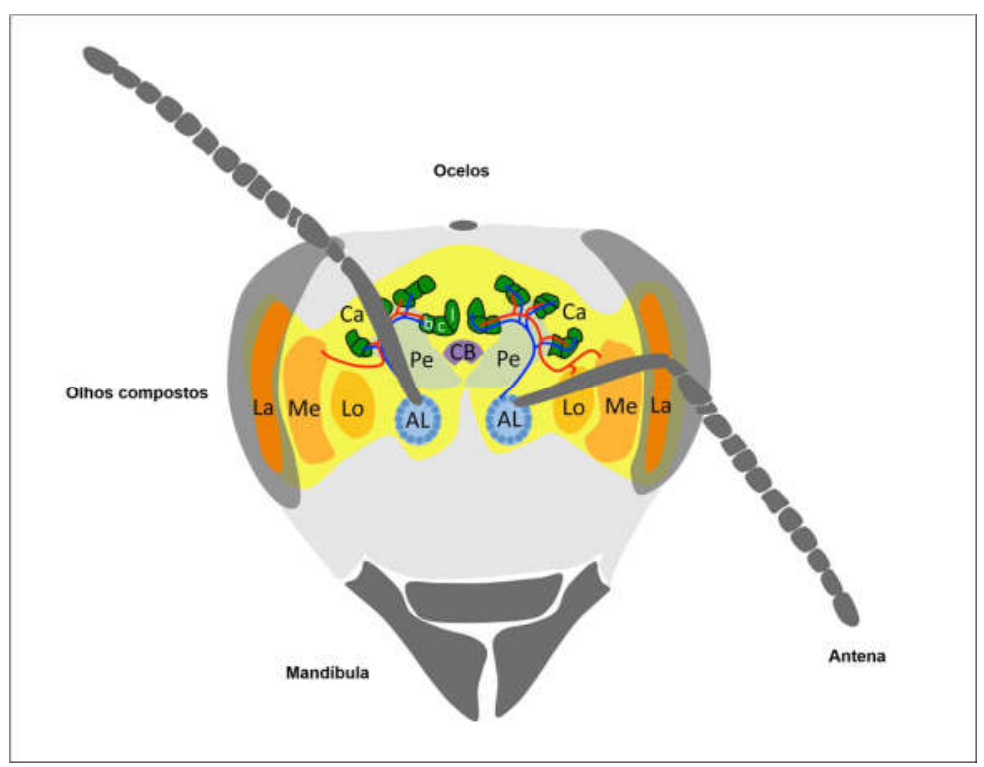

Figura 19. Representação esquemática do cérebro de uma abelha operária. Lamina (La), medula (Me), Lóbula (Lo) são estruturas que compõe o lobo visual e recebem sinais visuais dos olhos compostos. Os lobos antenais (AL) recebem sinais olfatórios da antena. Corpos cogumelares compostos por um peduncúlo $(\mathrm{Pe})$, dois cálices $(\mathrm{Ca})$. Corpo central $(\mathrm{CB})$. Adaptado de Lihoreau et al. (2012)

O lobo visual, composto pela lamina, medula e lóbula, recebem sinais sensórias oriundos dos olhos compostos. Os lobos antenais recebem os sinais dos neurônios sensórias olfatórios da antena. O corpo central é uma estrutura que conecta-se com todas as principais partes cerebrais e está envolvida com a coordenação das patas e controle motor. Os corpos cogumelares que processam informações multimodais e participam da aprendizagem e memória. Morfologicamente os corpos cogumelares são estruturas centrais em formato de cogumelo constituídos por um pedúnculo e dois cálices compartimentalizados, que recebem sinais olfatórios do lobo antenal e que recebe sinais dos lobos visuais e do anel basal (Lihoreau et al., 2012). Em abelhas, os corpos cogumelares são a região que mais sofrem alterações em suas proporções em virtude da divisão de trabalho na casta de operárias (Withers et al., 1993).

As abelhas exploram o ambiente antes de começarem a forragear e elas aprendem as relações espaciais dos objetos no ambiente durante seus voos exploratórios (Giurfa e Sandoz, 2012; Tedjakumala e Giurfa, 2013). Esse comportamento exploratório facilita a aprendizagem por associar a ação do 
animal com as consequências de seu comportamento. Esse tipo de associação constitui a base do condicionamento operante.

Neste contexto, abelhas vêm sendo utilizadas em vários estudos de aprendizagem associativa, embora em sua maioria esses estudos abordam a aprendizagem associativa por meio de testes de condicionamento clássico sendo a mais comum a aprendizagem associativa olfativa por meio de teste de reposta de extensão da probóscide (PER) (Giurfa e Sandoz, 2012; Matsumoto et al., 2012). O PER é utilizado como um modelo de estudo de aprendizagem clássica que vem sendo empregado a mais de 50 anos em estudos que abrangem tanto os aspectos comportamentais quanto dos eventos moleculares envolvidos nesse forma de aprendizagem (Giurfa e Sandoz, 2012). Nesse teste comportamental, a abelha aprende a associar um estimulo condicionado (CS), como a apresentação de um estímulo olfatório ou uma cor, como predizendo a ocorrência de um estímulo incondicionado (US), no caso, a apresentação de uma solução contendo sacarose (Takeda, 1961).

Estudos neuroproteômicos e de peptidomas cerebrais de abelhas vem sendo realizados com diferentes ênfases, tais quais investigações sobre alterações no proteoma cerebral de abelhas correlacionado com o estágio do desenvolvimento ontogenético da subcasta de abelhas operárias (Garcia et al., 2009; Hernández, 2009). Nessa mesma linha de avaliação das alterações do desenvolvimento ontogenético com foco no efeito dos neuropeptideos na regulação do comportamento social em abelhas operárias (Han et al., 2015).

Recentemente, (Da Silva Menegasso et al., 2017) realizaram análises proteômicas de extratos cerebrais de abelhas submetidas a PER identificaram 44 proteínas com diferença de abundância. As proteínas encontradas em sua maioria encontram-se relacionadas a processos metabólicos de compostos nitrogenados, heterocíclicos e aromáticos. No entanto não foram encontrados na literatura trabalhos com abordagens proteômicas no estudo de condicionamento operante em abelhas. 


\section{MATERIAIS E MÉTODOS}

\subsection{ANIMAIS}

Abelhas (Melipona quadrifasciata) operárias, forrageiras, provenientes de uma mesma colmeia, instalada no Laboratório de Psicologia da Aprendizagem do Departamento de Psicologia da Universidade Federal de São Carlos. A colmeia encontrava-se instalada sobre um aparador junto da janela e sua entrada era posicionada de modo que ao sair da colmeia, uma abelha poderia voar tanto para dentro da sala experimental como para o ambiente natural.

\subsection{MATERIAIS}

\subsubsection{Caixa de condicionamento operante para abelhas.}

Caixa de condicionamento operante adaptadas dos equipamentos desenvolvidos por Pessotti (1969). A caixa experimental encontrava-se sobre uma mesa de tampo preto, posicionada a uma distância de 1,5 m da colmeia. $\mathrm{Na}$ área superior da colmeia encontrava-se duas barras, a uma distância de $5,0 \mathrm{~cm}$ de um bebedouro, e a $6 \mathrm{~cm}$ de distância uma da outra. Neste experimento, apenas uma das barras foi utilizada. No interior da caixa, encontrava-se um reservatório contendo uma solução de sacarose $50 \%(\mathrm{~m} / \mathrm{v})$, e um mecanismo para a elevação de uma concha com aproximadamente $0,3 \mathrm{~mL}$ de xarope ao bebedouro. Cada barra encontrava-se presa a um mecanismo que podia fechar um sistema fotoelétrico, o qual acionava automaticamente um sistema que disponibiliza a solução de açúcar junto ao bebedouro (Figura 19). Na superfície da caixa encontrava-se uma área, equivalente a um semicírculo de $12 \mathrm{~cm}$ de diâmetro de acrílico translúcido para projeção de luz. O aparato era controlado eletronicamente por uma interface ligada a um microcomputador. O software para gerenciamento dos procedimentos e registro de dados foi desenvolvido pela mesma empresa que construiu o equipamento (Insight Equipamentos, Ribeirão Preto). 


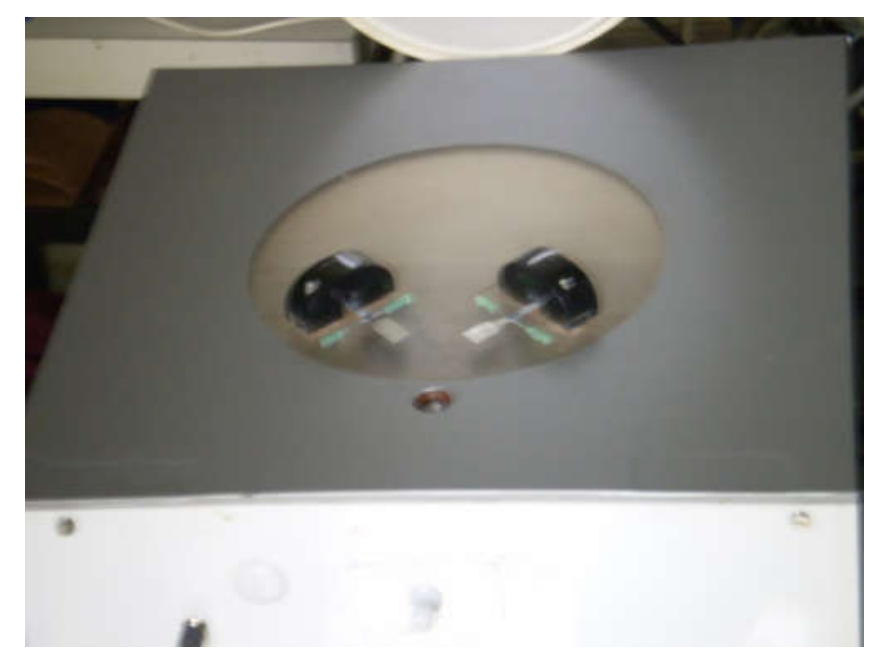

Figura 20. Caixa de condicionamento operante para abelhas. $O$ aparelho é composto por duas barras e um bebedouro onde é disponibilizado uma solução de sacarose $50 \%$ somente quando a abelha emite a resposta de pressão a uma das barras.

\subsection{METODOLOGIA}

\subsubsection{Experimento comportamental}

O experimento consistia na comparação das abelhas em 3 grupos com 20 abelhas em cada. Os grupos experimentais eram: grupo controle (E2-C), composto por operárias sem experiência com a situação experimental, recolhidas no início da manhã junto à colmeia e imediatamente submetidas à dissecação de seu cérebro; grupo treinado com 8 horas (E2-8) era composto por abelhas que foram submetidos a treinamento operante de pressão à barra tendo como reforço positivo a apresentação de xarope de sacarose; grupo treinado com 24 horas (E2-24), grupo submetido ao mesmo treino de condicionamento operante que as abelhas do grupo 8 , porém ao invés de terem seus cérebros dissecados após o final das sessões era aguardado 16 horas para que as mesmas fossem eutanasiadas. 


\subsubsection{Identificação do sujeito e modelagem de pouso sobre a caixa}

Um pires com xarope foi colocado junto à entrada da colmeia. Entre as abelhas que pousavam sobre o pires e começavam a sugar o xarope, uma foi escolhida ao acaso e marcada no dorso com tinta não tóxica conforme os procedimentos de Pessotti (1967). O pires foi sendo gradualmente deslocado em direção a caixa de condicionamento operante para abelhas localizado no interior da sala experimental. A resposta de voar da abelha identificada com tinta era modelada até que ela estivesse voando junto à caixa experimental.

Quando a abelha estivesse regularmente recolhendo xarope nessa área, algumas gotas de xarope eram depositadas próximo ao bebedouro de uma das caixas experimentais. Em visitas subsequentes, o tampo era limpo e o xarope passava a ficar disponível apenas no bebedouro.

\subsubsection{Modelagem da resposta de pressão à barra}

Quando a abelha estivesse voando sistematicamente ao aparelho e sugando o xarope, o acesso ao bebedouro passava a ser restrito: o xarope ficava disponível apenas com sua aproximação à barra. Em visitas subsequentes, o sujeito recebia reforço apenas quando tocasse a barra. Finalmente, apenas as respostas de pressão à barra eram reforçadas (ver Figura 20). 

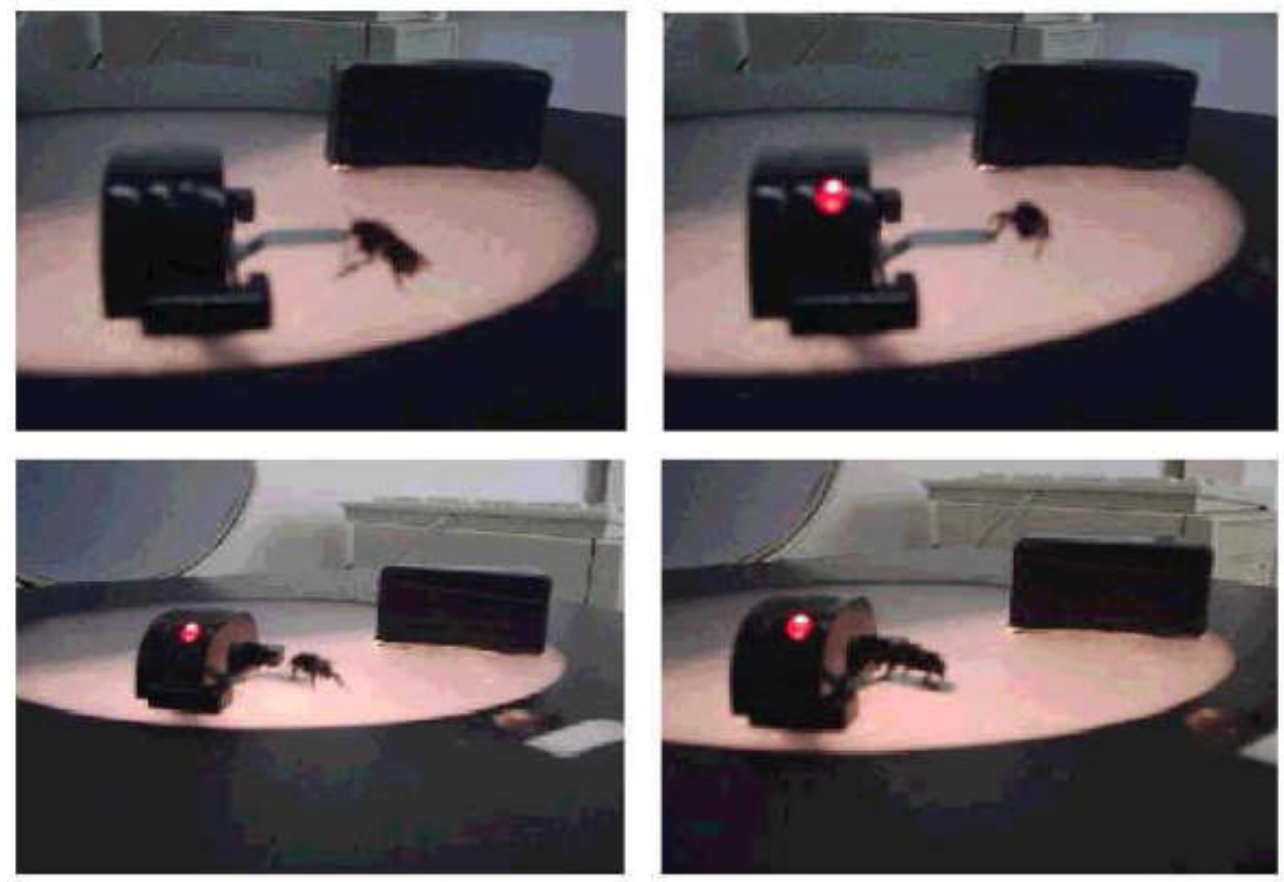

Figura 21. Diferentes etapas de modelagem de resposta instrumental (operante) com abelhas. O operandum era composto por uma barra de alumínio em uma porção externa (sobre a qual uma abelha se apoia, na foto) e uma peça de alumínio na outra extremidade, presas a um eixo também de alumínio e formando um sistema de alavanca. Quando uma abelha pressionava essa porção externa (barra), a outra extremidade se elevava fechando um circuito fotoelétrico e emitindo um sinal luminoso (LED vermelho) (credito da foto Antônio Maurício Moreno).

O procedimento era organizado em sessões de aproximadamente oito horas de duração e o trabalho era conduzido com apenas uma abelha por vez. Todas as abelhas do experimento (com exceção das abelhas do Grupo Controle), foram submetidas ao procedimento de modelagem da resposta operante (pressão-à-barra).

As sessões foram organizadas em blocos de 10 tentativas. Cada sessão era encerrada após 100 tentativas. Toda tentativa iniciava com a projeção de luz branca na superfície da caixa (ver Figura 2). Uma resposta de pressão-à-barra acionava o bebedouro com xarope por $55 \mathrm{~s}$. Em seguida, a luz era mantida apagada e o bebedouro era bloqueado por $10 \mathrm{~s}$.

Ao final da sessão, era conduzido o procedimento de dissecação do cérebro. Com outro grupo de abelhas, do mesmo modo, era conduzido treino de discriminação simples em uma única sessão com 100 tentativas, sendo definido o mesmo critério de aprendizagem utilizado com o primeiro grupo. Para este 
segundo grupo, no entanto, a dissecação era conduzida apenas na manhã do dia seguinte, ou seja, aproximadamente 16 horas após o início do procedimento. As abelhas do grupo controle eram operárias sem experiência com a situação experimental, recolhidas no início da manhã junto à colmeia e imediatamente submetidas à dissecação.

\subsection{EXTRAÇÃO DO CÉREBRO DE ABELHA}

Ao final do décimo bloco de pressão à barra as abelhas do grupo E2-8 eram capturadas e submetidas e anestesiadas em gelo, em seguida cada cérebro foi dissecado e macerado em $20 \mu \mathrm{L}$ de tampão de lise gelado (ureia 7 $\mathrm{M}$, tioureia $2 \mathrm{M}$, HEPES $20 \mathrm{mM}$ ) pH 8,5 contendo um coquetel de inibidores de proteases (cOmplete Mini, Roche Diagnostics, Manheim, Alemanha) e inibidores de fosfatases (PhosSTOP, Roche Diagnostics, Manheim, Alemanha). Em seguida, essa solução contendo cérebros foi imersa em nitrogênio líquido e armazenados a temperatura de $-20^{\circ} \mathrm{C}$.

O mesmo procedimento foi realizado com as abelhas do grupo E2-24, salvo que essas só tinha seus cérebros dissecados na manhã do dia seguinte.

Ao final dos experimentos foram obtidos dois pools para cada grupo, cada um contendo 10 cérebros. As amostras foram centrifugadas a $16.000 \times g$ por 15 min. O sobrenadante resultante foi submetido à quantificação proteica por fluorimetria através do Qubit assay kit (Life Technologies) de acordo com as instruções do fabricante.

\subsection{DIGESTÃO DE PROTEÍNAS E ANÁLISE VIA LC MS/MS}

Realizado conforme descrito no subitem 5.6 e 5.7 da metodologia do capítulo de ratos.

\subsection{IDENTIFICAÇÃO DE PROTEÍNAS CEREBRAIS}

Foram utilizados os mesmos parâmetros de buscas presentes no subitem 5.8 do capitulo de rato, salvo o banco de dados que foi utilizado. 
Os dados foram confrontados com o banco de dados de Melipona quadrifasciata (14.286 sequências baixadas do Uniprot em 23 de março de 2016). Uma taxa de falsos positivos foi estimada com a fusão do banco de dados com um banco decoy. A taxa de descoberta de falsos positivos (FDR) foi habilitada. Para os critérios de identificações finais, foram aplicados os filtros de FDR para peptídeos menor que $1 \%$ e, ao menos, um peptídeo único por proteína.

\subsection{ANÁLISE DE PROTEÍNAS COM DIFERENÇA NO PERFIL DE ABUNDÂNCIA}

Os arquivos raw referentes às corridas realizadas em triplicata dos de cada grupo experimental foram alinhados e analisados no programa Progenesis. A lista de features geradas neste programa foi submetida à busca no programa Peaks utilizando-se os parâmetros descritos na metodologia. A lista dos peptídeos/proteínas identificados nessa etapa foi exportada para o Progenesis e os conflitos resolvidos manualmente. Por meio dessa abordagem, label-free, foi possível determinar a quantificação relativa de 1281 proteínas. Os dados da quantificação relativa de cada proteína foram exportados do Progenesis e submetidos à análise estatística utilizando o programa $\mathrm{R}$ Studio pacote estatístico versão 3.3.1.

O programa $\mathrm{R}$ Studio envolveu, primeiramente, a análise de variância ANOVA com filtro de valor-p $<0,05$. Em seguida os valores-p obtidos foram corrigidos por meio da aplicação do teste de hipóteses múltiplas de acordo com a função de Benjamini-Hochberg com o método para estimativa de descoberta de falsos positivos baseado no método de q-valor controlado. Após essa análise, aplicou-se um filtro de $q<0,05$. Os dados das abundâncias das proteínas que possuíram q-valor < 0,05 foram então submetidos ao teste de Tukey da diferença honestamente significativa (HSD). 


\subsection{ANÁLISE DE ENRIQUECIMENTO DE VIAS}

A sequência das proteínas que apresentaram diferença de abundância entre os grupos foram submetidas à análise de enriquecimento no programa KOBAS 3.0. Foi utilizado o banco de vias KEGG para Apis melífera. O método estatístico utilizado para o enriquecimento foi o teste hipergeométrico/ teste exato de Fisher e para a correção de falsos positivos, o método de Benjamin e Hochberg.

\subsection{ANÁLISE DOS CLUSTERS DOS PADRÕES DE ABUNDÂNCIAS}

As médias das triplicatas dos dados de abundância das proteínas com diferenças no padrão de abundância entre os grupos foram submetidos a clusterização por Fuzzy c-means conforme descrito por Schwämmle e Jensen (2010). 


\section{RESULTADOS}

\subsection{PROTEOMA CEREBRAL DE Melipona quadrifasciata.}

Por meio de uma abordagem de proteômica shotgun foi possível identificar 3291 proteínas cerebrais de M. quadrifasciata nos três grupos avaliados. Desse total, 2653 proteínas foram identificadas no grupo E2-C, sendo que 257 proteínas foram observadas unicamente nesse grupo. No grupo de abelhas treinadas E2-8 foram identificadas 2755 proteínas sendo que 350 foram identificadas unicamente nessa condição. No grupo E2-24 foram identificadas 2478 proteínas no total e 168 identificadas exclusivamente nessa condição (Figura 21 e Tabela suplementar 7).

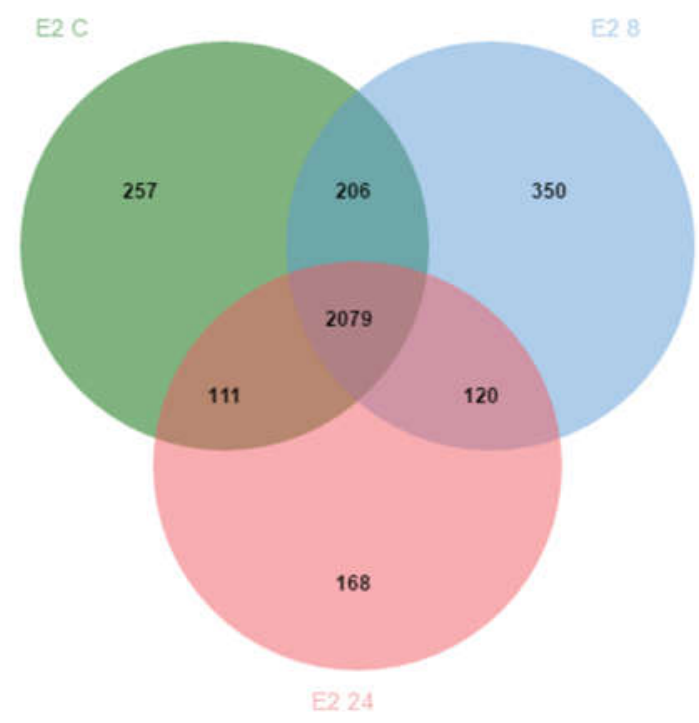

Figura 22. Número de proteínas cerebrais de abelhas $M$. quadrifasciata identificadas por cromatografia líquida acoplada a espectrometria de massas. E2 C representa o grupo de abelhas controle, abelhas experimentalmente ingênuas. E2 8 corresponde ao grupo de abelhas treinadas no paradigma operante a pressionar uma barra para receberem xarope, essa abelhas foram submetidas a 10 sessões de pressões e no final da última sessão tiveram seus cérebros dissecados. O grupo E2 24 representa abelhas que foram submetidos ao mesmo paradigma das abelhas do grupo E2 8, diferindo apenas do tempo em que o seu cérebro foi removido após o final do treinamento que foi de 16 horas após o final da sessão.

Até o momento não encontramos relatos na literatura de algum trabalho que descreva o proteoma cerebral de M. quadrifasciata. O único trabalho que encontramos abordou somente o proteoma presente na glândula salivar de 
abelhas operárias por meio de uma estratégia baseada em gel de eletroforese bidimensional que identificou 27 proteínas presentes nesse (Elias-Santos, 2013).

\subsection{ANÁLISE DE PROTEÍNAS COM DIFERENÇA NO PERFIL DE ABUNDÂNCIA}

Os arquivos raw referentes às corridas realizadas em triplicata dos de cada grupo experimental foram alinhados e analisados no programa Progenesis. A lista de features geradas neste programa foi submetida à busca no programa Peaks utilizando-se os parâmetros descritos na metodologia. A lista dos peptídeos/proteínas identificados nessa etapa foi exportada para o Progenesis e os conflitos resolvidos manualmente. Por meio dessa abordagem, label-free, foi possível determinar a quantificação relativa de 1281 proteínas. Os dados da

quantificação relativa de cada proteína foram exportados do Progenesis e submetidos à análise estatística utilizando o programa $\mathrm{R}$ Studio pacote estatístico versão 3.3.1.

O programa R Studio envolveu, primeiramente, a análise de variância ANOVA com filtro de valor-p $<0,05$. Em seguida os valores-p obtidos foram corrigidos por meio da aplicação do teste de hipóteses múltiplas de acordo com a função de Benjamini-Hochberg com o método para estimativa de descoberta de falsos positivos baseado no método de q-valor controlado. Após essa análise, aplicou-se um filtro de $q<0,05$. Essa análise resultou em 850 proteínas com diferença significativa de abundância em ao menos dois dos três grupos avaliados. Com o intuito de averiguar a diferença real entre os três grupos de abelhas analisados, os dados de abundâncias das 850 proteínas foram submetidos ao teste de Tukey da diferença honestamente significativa (HSD) (Tabela suplementar 8 ).

Em decorrência do elevado número de proteínas com diferenças nos perfis de abundância entre os grupos avaliados as sequências fastas das proteínas com diferença de abundância foram submetidas a análise no programa KOBAS contra o banco de Apís melífera. Foram identificadas 38 vias enriquecidas com valor-q inferior a $0.05>$, conforme apresentado na Tabela suplementar 9. Ainda assim, vale ressaltar que 281 das 850 proteínas que 
apresentaram diferenças de abundância não possuem anotações no banco de vias KEGG.

No geral a maioria das vias KEGG que obtiveram enriquecimento encontram-se envolvidas principalmente com o metabolismo de carboidratos, proteínas e ácidos graxos. Ainda assim, podemos destacar as vias de fototransdução com valor-q < 0,001; spliceossomo com valor-q < 0,002; fagossomo com valor-q de 0,02 e a via de vigilância da qualidade do RNA. Novamente como observado nos ratos submetidos a treinamento operante 0 processo de fagocitose encontram-se enriquecido, dando indícios que esse processo desempenha um importante papel nessa forma de aprendizagem. Alterações nas envolvidas com o controle da qualidade do RNA, bem como no seu processamento via splicing, sugerem que durante esse processo de aprendizagem que durante esse processo de aprendizagem por condicionamento operante ocorre a transcrição de determinadas isoformas de produtos gênicos. Essa hipótese pode ser corroborada pela observação de alguns fatores de fatores de transcrição e tradução com diferença no perfil de abundância ao longo dos treinamentos.

Após aplicação do teste de Tukey constatou-se que apenas 16 proteínas apresentaram diferenças estatisticamente significativas entre as três condições (Tabela 4). As demais 834 proteínas apresentam diferenças significativas apenas entre 2 dos 3 grupos avaliados. 
Tabela 4. Proteínas com abundância reduzida nas abelhas treinadas e diferentes entre os três grupos analisados.

\begin{tabular}{|c|c|}
\hline Número de acesso & Proteína \\
\hline A0A0M8ZQU0 & Regucalcin \\
\hline AOA0M8ZWS9 & Cytoplasmic protein NCK1 \\
\hline A0A0M9A6G8 & Sarcalumenin \\
\hline A0A0M9A871 & Uncharacterized protein \\
\hline A0A0M9A935 & Transferrin \\
\hline A0A0M9AAR7 & HemK methyltransferase family member 1 \\
\hline A0A0M9ABF6 & Eukaryotic translation initiation factor 3 subunit $D$ \\
\hline A0A0M9ABG2 & Prohormone-2 \\
\hline AOAONOBEY9 & Alpha-glucosidase \\
\hline AOAONOBIR9 & Antithrombin-III \\
\hline AOAONOBKDO & Angiotensin-converting enzyme \\
\hline AOAONOBKL4 & Gamma-glutamyl hydrolase \\
\hline A0A0N0U4Q3 & F-box/LRR-repeat protein 7 \\
\hline AOAON0U709 & Prefoldin subunit 4 \\
\hline
\end{tabular}

Foi realizada a classificação ontológicas dessas proteínas com diferença de abundância entre os três grupos. Os termos GO com relação ao componente celular para essas proteínas indicam três proteínas como sendo componente integral da membrana, duas proteínas pertencentes ao espaço extracelular, o envolvimento de complexos de pré-iniciação eucarióticos (48S, $43 \mathrm{~S}$ ), além de um proteínas pertencente ao fator 3 do complexo de iniciação da tradução, uma proteína constituinte do ribossomo, e uma pertencente ao complexo prefoldina.

Além disso, essas proteínas foram classificadas com relação aos processos biológicos que encontram-se envolvidas. Observou-se que os seguintes processos biológicos encontram-se alterados: proteólise, metabolismo de carboidratos, regulação catalítica, metilação de proteínas, metabolismo da glutamina, regulação do início da tradução, transporte de íons, dobramento de proteínas, homeostasia do íon ferro. 
As proteínas que apresentaram diferença em apenas dois dos três grupos de abelhas avaliados foram separadas de acordo com o grupo em que haviam os maiores níveis de abundância e nos que apresentavam os menores níveis. Essa divisão foi aplicada com o intuito de averiguar que diferenças ocorriam entre os tempos de treinamento.

$\mathrm{Na}$ Tabela 5 encontram-se apresentadas as quatro proteínas que tiveram aumento de abundância em abelhas do grupo E2-24 e menores níveis em abelhas do grupo E2-8.

Tabela 5. Lista de proteínas com aumento de abundância entre abelhas do grupo E224 e que apresentaram menores níveis em abelhas do grupo E2-8.

\begin{tabular}{cc}
\hline $\begin{array}{c}\text { Número de } \\
\text { acesso }\end{array}$ & Proteína \\
\hline A0A0M8ZPA9 & Tetra-peptide repeat homeobox 1-like \\
A0A0M8ZRH3 & Endochitinase A1-like \\
A0A0M9A6Q8 & DNA-directed RNA polym.I, II, and III subunit RPABC3 \\
A0A0N0BE26 & Kunitz-type proteinase inhibitor kalicludin-1 \\
\hline
\end{tabular}

A proteínas DNA-directed RNA polimerase encontra-se envolvida no processo de transcrição. A única informação que se tem sobre o inibidor de proteinase tipo Kunitz é que ele é um inibidor de serina endopeptidase. Não foram encontradas informações sobre as outras duas proteínas, por meio de análise de suas sequências elas são preditas como constituintes da membrana plasmática.

Na Tabela 6 encontram-se listadas as 70 proteínas que foram observadas com maiores níveis de abundância em abelhas pertencentes ao grupo E2-8 e menores níveis no grupo E2-24. 
Tabela 6. Lista de proteínas que tiveram maiores níveis de abundância em abelhas do grupo E2-8 e uma diminuição de abundância em abelhas do grupo E2-24.

\begin{tabular}{|c|c|}
\hline $\begin{array}{c}\text { Número de } \\
\text { acesso }\end{array}$ & Proteína \\
\hline A0A0M8ZN10 & S-(hydroxymethyl)glutathione dehydrogenase \\
\hline AOA0M8ZNU4 & 6-phosphofructokinase \\
\hline A0A0M8ZP65 & Ser/Thr-protein phosphatase 2B catalytic subunit 3 \\
\hline A0A0M8ZPJ4 & Protein retinal degeneration $B$ \\
\hline A0A0M8ZPV4 & Tyramine beta-hydroxylase \\
\hline AOA0M8ZQE2 & AP-2 complex subunit sigma \\
\hline A0A0M8ZQS6 & Putative actin-related protein $2 / 3$ complex subunit 2 \\
\hline AOAOM8ZQS9 & Voltage-dependent L-type calcium channel subunit beta- 2 \\
\hline A0A0M8ZR16 & $\mathrm{Ca}^{2+} /$ calmodulin-dependent protein kinase type II $\alpha$-chain \\
\hline A0A0M8ZRV2 & Ser/Thr-protein phosphatase 2B catalytic subunit 2 \\
\hline A0A0M8ZTH3 & Serine-enriched protein \\
\hline A0A0M8ZTI8 & Cat eye syndrome critical region protein 5 like protein \\
\hline AOAOM8ZTU9 & Type I inositol 1,4,5-trisphosphate 5-phosphatase \\
\hline A0A0M8ZU64 & Glutathione peroxidase \\
\hline A0A0M8ZUI2 & Lysosomal Pro-X carboxypeptidase \\
\hline A0A0M8ZUV1 & Protein RUFY3 \\
\hline A0A0M8ZV30 & Microtubule-associated protein RP/EB family member 1 \\
\hline A0A0M8ZWA1 & Anion exchange protein \\
\hline A0A0M8ZXV7 & Xaa-Pro aminopeptidase 1 \\
\hline A0A0M8ZXX1 & Cytoplasmic phosphatidylinositol transfer protein 1 \\
\hline A0A0M8ZYL9 & Protein angel like protein 2 \\
\hline A0A0M8ZZR4 & Protein Dom3Z \\
\hline A0A0M8ZZU6 & Vesicle-fusing ATPase 1 \\
\hline A0A0M8ZZZ7 & Liprin-alpha-2 \\
\hline AOA0M9A0D3 & Alanine aminotransferase 2 \\
\hline AOAOM9A0Z9 & Collagen alpha-2(I) chain \\
\hline A0A0M9A1N6 & Protein 4.1 like protein \\
\hline A0A0M9A236 & Collagen alpha- $1(\mathrm{IV})$ chain \\
\hline A0A0M9A2M2 & Histone deacetylase Rpd3 \\
\hline A0A0M9A4Y2 & Squamous cell carcinoma antigen recognized by T-cells 3 \\
\hline
\end{tabular}




\begin{tabular}{|c|c|}
\hline $\begin{array}{c}\text { Número de } \\
\text { acesso }\end{array}$ & Proteína \\
\hline A0A0M9A572 & MATH and LRR domain-containing PFE0570w-like \\
\hline & Dual specificity mitogen-activated protein kinase kinase \\
\hline A0A0M9A611 & dSOR1 \\
\hline A0A0M9A6J6 & DmX-like protein 2 \\
\hline A0A0M9A7T4 & Uridine phosphorylase 1 \\
\hline A0A0M9A9U8 & Sideroflexin \\
\hline A0A0M9AA66 & Glutaminase kidney isoform, mitochondrial \\
\hline & Guanine nucleotide-binding prot. $G(I) / G(S) / G(T)$ subunit $\beta$ - \\
\hline A0A0M9AA79 & 1 \\
\hline A0A0M9AAE2 & RWD domain-containing protein 1 \\
\hline A0A0M9AAF9 & Protein N-terminal glutamine amidohydrolase \\
\hline A0A0M9AAS9 & Protein kinase $\mathrm{C}$ \\
\hline AОАОМ9ААТО & WD repeat-containing protein 37 \\
\hline A0А0M9AB86 & Glutamate decarboxylase 1 \\
\hline A0A0M9ABZ6 & Mitogen-activated protein kinase \\
\hline A0A0M9ADD8 & Rho-type guanine exchange factor isoform X2 \\
\hline AOAONOBBB2 & G protein-coupled receptor kinase 1 \\
\hline AOAONOBBJ6 & Guanine nucleotide-releasing factor 2 \\
\hline AOAONOBCKO & Protein ROP \\
\hline A0A0N0BD57 & Cystathionine gamma-lyase \\
\hline AOAONOBDY3 & Threonine--tRNA ligase, cytoplasmic \\
\hline AOAONOBEA3 & Glutathione S-transferase theta-1 \\
\hline AOAONOBEV7 & Tubulin beta- 1 chain \\
\hline AOAONOBFV 5 & AP complex subunit beta \\
\hline AOAONOBGS3 & Cytoplasmic dynein 1 light intermediate chain 2 \\
\hline AOAONOBHP7 & GMP reductase \\
\hline AOAONOBHX3 & Eukaryotic translation initiation factor 4 gamma 2 \\
\hline A0AONOBIA1 & Enoyl- delta isomerase mitochondrial-like \\
\hline AOAONOBIQ4 & Calcium uniporter protein, mitochondrial \\
\hline AOAONOBIT6 & FUN14 domain-containing protein 1 \\
\hline AOAONOBK80 & TPPP family CG45057 \\
\hline
\end{tabular}




\begin{tabular}{cc}
\hline $\begin{array}{c}\text { Número de } \\
\text { acesso }\end{array}$ & Proteína \\
\hline AOA0N0BKT7 & \\
AOAON0U482 & Uncharacterized protein \\
AOA0N0U4N5 & Prolyl endopeptidase \\
AOAON0U564 & Protein NDRG3 \\
AOA0N0U5U1 & Protein phosphatase 1 regulatory subunit 14B \\
\hline
\end{tabular}

Objetivando descobrir em quais processos biológicos, componentes celulares e atividade enzimáticas as 70 proteínas que apresentaram os maiores níveis de abundância em abelhas do grupo E2-8 e os menores níveis de abundância em abelhas do grupo E2-24 tiveram suas sequências analisadas pelo programa Blast2GO. A partir dessas análises podemos destacar os seguintes processos biológicos com alterações: fosforilação de proteínas (6), processo biossintéticos de macromoléculas, expressão de genes (6), processo biossintéticos de compostos nitrogenados (5), organização de componentes celulares (4), transdução de sinal (4), processo metabólico do RNA (4). Para componentes celulares temos proteínas que são componentes integrais de membrana (9), proteínas que se associam em complexos (7), que fazem parte do citoesqueleto (4), ligadas a membrana intracelular de organelas (3).

Dentre as proteínas com maiores níveis no grupo E2-8 e menores no grupo E2-24 podemos destacar proteínas envolvidas no processo de fosforilação como, a-CaMKII, PKC, 6-fosfofrutocinase, MAPK e proteínas envolvidas com a desfoforilação como a proteína fosfatase 1 subunidade regulatória 14B, Ser/Thrproteína fosfatase $2 \mathrm{~B}$ subunidade catalítica 3 , Ser/Thr- proteínas fosfatse $2 \mathrm{~B}$ subunidade catalítica 2, proteína fosfatase de inositol trifosfato. Eventos de fosforilação e desfosforilação estão envolvidos na modulação da excitabilidade dos neurônios, fortalecimento de sinapses existentes, sinaptogênese e até mesmo neurogênese em adultos (Kandel, 2012; Giese e Mizuno, 2013).

A a-CaMKII, uma proteína que é amplamente relatada na literatura como crucial no processo de diferentes tipos de aprendizagem e memória principalmente pelo seu papel na inserção de receptores AMPA na membrana favorecendo assim a LTP (Malinow et al., 1989; Fink e Meyer, 2002; Shonesy et 
al., 2014; Baucum et al., 2015; Lisman e Raghavachari, 2015; Scholl et al., 2015; Juárez-Muñoz et al., 2017). Estudos realizados por Scholl e colaboradores (2015) mostram que abelhas que tiveram knockdow no gene para CaMKII tiveram um rompimento na formação de LTM para testes de aprendizagem olfatória, mostrando que ela é essencial para a formação de LTM em abelhas.

A via de sinalização mediada por MAPK tem como um de seus resultados a fosforilação do fator de transcrição CREB. Estudos realizados por Felsenberg et al. (2015) demonstram diferentes níveis de fosforilação de CREB em abelhas treinadadas por aprendizagem olfatória por PER.

Além disso, observou-se que as proteínas Arp2/3 e a proteína 4.1 que apresentavam uma maior abundância no grupo E2-8 e menores níveis em E224. Ambas proteínas envolvidas com a organização do citoesqueleto. Cabe ressaltar que proteínas homologas a estas também foram encontradas como diferencialmente abundantes nos ratos que foram submetidos ao treinamento operante discriminativo. Em ratos treinados Arp2/3 apresentou uma diminuição de abundância quando comparado ao seu controle. A partir dessa observação, pode-se concluir que Arp2/3 é uma proteína que encontra-se envolvida no processo de aprendizagem por condicionamento operante tanto em ratos como em abelhas, mas principalmente que o aumento dos seus níveis deve ocorrer no início desses treinamentos, e que quando se tem um prolongamento do número de sessões de treinamento e do tempo após o início da sessão os seus níveis tendem a diminuir, comportamento semelhante ao observado por Kelly e Deadwyler (2002) para os níveis de Arc/Arg3.1.

No que diz respeito aos níveis da proteína 4.1, apresentou um aumento em ambos modelos estudados, como discutido anteriormente no capítulo de ratos. Os dados aqui apresentados corroboram os relatos de Walensky (1998), fortalecendo a hipótese de que a proteínas 4.1 desempenha um papel importante na aprendizagem e formação de memórias.

Embora possa se retirar informações importantes sobre os processos que podem estar ocorrendo tomando-se como base que grupo possuía os maiores e menores níveis de certas proteínas cerebrais, isso não reflete a dinâmica de como esses níveis de proteína variam ao longo do processo de aprendizagem. 
Objetivando então investigar quais os perfis de abundâncias as proteínas que apresentaram diferenças entre os grupos se enquadravam foi realizada a análise de agrupamentos por clustering. Por meio dessa análise as proteínas foram agrupadas em 3 clusters de padrões de abundância (FIGURA 22).

O cluster 1 é constituído por 142 proteínas, no cluster 2 foram agrupadas 173 proteínas e o cluster 3 foi o que apresentou o maior número de membros com 295 proteínas. Com o intuito de ser ter uma melhor compreensão sobre quais processos biológicos são alterados conforme os cluster obtidos, as proteínas de cada um desses cluster foram submetidas a análise de enriquecimento de vias no programa KOBAS.

Algumas das proteínas do cluster 1 encontram-se super-representadas nas vias, com seus respectivos q-valores associados, transporte de RNA $(0,0018)$, spliceossomo $(0,0033)$ e fosforilação oxidativa $(0,049)$.

Para o cluster 2, observamos as seguintes vias enriquecidas: metabolismo de ácidos graxos (0,0002), biossíntese de aminoácidos $(0,001)$, metabolismo do piruvato $(0,001)$, proteassomo $(0,002)$, ciclo do ácido citríco $(0,002)$, metabolismo do ascorbato e aldarato $(0,003)$, endocitose $(0,005)$, enlogação de ácidos graxos $(0,005)$, processamento de proteínas no retículo endoplasmático $(0,006)$, metabolismo de butanoato $(0,006)$, via das pentose fosfato $(0,01)$, fototransdução $(0,02)$, fosforilação oxidativa $(0,03)$, degradação de lisina $(0,04)$. 
Cluster 1

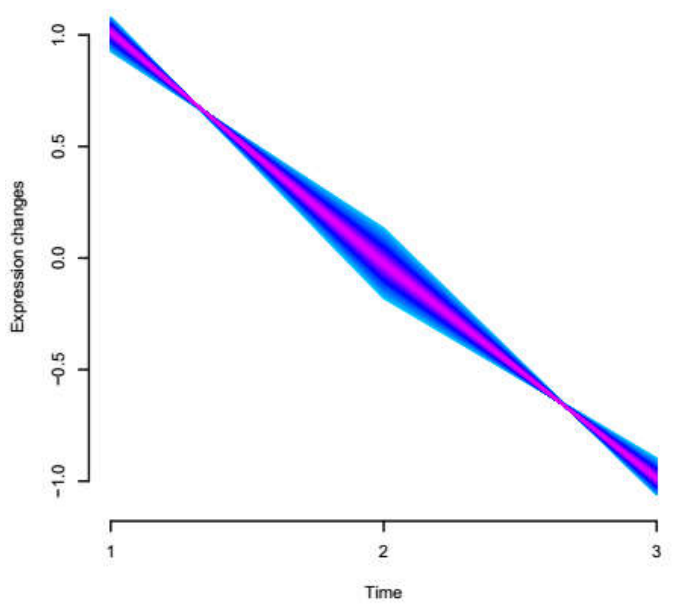

Cluster 3
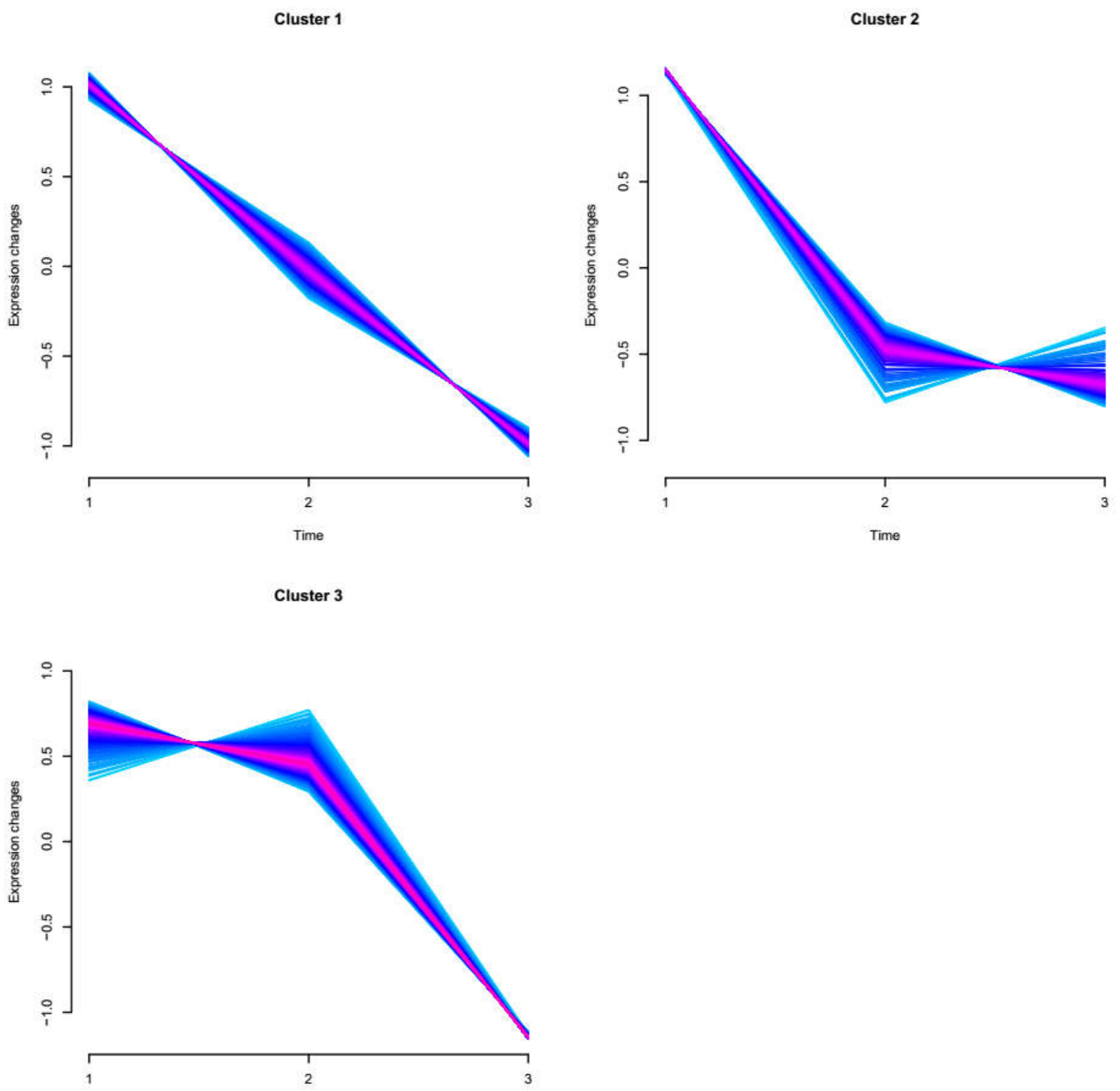

FIGURA 22. Linhas de tendência da expressão de proteínas durante o processo de aprendizagem operante em abelhas (M. quadrifasciata). A posição 1 do eixo das ordenadas representa o grupo de abelhas controle, a posição 2 representa o grupo de abelhas treinadas que tiveram seus cérebros removidos imediatamente após o fim do treinamento, e o 3 representa o grupo de abelhas submetidas ao treinamento operante de pressão a barra mas que só tiveram seus cérebros extraídos 24 horas após o início do treinamento.

O cluster 3 foi o que apresentou o maior número de vias alteradas. As vias super-representadas para esse cluster foram: metabolismo de frutose e manose $\left(1,6 \times 10^{-4}\right)$, biossíntese de arginina $\left(1,7 \times 10^{-4}\right)$, interconversão de pentose $e$ glicoronato $\left(4,9 \times 10^{-4}\right)$, endocitose $\left(1,8 \times 10^{-3}\right)$, metabolismo de arginina e prolina $\left(1,9 \times 10^{-3}\right)$, metabolismo de butanoato $(0,003)$, metabolismo do glioxilato $\mathrm{e}$ dicarboxilato $(0,003)$, fagossomo $(0,003)$, metabolismo da galactose $(0,006)$, 
metabolismo da beta alanina $(0,006)$, fosforilação oxidativa $(0,007)$, metabolismo de selenocompostos, via de vigilância de mRNA $(0,011)$, fototransdução $(0,015)$, via de sinalização $\operatorname{mTOR}(0,025)$, degradação de valina, isoleucina e leucina $(0,026)$, via das pentose fosfato $(0,026)$, via de sinalização Hippo $(0,026)$, proteassomo $(0,03)$, biossíntese de aminoacil-tRNA $(0,034)$, metabolismo de purinas $(0,036)$, transporte de RNA $(0,039)$, metabolismo de triptofano $(0,039)$, processamento de proteínas no retículo endoplasmático $(0,041)$, degradação de ácidos graxos $(0,041)$, metabolismo da histidina $(0,046)$.

Baseado nas análises por cluster podemos concluir que proteínas envolvidas com spliceossomo, e transporte de RNA possuem uma rápida queda em seus níveis de abundância nas abelhas submetidas ao condicionamento operante e isso segue uma tendência ao de seguir caindo ao longo das 24 horas após o início do treinamento. Proteínas envolvidas nos processos metabólicos envolvendo carboidratos, lipídios e proteínas, degradação mediada pelo proteassomo e endocitose apresentam um tendência a ter uma redução em seus níveis em uma taxa de aceleração acentuada nas primeiras 8 horas de treinamento e tende a permanecer nesses níveis mais baixos. No entanto, proteínas envolvidas com processos envolvendo RNA, tais como a via de vigilância de RNA, transporte de RNA e biossíntese de aminoacil tRNA apresentam uma tendência a manterem seus níveis nas primeiras 8 horas de treinamento e depois desse tempo tendem a ter uma rápida queda em seus níveis ao menos até as 24 horas após o início do treinamento, o mesmo acontece para o processamento de proteínas no retículo endoplasmático. 


\section{CONCLUSÃO}

Os resultados mostram, pela primeira vez, que o treinamento de abelhas no paradigma de condicionamento operante ao longo do tempo altera o proteoma cerebral do inseto. Essas proteínas encontram-se relacionadas a vários processos metabólicos envolvendo carboidratos, lipídios e aminoácidos; síntese, estabilização e degradação de RNAs; organização de proteínas de membrana; regulação da transdução de sinal; e regulação da plasticidade sináptica.

É importante ressaltar que, embora as abelhas utilizadas nesse experimento tenham tido seu genoma sequenciado e disponibilizado há pouco tempo, muitas informações, principalmente no que concernem a processos biológicos e vias, ainda precisam ser anotadas, visto que $33 \%$ das proteínas com diferença de abundância não possuíam anotações em vias KEGG, o que torna difícil a compreensão dos dados.

Foram observadas apenas 16 proteínas com diferença de abundância entre os três grupos. Foram identificadas proteínas envolvidas em processos de fosforilação e desfosforilação que dão indícios de que o processo de aprendizagem por condicionamento operante, ao menos em fase inicial, não apresenta grandes variações nos níveis das proteínas, mas sim que a modulação de sua atividade esteja associada a sua ativação ou inativação por meio de modificações pós-traducionais. Destacam-se a presença diferencial das proteínas CaMKII e MAPK, que tiveram um aumento de sua abundância nos animais analisados imediatamente após o final do treinamento e menores níveis em animais do grupo avaliado 24 h após o início do treino. 


\section{CAPÍTULO III}

\section{ANÁLISE DO INTERATOMA ENTRE MRJP1 E PROTEÍNAS CEREBRAIS DE ABELHAS}

Manuscrito em revisão ao periódico Scientific Report 


\title{
Interactome analysis of the major royal jelly protein 1 and brain proteins from honey bee
}

\author{
Jaques M. F. de Souza ${ }^{1,+}$, Gabriel C. N. da Cruz $^{1,2+}$, Luis Henrique F. \\ do Vale ${ }^{1,+}$, Carlos A. O. Ricart ${ }^{1}$, Neil L. Kelleher ${ }^{3}$ and Marcelo V. de Sousa ${ }^{1^{*}}$
}

${ }^{1}$ Brazilian Center of Protein Research, Laboratory of Protein Chemistry and Biochemistry, Department of Cell Biology, University of Brasilia, Brasilia-DF, 70910-900, Brazil.

${ }^{2}$ Technical-Scientific Department, São Paulo State Police, Catanduva-SP, 15809-007, Brazil.

${ }^{3}$ Proteomics Center of Excellence, Northwestern University, Evanston, IL, USA.

*mvsousa@unb.br

+these authors contributed equally to this work

\section{ABSTRACT}

Differentiation of honey bee larvae into queen is attributed to the glycoprotein major royal jelly protein 1 (MRJP1). Also found in the honey bee brain, MRJP1 functions are still unknown. During development from nurse to forager, MRJP1 concentration decreases in the worker brain. We analyzed interactions of honey bee brain proteins with MRJP1 by means of affinity purification, protein identification by LC-MS/MS, GO terms categorization and KEGG pathway mapping. A total of 120 honey bee brain proteins were identified. Several were anti-oxidant proteins. Also, protein kinase $A(P K A)$, protein kinase $C$ (PKC) and calcium/calmodulin-dependent kinase type II (CAMK II) were present. In addition to serving as a substrate, MRJP1 may act as an anchoring protein for protein kinases, with possible regulatory function. GO term enrichment analysis revealed statistically significant $p$ values for microtubule associated complex, neurotransmitter secretion and glycolytic process. Pathway analyses showed that protein kinases were marked in 
several neuronal pathways that control gene expression, neuronal excitability, exocytosis, endocytosis, synaptic plasticity, cytoskeletal remodeling and axon attraction/repulsion. Other pathways, such as focal adhesion, adherens junction, tight junction, gap junction, apoptosis, phagosome and regulation of cytoskeleton presented actin and other cytoskeleton-related proteins. Our results reinforce the hypothesis of polyfunctionality of MRJP1.

\section{Introduction}

Royal jelly (RJ) is a secretion produced by the hypopharyngeal gland of nurse worker honey bees (Apis mellifera) to feed larvae after hatching from eggs. Female larvae fated to develop into queens receive solely RJ throughout their development, while larvae that are to mature into worker bees pass to be fed with a mixture of RJ, honey and pollen after the third day 1 . $\mathrm{RJ}$ is composed of water (60-70\%), proteins (12-15\%); sugars (10-16\%) and lipids (3-6\%), with traces of vitamins, salts and free amino acids also present ${ }^{2}$.

Royal jelly proteins have been analyzed since $1960^{3}$, such that RJ proteome profiles are now well characterized ${ }^{4-13}$. The principal protein components of RJ are referred to as major royal jelly proteins (MRJPs $)^{14,15}$, as well as other names such as apalbumins and royalactins ${ }^{1}$. Initial studies described two mrjp genes, but recent molecular biology and protein chemistry analysis ${ }^{15-}$

21 identified nine mrjp genes and one mrjp-like gene based on. MRJPs proteins show molecular masses ranging from 47 to $80 \mathrm{KDa}^{14}$. In addition to honey bees, other hymenopterans, such as bumble bees, ants and wasps, also possess mrjp genes ${ }^{1}$. Primarily described as having a nutritional role, MRJPs are now considered as polyfuncional proteins ${ }^{1,2}$.

MRJP1, the most abundant RJ protein, is a $56,1 \mathrm{KDa}^{4,7,10-13,21-25}$ glycoprotein that is glycosylated at five sites (N44, N88, N247, N313, and N319) 1,2,14,26-31. In addition to a nutritional function, it was described as the determinator for the differentiation of larvae into queen via an egfr-mediated signaling cascade 1,2,27,29,32-35. However, criticism against this hypothesis has been published, with sugars also appearing to be important differential determinants of the caste dimorphism ${ }^{4,7,10-13,16,18,21-26,32,33,36-43}$. More recently, MRJP1 was postulated to be not necessary for triggering queen larval development in a replication of the original experiment ${ }^{4,7,10-14,21-26,36,44,45}$. A reply to the criticism claimed that the experimental replication was not conducted exactly as in the original work, in particular with regard to the amount of MRJP1 supplied to queen-destined larvae ${ }^{1,14,26,44,46-48}$. In addition to the potential role in triggering queen larval development, an 
antimicrobial role has also been described for MRJP1, which was proposed to harbor three antimicrobial peptides ${ }^{14,16,18,21,26,29,37,38,40,49,51-53}$.

While little is known about MRJP1 functions in the royal jelly, even less is understood regarding the roles of this protein in other honey bee tissues. As a matter of fact, MRJP1 is present in brain ${ }^{1,14,29,53-55}$ and in most of the other 29 insect body parts, as surveyed in a comprehensive proteomics studies ${ }^{1,2,11,31,55}$.

During behavioral and ontogenetic development from nurse to forager, the concentration of MRJP1 decreases in the honey bee worker brain 1,2,12,21,29,31,56. In parallel, some other proteins are down-regulated, while a set of up-regulated proteins arises. Still the most abundant protein in the honeybee brain, MRJP1 degradation during worker aging and behavioral shift suggest that amino acids released by this protein may become engaged in synthesis of new proteins $^{21,28,29,32,57,58}$. However, MRJP1 may carry a plethora of other functions in the honey bee brain, as observed in many other examples of multifunctional proteins in the literature.

A useful and common strategy to determine possible functions for a given protein is to determine its interacting partners ${ }^{4,7,10-13,22-25,39,42,43,59-62}$. In order to suggest possible biological functions for MRJP1, we analyzed its interactome with brain proteins from honey bee. For this, an affinity chromatography assay was developed to capture MRJP1-binding proteins. Identification of these proteins was performed by LC-MS/MS, followed by their categorization according to GO terms and metabolic pathway mapping via the KEGG database.

\section{Results}

\section{MRJP1 interactome with 118 different proteins}

MRJP1 was purified as previously described ${ }^{14,21,26,63}$. For the current work, MRJP1 purity was determined not only by SDS-PAGE, but also by mass spectrometry (MS) (Fig. 1). The molecular mass of MRJP1 was also determined by MS as 52,098.973 kDa. There were two other peaks on the spectrum, which are not contaminants, since they can be assigned to the doubly charged MRJP1 (m/z 25,998.688) and to apisimin ( $\mathrm{m} / \mathrm{z}$ at 5,493.642), a naturally occurring MRJP1 binding peptide1,47,64. Some extra minor bands seen on the SDS-PAGE gel above and 
below the MRJP1 main band were determined as MRJP1 fragments (lower MWs) and MRJP1 dimer / oligomers (higher MWs) by MALDI-TOF peptide mass fingerprinting (Supplementary Fig. 1).

The interactome between MRJP1 and honey bee brain proteins was determined by LCMS/MS protein identification after purifying the MRJP1-brain protein complexes. For this, purified MRJP1 was coupled to activated thiol-Sepharose resin (MRJP1-Sepharose). The reversibility of this reaction was demonstrated by eluting MRJP1 from the resin with $25 \mathrm{mM}$ DTT in binding buffer. The honey bee brain protein extract was incubated with MRJP1-Sepharose. The unbound material was exhaustively washed. Complex MRJP1-ligands were then uncoupled from the resin. The contents of the fractions from all the steps of the affinity separation were analyzed by SDSPAGE (Fig. 1). A control experiment was conducted to check if any brain protein would interact with the resin (with no MRJP1 linked to it). Thiol biding groups were blocked with iodoacetamide. Subsequently, a brain extract was run through the column, washed with assay buffer containing $200 \mathrm{mM} \mathrm{NaCl}$ followed by assay buffer containing $25 \mathrm{mM}$ DTT. The eluted materials were analyzed by SDS-PAGE. Only three protein bands could be detected by silver staining the gel. These were identified as keratins by MALDI-TOF peptide mass fingerprinting (Supplementary Fig. 2). Although freshly prepared solutions were employed, with great care throughout,experiment procedures, keratin contamination occurred during the process. However, and importantly, results revealed that no honey bee brain proteins stuck to the resin in the control experiment.

In order to visualize the profile of the MRJP1-honey bee brain protein interactome, 2DE was employed. The main protein spots corresponded to MRJP1, as expected, based upon their location in the 2DE gel as previously determined $16,18,21,26,37,38,40,65,66$. In addition, over two hundred protein spots were detected combining two $\mathrm{pH}$ ranges, 4-7 and 6-11, with prevalence of protein spots in the alkaline region (Fig. 2).

For the identification of proteins present in such an interactome, we relied on LC-MS/MS using capillary column chromatography in tandem with FT ion cyclotron mass spectrometry, followed by protein identification against the Apis mellifera sequence database using Peaks (Supplementary Table 1). The MS/MS raw data was deposited in PeptideAtlas under the Dataset Identifier PASS00961 (www.peptideatlas.org/PASS/PASS00961). As a high number of matches provided uncharacterized entries, all the sequences were then submitted to an analysis using Blast2GO against its own non-redundant database. This analysis resulted in 120 protein entries (Supplementary Table 1), most of which act as enzymes in various processes.

\section{Categorization of the identified MRJP1-binding proteins}


A preliminary view of Supplementary Table 1 reveals a high number of enzymes, many belonging to intermediary metabolic pathways. In order to categorize the MRJP1-binding proteins into functional gene ontology (GO) terms, according to molecular function, biological process and cellular component, Blast2GO was also utilized.

Concerning molecular function, GO categorization (Fig. 3a) revealed that most proteins belonged to ATP binding (27), oxidoreductase activity (23) and metal ion binding (19) functions. With regard to biological processes (Fig. 3b), a broad range of MRJP1-interacting protein categories were assigned. In agreement with the molecular function categories, a high number of proteins were associated with oxidation-reduction processes (28 proteins), such as thioredoxin, thioredoxin reductase, glutaredoxin, glutathione peroxidase and superoxide dismutase. A considerable number were also classified into phosphorylation processes (20 proteins), such as arginine kinase, protein kinase A (PKA), and protein kinase $C$ (PKC) calcium/calmodulindependent kinase type II (CAMK II). Also, it was noteworthy that several proteins were related to nitrogen metabolism, more specifically to amino acid biosynthesis, as well as to protein translation (Fig. 3b). Cellular component classification (Fig. 3c) led mainly to ontologies associated to cytoskeleton (8), such as tubulin beta-1 chain, actin-4, cofilin actin-depolymerizing factor homolog, profilin, TPPP (tubulin polymerization-promoting protein) and microtubule-associated tau isoform X1. A number were also classified to ribosome (6), eukaryotic initiation factor 4A-I, elongation factor mitochondrial-like, elongation factor 1-alpha and translation elongation factor 2 and elongation factor 1-gamma.

Although not evident in the categorization pie charts, visual inspection of Supplementary Table 1 also revealed a number of chaperone proteins, namely a $60 \mathrm{kDa}$ heat shock mitochondrial, a heat shock 83 , a heat shock $70 \mathrm{kDa} 4$ isoform $X 1$, a heat shock $70 \mathrm{kDa}$ cognate 4 and a dnaJ homolog subfamily A member 1 . Other interesting proteins that may perform important regulatory roles comprised an arrestin homolog, a lethal(2)essential for life-like, an annexin B9-like isoform X2, a ROP isoform X1, a rab GDP dissociation inhibitor beta, a 14-3-3 (epsilon and zeta), a type I inositol 1,4,5-trisphosphate 5-phosphatase, a synapsin, serinethreonine phosphatase $2 A 65 \mathrm{kD}$ a regulatory subunit $A$ alpha isoform, a ras-related $R a b-3$ isoform $X 1$, and a neurocalcin homolog and dynamin isoform X1. Finally, MRJP3 and MRJP7 were also observed among the MRJP1 binding proteins.

GO term enrichment analysis revealed statistically significant $p$ values for microtubule associated complex (GO:0005875) as cellular component, with a p-value of 0.025, as well as for neurotransmitter secretion (GO:0007269), with p-value of 0.035 , and glycolytic process (GO:0006096), with a p-value of 0.039 , as biological process. 


\section{Pathway mapping for MRJP1-binding proteins}

BLASTKOALA was used together with the eukaryotic KEGG pathway database for the visualization of signaling and metabolic pathways in which MRJP1-binding proteins act. In total, 98 proteins were assigned to 112 pathways (Supplementary Table 2), as some proteins were present in more than one pathway.

In relation to Metabolism, many proteins that bind to MRJP1 were categorized in the carbohydrate and amino acid metabolism pathways. In relation to Genetic Information Processing, six MRJP1-binding proteins were classified in protein processing in endoplasmic reticulum pathways. In regard to Environmental Information Processing, which is related to molecular transport and signal transduction from the environment into cell systems through the membrane, a total of 20 signal transducing pathways possessed MRJP1-binding proteins, from which PKA, PKC and CAMKII were the most commonly found. In Organismal Systems pathways, cholinergic, dopaminergic, GABAergic, glutamatergic and serotoninergic synaptic pathways, as well as long-term depression (LTD), long-term potentiation (LTP), photo, olfactory and taste transduction pathways, were also under control of PKA, PKC and CAMKII, amongst others. PKC, CAMKII and cofilin were observed in axon guidance pathways. These and other cytoskeletonrelated proteins (actin subunits, tubulin subunits, myosin and profilin) were also placed in specific pathways, such as focal adhesion, adherens junction, tight junction, gap junction, apoptosis, phagosome and regulation of actin cytoskeleton.

Upon examining downstream effects regulated by PKA, PKC and CAMKII, numerous learning and memory-related processes were observed, such as gene expression, neuronal excitability, exocytosis, endocytosis, synaptic plasticity, cytoskeletal remodeling and axon attraction/repulsion (Figs. 4, 5 and 6 and Supplementary Figs. 3-11).

\section{Discussion}

The MRJP1 characterized in the present work was shown to be in a highly pure state by both SDS-PAGE and MS (Fig. 1 and Supplementary Fig. 1). Only MRJP1 singly and doubly charged monomers were observed on the MS spectrum together with its interacting peptide

apisimin. As far as we know, this is the first report of the exact molecular mass of MRJP1, at $52,096.973 \mathrm{kDa}$, as determined by MS. SDS-PAGE analysis demonstrated the binding of some 
brain proteins to MRJP1, while most of the brain proteome passed through the affinity chromatographic column without binding to MRJP1. The extra faint MRJP1 fragments, whose bands can be seen on the SDS-PAGE gel, probably arise during SDS-PAGE sample preparation, since they were not observed by MALDI-TOF MS. The higher MW MRJP1 bands can be attributed to dimeric and oligomeric species ${ }^{21}$.

MRJP1 from royal jelly and brain are exactly the same protein ${ }^{14,21,67,68}$, such that we performed the affinity chromatography of brain proteins using MRJP1 purified from royal jelly for the sake of higher yield. A total of 120 honey bee brain proteins bound to MRJP1. The 2DE profile provided the distribution of MRJP1-interacting proteins in terms of experimental pl and size (Fig. 2). A prevalence of proteins with pl above 6 was observed. This is an interesting finding since 2DE maps usually show a higher number of acidic than alkaline protein spots for several different biological samples ${ }^{69}$. Therefore, it is possible that the acidic nature of MRJP1 favors its interaction with alkaline proteins.

The total number of 120 MRJP1-binding proteins was determined with great confidence, which was guaranteed by both a carefully conducted affinity purification experiment and a highly stringent mass spectrometry protein identification. A whole-body, cross-gender and cross-caste honey bee proteome mapping documented a total of 2,288 proteins ${ }^{1,55}$. Another more specific proteomic analysis identified a total of 2,742 proteins in the nurse and forager worker brains ${ }^{1,2,31}$. A more recent work employed modern nLC-Orbitrap Q-Exactive mass spectrometer to identify a total of 5,052 proteins in mushroom bodies ${ }^{21,56}$. This number of identified proteins may be lower than the potential total number of proteins in the honey bee brain, because the honey bee genome annotation is still incomplete and deficient ${ }^{28,58}$, making protein identification by mass spectrometry not as comprehensive as possible. Thus, the percentage of MRJP1-binding proteins may represent less than $2.3 \%$ of the total honey bee brain proteins, although the diversity of the GO categories defined in the present work is very heterogeneous (Fig. 3 and Supplementary Table 1).

Despite the initial observation of such heterogeneity regarding GO terms, it was noteworthy the over-representation of MRJP1-binding proteins in oxidation-reduction processes was noteworthy. These included thioredoxin, thioredoxin reductase, glutaredoxin, glutathione peroxidase and superoxide dismutase (Supplementary Tables 1 and 2, Fig. 3). Honey bees are exposed to environmental and metabolic stresses that lead to the formation of reactive oxygen species (ROS), which are potentially damaging to molecular systems of the insect and are related to decreased life $\operatorname{span}^{27,30}$ as well as to deficits in learning ${ }^{33-35}$. However, honey bees possess an antioxidant system to cope with free radical species ${ }^{36,41}$. The complexation of so many antioxidant proteins to MRJP1 points to a possible role as a regulatory protein associated with protection of 
the honey bee brain against ROS and, consequently, against learning deficits and premature aging.

Vitellogenin, a large lipid transport, egg-yolk precursor protein, related to processes like reproduction, endocrine regulation and behavior ${ }^{44,45}$, was also found to be associated to honey bee longevity ${ }^{46,48}$, since it has membrane affinity that is connected to cell damage recognition and antioxidant function ${ }^{49-51}$. RNAi-induced vitellogenin knockdown provoked an increase in lifespan of honey bee workers, and the potential mechanism causing the longer lifespans was reported to be an up-regulation of genes related to defense against oxidative damage $29,52,53$. Similarly to MRJP1, vitellogenin was detected in the honey bee brain, specifically in glial cells, and also instigated questions concerning protective roles against oxidative damage and aging of brain cells ${ }^{54}$.

Equally interesting was the finding of MRJP1-binding proteins belonging to phosphorylation processes, especially AGC kinases group [including protein kinase A (PKA) and protein kinase $\mathrm{C}(\mathrm{PKC})$ ] and CAMK kinases group [including calcium/calmodulin-dependent kinase type II (CAMK II)] (Supplementary Tables 1 and 2, Fig. 3). If MRJP1 was able to bind kinases, it could be a substrate of those phosphorylating enzymes. Actually, MRJP1 from royal jelly has been shown to be a phosphorylated protein ${ }^{11}$. More recently, phosphorylation sites were mapped on MRJP1 and other royal jelly proteins, so that PKA, PKC, CAMK and other possible kinases were suggested to phosphorylate MRJP1 on 10 different sites altogether ${ }^{12}$. It is very likely that the cerebral MRJP1 is also a phosphoprotein.

As well as acting as a substrate, MRJP1 may also serve as an anchoring or scaffold protein for bee brain protein kinases and all other MRJP1-binding proteins, with possible regulatory effects over them. Mechanisms controlling protein kinase activation and inhibition are diverse and kinase specific, but interactions with other proteins comprise a significant regulatory characteristic for the protein kinase superfamily, with general repercussions on the biochemistry and biology of living organisms ${ }^{57}$. For example, the A-kinase anchor proteins (AKAPs) form a class of structurally diverse scaffold proteins to which PKA and other signaling proteins anchor [including phosphodiesterases ( $\underline{\text { PDEs }}$ ), phosphatases and other kinases ( $\underline{\mathrm{PKC}}$ and $\underline{\mathrm{MAPK}}$ )]. These multi-protein complexes are then driven to specific locations ${ }^{59-62}$. AKAPs signaling complexes take place in neuronal processes that exert, for example, regulation of excitatory synaptic plasticity63. AKAPs also are found in invertebrates such as Drosophila melanogaster64, where, interestingly, they are involved in cognitive processes such as memory formation ${ }^{65,66}$. Although no AKAP has been characterized in Apis species yet, they are certainly also important for cerebral processes in the honey bee. On the other hand, the role of phosphorylation of the brain transcription factor cAMP-response element binding protein Apis mellifera (amCREB) by 
PKA, leading to behavioral responses, has clearly been established ${ }^{67,68}$. Similarly, the action of PKC1,70, PKC-binding protein 2,71 , CAMKII ${ }^{32,72}$ and CAMKII binding proteins ${ }^{4,7,10-13,22-25,73}$ on behavioral and cognitive processes in the honey bee is well known. In fact, there is increasing interest in the honey bee as a model for behavior and learning research, where signaling networks containing all the classical molecular components have been constructed ${ }^{14,26,74,75}$.

In our pathway mapping, not surprisingly, the above-mentioned kinases were highlighted in several neuronal pathways that control gene expression, neuronal excitability, exocytosis, endocytosis, synaptic plasticity, cytoskeletal remodeling and axon attraction/repulsion (Figs. 4, 5 and 6 and Supplementary Figs. 3-11). In axon guidance pathways (Supplementary Table 2), cofilin was found in addition to PKC and CAMKII. Other pathways, such as focal adhesion, adherens junction, tight junction, gap junction, apoptosis, phagosome and regulation of actin cytoskeleton also presented these and other cytoskeleton-related proteins (actin subunits, tubulin subunits, myosin and profilin) (Supplementary Table 2). Coincidently, immunocytochemistry and electron microscopy analyses have shown MRJP1 associated with proteins of filamentous structures of the cytoskeleton of honey bee brain cells, in the antennal lobe, optical lobe and mushroom body ${ }^{1,29}$. An interesting report suggested that changes in the proteome and phosphoproteome, particularly the higher phosphorylation of cytoskeleton, are involved in triggering embryo-larva transition of honeybee worker ${ }^{16,18,21,26,37,38,40,76}$. Undoubtedly, there is now considerable understanding on how the cytoskeleton is intrinsically associated with brain development and plasticity in animals ${ }^{14,77,78}$, including Drosophila ${ }^{1,79}$ and honey bee be, $^{1,20}$.

Three proteins involved in the MRJP1 interactome, which although not well characterized in Apis mellifera, still deserve attention: synapsin, neurocalcin and dynamin (Supplementary Table 1). In social insects, brain plasticity is associated to synapsins, which were found to interact with MRJP1. Synapsins are substrates for PKA, localize in presynaptic boutons, and fine tune neurotransmitter release by reversibly attaching synaptic vesicles to actin ${ }^{21,81}$. In a probable situation, MRJP1 would anchor and enclose three major players (PKA, synapsin and actin) in neurotransmitter release with consequences in synaptic plasticity.

Contrary to a previous study, where MRJP1-calmodulin interaction was observed in an assay using a calmodulin affinity column to capture brain proteins from worker honey bees ${ }^{28,82}$, this interaction was not observed in the present work. However, a neurocalcin homolog, which is a calcium-binding and sensing protein, took part in the MRJP1 interactome (Supplementary Table 1). Evidence that neurocalcin may be up-regulated during behavior acquisition came from the finding that it was more abundant in forager than in nurser brains ${ }^{27,31}$. In our pathways mapping, dynamin was placed in the synaptic vesicle cycle, endocytosis, calcium reabsorption and phospholipase D signaling pathways (Supplementary Table 2). A dynamin homolog gene, atlastin, which has potential neurodevelopmental and behavioral effects, was previously identified as a candidate gene Influencing honey bee grooming behavior in response to varroa mites ${ }^{33,83}$. 
Apart from synapsin, neurocalcin and dynamin, other MRJP1-binding proteins may carry important regulatory roles: arrestin homolog, lethal(2)essential for life-like, annexin B9-like isoform X2, ROP isoform X1, rab GDP dissociation inhibitor beta, 14-3-3 (epsilon and zeta), type I inositol 1,4,5-trisphosphate 5-phosphatase, serine-threonine phosphatase 2A $65 \mathrm{kDa}$ regulatory subunit $A$ alpha isoform, ras-related Rab-3 isoform X1, and dynamin isoform X1. Out of these, ROP isoform X1, rab GDP dissociation inhibitor beta and ras-related Rab-3 isoform X1 were found within the enriched GO term neurotransmitter secretion (GO:0007269). We also reported that the MRJP1 interactome contain many proteins falling into carbohydrate and amino acid metabolism as well as in protein processing in endoplasmic reticulum. As a matter of fact, seven enzymes are included in the enriched GO term glycolytic process (GO:0006096), perhaps indicating that MRJP1 may have some regulatory action on the energy metabolism. It is also possible to pick examples of chaperones such as $60 \mathrm{kDa}$ heat shock mitochondrial, heat shock 83 , heat shock 70 $\mathrm{kDa} 4$ isoform X1, heat shock $70 \mathrm{kDa}$ cognate 4 and dnaJ homolog subfamily A member 1 , that interact with MRJP1. Two other major royal jelly proteins with unknown functions, MRJP3 and MRJP7, are also among the MRJP1 binding proteins. The cellular component GO term microtubule associated complex (GO:0005875) also encompass proteins such as $60 \mathrm{kDa}$ heat shock mitochondrial, 14-3-3 epsilon and myosin-IIlb isoform X1.

Whilst it is beyond the scope of this work to discuss each of the MJP1-binding proteins, our results reinforce the hypothesis of multifunctionality of MRJP1, as suggested by other authors $1,2,12,27,29,36,38,49$. However, a question that must be posed is whether all of the 120 proteins bind directly to MRJP1 or are associated to naturally occurring protein complexes. Further work must be performed to identify direct MRJP1-protein interactions. Such a task may be accomplished by applying cross-linking and hydrogen-deuterium exchange followed by mass spectrometry analysis. Detection and analysis of protein complexes that occur in the honey bee brain would also be relevant, given that many would contain MRJP1. Such natural complexes could be characterized by a combination of native two-dimensional electrophoresis and mass spectrometry, both in its bottom up and top down approaches.

\section{Methods}

Honey bees and chemicals

Honey bee (Apis mellifera) forager workers were obtained from Vereda Rosa Apiaries 
(Brasilia, DF, Brazil), and royal jelly from Apivita (Rio Claro, SP, Brazil). Protease inhibitor mixture cOmplete Mini was purchased from Roche (Mannheim, Germany); Thiol-Sepharose 4B resin and 2D Quant kit from GE Healthcare (Upsala, Sweden); and sequencing grade trypsin from Promega (Madison, WI, USA). All other chemicals were purchased from Sigma (St. Louis, MO, USA) in analytical grade or superior.

Brain proteome extraction

Honey bees were anesthetized with chloroform. Heads were dissected and brains obtained after careful removal of the hypopharyngeal and post-cerebral glands. Brains were immediately washed with cold assay buffer (50 mM tris-HCL pH 7.5, $1 \mathrm{mM}$ EDTA,100 mM NaCl) containing 1 tablet of cOmplete Mini protease inhibitors per $\mathrm{L}$, frozen in liquid nitrogen, macerated and stored at $-80^{\circ} \mathrm{C}$ until use.

Affinity chromatography

MRJP1 was purified as previously described ${ }^{21,44}$. Briefly, $250 \mathrm{mg}$ of royal jelly (Apivita, Rio Claro, Brazil) were diluted in $1.2 \mathrm{~mL}$ of $50 \mathrm{mM}$ Tris- $\mathrm{HCl} \mathrm{pH} 7.5$ (buffer A) containing $10 \mathrm{mM}$ EDTA and a tablet of proteases inhibitors (cOmplete Mini, Roche, Mannheim, Germany). The RJ solution was vortex stirred for $2 \mathrm{~min}$, and centrifuged at $16,000 \mathrm{~g}$ for $30 \mathrm{~min}$ at room temperature. The soluble material was submitted to FPLC chromatography using an anion-exchange Mono- $Q$ HR 10/10 column (Pharmacia, Uppsala, Sweden). The column ( $8 \mathrm{~mL}$ ) was equilibrated with buffer A under a $1.5 \mathrm{~mL} / \mathrm{min}$ flow. Elution was performed using a $0-1 \mathrm{M} \mathrm{NaCl}$ in buffer $A$ with the following scheme: 0-10 min, buffer A; 10-60 min, 0-0.2 M NaCl; $60-90 \min , 0.2-0.5 \mathrm{M} \mathrm{NaCl}$; 90-95 min, 0.5- $1 \mathrm{M} \mathrm{NaCl}$; 95-100 min, $1 \mathrm{M} \mathrm{NaCl}$. All the solutions were filtered through $0.22 \mu \mathrm{m}$ pore filter and degassed before use. The chromatographic run was conducted at room temperature, and accompanied by optical absorption at $280 \mathrm{~nm}$. The MRJP1 fraction was dialyzed against distilled water at $4{ }^{\circ} \mathrm{C}$ and lyophilized.

Thiol-Sepharose 4B was activated following manufacturer's instructions for packing a disposable plastic column with $400 \mu \mathrm{L}$ of resin. The activated, packed resin was thoroughly washed with Milli-Q water. The resin was then equilibrated with $25 \mathrm{~mL}$ of assay buffer under a flow rate of $0.3 \mathrm{~mL} / \mathrm{min}$ at room temperature. The absorbance of the efflux was monitored at 280 $\mathrm{nm}$. MRJP1 was then reversibly coupled to the resin through free cysteines residues. Saturating quantity of MRJP1 (3.5 mg) was dissolved in $2 \mathrm{~mL}$ of assay buffer, and allowed to incubate with the activated resin for $2 \mathrm{~h}$ at $4{ }^{\circ} \mathrm{C}$. The excess of protein not bound to the resin was washed away by assay buffer for extra $5 \mathrm{~min}$ after the absorbance at $280 \mathrm{~nm}$ had reached the baseline. The honey bee brain proteome was thawed, centrifuged at $16,000 \mathrm{~g}$ for $15 \mathrm{~min}$. The supernatant, 
containing around $500 \mu \mathrm{g}$ of proteins as determined by 2D Quant kit, was then incubated with the matrix (MRJP1-Sepharose) for $2 \mathrm{~h}$ at $4^{\circ} \mathrm{C}$. The unbound proteins were washed away with assay buffer until the absorbance at $280 \mathrm{~nm}$ reached the baseline and for $5 \mathrm{~min}$ more. The complexes MRJP1-brain proteins complex were then eluted from the matrix by applying assay buffer containing $25 \mathrm{mM}$ dithiothreitol (DTT). The MRJP1-brain proteins fraction was vacuum concentrated, and then precipitated by adding three times the sample volume of ice-cold acetone at $-20^{\circ} \mathrm{C}$ followed by an incubation at $-80^{\circ} \mathrm{C}$ for $30 \mathrm{~min}$, followed by centrifugation at 15,000 $g$ at $4{ }^{\circ} \mathrm{C}$ for $10 \mathrm{~min}$. The supernatant was discarded, and the centrifugation was repeated. Finally, the sample was dried in a vacuum centrifuge concentrator.

A batch $(400 \mu \mathrm{L})$ of control resin (with no MRJP1 bound to it) was subjected to reduction with $1 \mathrm{~mL}$ of $25 \mathrm{mM}$ DTT in assay buffer at $56^{\circ} \mathrm{C}$ for $1 \mathrm{~h}$ followed by alkylation with $1 \mathrm{~mL}$ of 300 $\mathrm{mM}$ iodoacetamide in assay buffer at room temperature for $45 \mathrm{~min}$ in the dark. The control resin was equilibrated with $25 \mathrm{~mL}$ of assay buffer, and incubated with the honey bee brain extract as described above. The column was washed with assay buffer until the absorbance at $280 \mathrm{~nm}$ reached the baseline plus extra $5 \mathrm{~min}$, then with $200 \mathrm{mM} \mathrm{NaCl}$ in assay buffer for $5 \mathrm{~min}$, and with $25 \mathrm{mM}$ DTT in assay buffer for $5 \mathrm{~min}$. The eluted material was treated as described above.

\section{SDS-PAGE and 2D Electrophoresis}

Protein contents from the affinity-purified fractions were analyzed by sodium dodecyl sulfate polyacrylamide gel electrophoresis (SDS-PAGE) $)^{46,84}$ on $10 \%$ gels. Samples were dissolved in sample buffer $(62.5 \mathrm{mM}$ tris- $\mathrm{HCl} \mathrm{pH} \mathrm{6.8,2 \%} \mathrm{SDS,} 10 \%$ glycerol, $100 \mathrm{mM}$ DTT and $0.01 \%$ bromophenol blue). Electrophoretic separation was conducted in running buffer $(25 \mathrm{mM}$ tris- $\mathrm{HCl} \mathrm{pH} \mathrm{8.5,} 0.192 \mathrm{M}$ glycine, $0.1 \% \mathrm{SDS}$ ) at $30 \mathrm{~mA}$ constant current at $20^{\circ} \mathrm{C}$. Molecular mass markers were phosphorylase b (97.0 kDa), BSA (66.0 kDa), ovalbumine (45.0 kDa), carbonic anhydrase $(30.0 \mathrm{kDa})$, trypsin inhibitor $(20.1 \mathrm{kDa})$ e $\alpha$-lactalbumine $(14.4 \mathrm{kDa})$. Protein bands were visualized by silver staining.

The profile of MRJP1-brain proteins interactome (160 $\mu \mathrm{g}$ per gel) was visualized by twodimensional electrophoresis (2DE) as previously described ${ }^{21,49,51}$, in which the first dimension of isoelectric focusing (IEF) was carried out on $18 \mathrm{~cm}$ IPG strips (GE Healthcare) in pH ranges 4-7 and $6-11$, followed by a second dimension of SDS-PAGE with gradient gels from 8 to $15 \%$. Protein spots were also silver stained.

\section{MALDI-TOF MS}


MRJP1 purity and molecular mass were determined by matrix-assisted laser desorption/ ionization time-of-flight (MALDI-TOF) mass spectrometry (MS) on a Reflex IV equipment from Bruker (Bremen, Germany). Native MRJP1 was mixed with a fresh sinapinic acid solution (20 $\mu \mathrm{g} / \mathrm{mL}$ in $0.1 \%$ TFA in $50 \%$ acetonitrile), and dried on a stainless Bruker MTP 384 plate. Spectra were generated in positive linear mode using Bruker FlexControl v. 2.4, and analyzed with Bruker FlexAnalysis v. 2.4.

Protein digestion

The protein fraction containing MRJP1-brain proteins was resuspended in $8 \mathrm{M}$ urea, 75 $\mathrm{mM}$ ammonium bicarbonate followed by reduction using $10 \mathrm{mM} \mathrm{DTT}$ for $1 \mathrm{~h}$ at room temperature, and alkylation with $50 \mathrm{mM}$ iodoacetamide for $30 \mathrm{~min}$ in the dark. Samples were diluted to a final concentration of $1 \mathrm{M}$ urea with $100 \mathrm{mM}$ ammonium bicarbonate. The protein sample was digested using Promega sequencing-grade modified trypsin at an enzyme/substrate ratio of 1:50 for $18 \mathrm{~h}$ at $37^{\circ} \mathrm{C}$. Proteolysis was stopped by addition of trifluoracetic acid at $1 \%$ final concentration. The resulting tryptic peptides were desalted on a C18 zip tip (Millipore, Billerica, MA, USA). The organic solvent present in the peptide mixture was removed by a vacuum centrifuge concentrator.

Protein identification by LC-MS/MS

Analysis was performed on a hybrid linear ion trap-7 Tesla FT-ICR mass spectrometer (Thermo Scientific, San Jose, CA, USA). The mass spectrometer was online coupled to an Eksigent nanoLC 1D Plus (Eksigent, Dublin, CA, USA) instrument (Thermo Fisher Scientific, San Jose, CA, USA). The chromatography system was equipped with an in-house packed $2 \mathrm{~cm} \times 150$ $\mu \mathrm{m}$ i.d. pre-column (Jupiter C18, $3 \mu \mathrm{m}, 300 \AA$, Phenomenex) and with $20 \mathrm{~cm} \times 75 \mu \mathrm{m}$ i.d column (Jupiter $\mathrm{C} 18,3 \mu \mathrm{m}, 300 \AA$, Phenomenex). The peptides resulted from the digestion of the complex MRJP1-bee brain proteins were suspended in $20 \mu \mathrm{L}$ mobile phase B (95\% water, $5 \%$ acetonitrile, $0.2 \%$ formic acid) prior injection into the nanoLC system. The separation was carried out at a flow rate of $300 \mathrm{~nL} / \mathrm{min}$ using an 80 min gradient of mobile phase A (95\% water, 5\% acetonitrile, 0.2 $\%$ formic acid) and mobile phase B (5\% water, 95\% acetonitrile, $0.2 \%$ formic acid). The gradient started at $5 \%$ of mobile phase $B$ in mobile phase A over $10 \mathrm{~min}$, then rose to $45 \%$ in $40 \mathrm{~min}$, followed by a steep increase to $90 \%$ over $5 \mathrm{~min}$, where it was held for $5 \mathrm{~min}$, and then returned to $5 \%$ B over $5 \mathrm{~min}$, followed by column re-equilibration for $15 \mathrm{~min}$. The mass spectra were acquired using Xcalibur (version $2.2 \mathrm{SP}$ 1.78, Thermo Fisher Scientific) operating in datadependent acquisition (DDA) mode. DDA cycle consisted of a survey scan in FTMS comprising an $\mathrm{m} / \mathrm{z} 400-1600$ range under the resolution of 50,000 at $\mathrm{m} / \mathrm{z} 400$. The eight most abundant ions were fragmented by collision induced dissociation (CID) with a normalized fragmentation energy 
of $35 \%$ and automatic gain control (AGC) of $1 \times 10^{6}$. The CID fragmentation spectra were acquired in the ion trap analyzer with a $2 \mathrm{~m} / \mathrm{z}$ isolation width and AGC $1 \times 10^{4}$. Ions with charge state $\geq 4$ were excluded. The dynamic exclusion was enabled with a repeat count of 3 , repeat duration of $45 \mathrm{~s}$ and exclusion duration of $120 \mathrm{~s}$.

The identification of proteins was performed by the processing of raw files (deposited in PeptideAtlas under the Dataset Identifier PASS00961) with PEAKS (version 7.0, Bioinformatics Solutions Inc., Waterloo, ON, Canada). Mass spectra were searched against a sequence database of Apis mellifera, downloaded from UniProtKB on July 20, 2016, totaling 16,997 entries. The search parameters settled up were: FTMS as instrument, trypsin as enzyme, CID as fragmentation, scan filter greater than 0.65 ; mass tolerance at $10 \mathrm{ppm}$ for MS1 and $0.5 \mathrm{Da}$ for MS2; tryptic cleavage specificity with up 2 missed cleavages; carbamidomethylation of cysteine as fixed modification and oxidation of methionine: acetylation of $\mathrm{N}$-terminal of protein as variable modification and up to three posttranslational modification per peptide. The rate of false positives was estimated by using the target database with a decoy database. The final criteria for identification were a cut-off false discovery rate (FDR) for peptides $\leq 0.01 \%$ and at least two unique peptides per protein.

GO term categorization, enrichment analysis and pathway mapping of identified proteins

FASTA sequences from the list of identified proteins were uploaded onto BLAST2GO, version 3.3.5 $29,53,85$. Default analysis values were used as recommended by the program. $A$ sequence similarity search was performed using the BLASTp algorithm against a BLAST2GO non-redundant protein $(\mathrm{nr})$ sequence database (08.06.2016). Search parameters were e-Blast expectation filter of $1 \times 10^{-3}$, analysis of early 20 hits, the minimum length of alignment of 33 amino acids and low complexity filter enabled. Mapping of GO terms associated with the hits obtained with BLAST was performed. The annotation threshold was $55, \mathrm{GO}$ weight set to 5 and $\mathrm{E}$-value of the hit filtered at $1 \times 10^{-6}$. For enrichment analysis, FASTA sequences were clustered with OrthoVenn software using default parameters ${ }^{86}$. Clusters were then compared against the $A$. mellifera clustered database. The overlap of clusters was analyzed for $\mathrm{GO}$ enrichment analysis. The individual protein functions were associated with ortholog groups for placement into KEGG pathways by the use of BLASTKOALA 1,55,87 available at (http://www.kegg.jp/blastkoala). This search was performed under default parameters against the "family_eukaryotes" KEGG Genes Database.

\section{References}


1. Buttstedt, A., Moritz, R. F. A. \& Erler, S. Origin and function of the major royal jelly proteins of the honeybee ( Apis mellifera) as members of the yellowgene family. Biol Rev 89, 255-269 (2014).

2. Buttstedt, A., Moritz, R. F. \& Erler, S. More than royal food - Major royal jelly protein genes in sexuals and workers of the honeybee Apis mellifera. Front. Zool. 10, 72 (2013).

3. Patel, N. G., Haydak, M. H. \& Gochnauer, T. A. Electrophoretic Components of the Proteins in Honeybee Larval Food. Nature 186, 633-634 (1960).4. Santos, K. S. et al. Profiling the proteome complement of the secretion from hypopharyngeal gland of Africanized nurse-honeybees (Apis mellifera L.). Insect Biochem. Mol. Biol. 35, 85-91 (2005).

5. Scarselli, R. et al. Towards royal jelly proteome. Proteomics 5, 769-776 (2005).

6. $\mathrm{Li}, \mathrm{J}$., Wang, T., Zhang, Z. \& Pan, Y. Proteomic analysis of royal jelly from three strains of western honeybees (Apis mellifera). J. Agric. Food Chem. 55, 8411-8422 (2007).7. Schönleben, S., Sickmann, A., Mueller, M. J. \& Reinders, J. Proteome analysis of Apis mellifera royal jelly. Anal Bioanal Chem 389, 1087-1093 (2007).

8. Furusawa, T. et al. Comprehensive royal jelly (RJ) proteomics using one- and two-dimensional proteomics platforms reveals novel RJ proteins and potential phospho/glycoproteins. J. Proteome Res. 7, 3194-3229 (2008).9. Yu, F., Mao, F. \& Jianke, L. Royal jelly proteome comparison between A. mellifera ligustica and A. cerana cerana. J. Proteome Res. 9, 2207-2215 (2010).

10. Han, B. et al. Novel royal jelly proteins identified by gel-based and gel-free proteomics. J. Agric. Food Chem. 59, 10346-10355 (2011).

11. Zhang, L. et al. Towards posttranslational modification proteome of royal jelly. J Proteomics $\mathbf{7 5 , 5 3 2 7 - 5 3 4 1}$ (2012).

12. Han, B. et al. In-depth phosphoproteomic analysis of royal jelly derived from western and eastern honeybee species. J. Proteome Res. 13, 5928-5943 (2014).

13. Zhang, Y., Zhang, G., Huang, X. \& Han, R. Proteomic analysis of Apis cerana and Apis mellifera larvae fed with heterospecific royal jelly and by CSBV challenge. PLoS ONE 9, e102663 (2014).

14. Hanes, J. \& Šimúth, J. Identification and partial characterization of the major royal jelly protein of the honey bee ( Apis melliferaL.). Journal of Apicultural Research 31, 22-26 (1992).

15. Schmitzová, J. et al. A family of major royal jelly proteins of the honeybee Apis mellifera L. Cell. Mol. Life Sci. 54, 1020-1030 (1998).

16. KLAUDINY, J., Kulifajova, J. \& Crailsheim, K. New approach to the study of division of labour in the honeybee colony (Apis mellifera L.). Apidologie (1994).

17. Malecova, B. et al. Honeybee (Apis mellifera L.) mrjp gene family: computational analysis of putative promoters and genomic structure of mrjp1, the gene coding for the most abundant protein of larval food. Gene 303, 165175 (2003).

18. Albert, Š. \& Klaudiny, J. The MRJP/YELLOW protein family of Apis mellifera: Identification of new members in the EST library. J. Insect Physiol. 50, 51-59 (2004).

19. Drapeau, M. D., Albert, S., Kucharski, R., Prusko, C. \& Maleszka, R. Evolution of the Yellow/Major Royal Jelly Protein family and the emergence of social behavior in honey bees. Genome Research 16, 1385-1394 (2006).

20. Weinstock, G. M. et al. Insights into social insects from the genome of the honeybee Apis mellifera. Nature 443, 931-949 (2006). 
21. Cruz, G. C. N. et al. Calcium effect and pH-dependence on self-association and structural stability of the Apis mellifera major royal jelly protein 1. Apidologie 42, 252-269 (2011).

22. Scarselli, R. et al. Towards royal jelly proteome. Proteomics 5, 769-776 (2005).

23. Li, J., Li, H., Zhang, Z. \& Pan, Y. Identification of the proteome complement of high royal jelly producing bees (Apis mellifera) during worker larval development. Apidologie 38, 545-557 (2007).

24. Furusawa, T. et al. Comprehensive Royal Jelly (RJ) Proteomics Using One- and Two-Dimensional Proteomics Platforms Reveals Novel RJ Proteins and Potential Phospho/Glycoproteins. J. Proteome Res. 7, 3194-3229 (2008).

25. Yu, F., Mao, F. \& Jianke, L. Royal jelly proteome comparison between A. mellifera ligustica and A. cerana cerana. J. Proteome Res. 9, 2207-2215 (2010).

26. Schmitzová, J. et al. A family of major royal jelly proteins of the honeybee Apis mellifera L. Cell. Mol. Life Sci. 54, 1020-1030 (1998).

27. Kamakura, M. Royalactin induces queen differentiation in honeybees. Nature 473, 478-483 (2011).

28. Feng, M. et al. In-Depth N-Glycosylation Reveals Species-Specific Modifications and Functions of the Royal Jelly Protein from Western (Apis mellifera) and Eastern Honeybees (Apis cerana). J. Proteome Res. 14, 53275340 (2015).

29. Garcia, L. et al. Proteomic Analysis of Honey Bee Brain upon Ontogenetic and Behavioral Development. J. Proteome Res. 8, 1464-1473 (2009).

Keller, L. \& Jemielity, S. Social insects as a model to study the molecular basis of ageing. Experimental Gerontology 41, 553-556 (2006).

31. Hernández, L. G. et al. Worker Honeybee Brain Proteome. J. Proteome Res. 11, 1485-1493 (2012).

32. Patel, N. G., Haydak, M. H. \& Gochnauer, T. A. Electrophoretic components of the proteins in honeybee larval food. Nature 186, 633-634 (1960).

33. Leimar, O., Hartfelder, K., Laubichler, M. D. \& Page, R. E. Development and evolution of caste dimorphism in honeybees - a modeling approach. Ecol Evol 2, 3098-3109 (2012).

34. Amdam, G. V., Fennern, E., Baker, N. \& Rascón, B. Honeybee associative learning performance and metabolic stress resilience are positively associated. PLoS ONE 5, e9740 (2010).

35. Baker, N., Wolschin, F. \& Amdam, G. V. Experimental Gerontology. EXG 47, 764-772 (2012).

36. Buttstedt, A., Ihling, C. H., Pietzsch, M. \& Moritz, R. F. A. Royalactin is not a royal making of a queen. Nature 537, E10-2 (2016).

37. Malecová, B. et al. Honeybee (Apis mellifera L.) mrjp gene family: computational analysis of putative promoters and genomic structure of mrjp1, the gene coding for the most abundant protein of larval food. Gene 303, 165175 (2003).

38. Drapeau, M. D., Albert, S., Kucharski, R., Prusko, C. \& Maleszka, R. Evolution of the Yellow/Major Royal Jelly Protein family and the emergence of social behavior in honey bees. Genome Research 16, 1385-1394 (2006).

39. Hayes, S., Malacrida, B., Kiely, M. \& Kiely, P. A. Studying protein-protein interactions: progress, pitfalls and solutions. Biochem. Soc. Trans. 44, 994-1004 (2016).

40. Weinstock, G. M. et al. Insights into social insects from the genome of the honeybee Apis mellifera. Nature 443, 931-949 (2006).

41. Weirich, G., Collins, A. \& Williams, V. Antioxidant enzymes in the honey bee, Apis mellifera. Apidologie 33, 3- 
14 (2002).

42. Feng, S., Zhou, L., Huang, C., Xie, K. \& Nice, E. C. Interactomics: toward protein function and regulation. Expert Rev Proteomics 12, 37-60 (2015).

43. Zhang, B., Park, B. H., Karpinets, T. \& Samatova, N. F. From pull-down data to protein interaction networks and complexes with biological relevance. Bioinformatics 24, 979-986 (2008).

44. Kamakura, M. Kamakura replies. Nature 537, E13 (2016).

45. Nelson, C. M., Ihle, K. E., Fondrk, M. K., Page, R. E. \& Amdam, G. V. The Gene vitellogenin Has Multiple Coordinating Effects on Social Organization. PLoS Biol 5, e62 (2007).

46. Fontana, R. et al. Jelleines: a family of antimicrobial peptides from the Royal Jelly of honeybees (Apis mellifera). Peptides 25, 919-928 (2004).

47. Bilikova, K. et al. Apisimin, a new serine-valine-rich peptide from honeybee (Apis mellifera L.) royal jelly: purification and molecular characterization. FEBS Lett. 528, 125-129 (2002).

48. Corona, M., Velarde, R. A., Remolina, S. \& Moran-Lauter, A. and Robinson, GE (2007). Vitellogenin, juvenile hormone, insulin signaling and queen honey bee longevity. Proc. Natl. Acad. Sci. USA

49. Brudzynski, K. \& Sjaarda, C. Honey glycoproteins containing antimicrobial peptides, Jelleins of the Major Royal Jelly Protein 1, are responsible for the cell wall lytic and bactericidal activities of honey. PLoS ONE 10, e0120238 (2015).

50. Havukainen, $\mathrm{H}$. et al. Vitellogenin recognizes cell damage through membrane binding and shields living cells from reactive oxygen species. J. Biol. Chem. 288, 28369-28381 (2013).

51. Brudzynski, K., Sjaarda, C. \& Lannigan, R. MRJP1-containing glycoproteins isolated from honey, a novel antibacterial drug candidate with broad spectrum activity against multi-drug resistant clinical isolates. 6, 711 (2015).

52. Ihle, K. E., Fondrk, M. K., Page, R. E. \& Amdam, G. V. Genotype effect on lifespan following vitellogenin knockdown. Experimental Gerontology 61, 113-122 (2015).

53. Peixoto, L. G. et al. Identification of major royal jelly proteins in the brain of the honeybee Apis mellifera. $J$. Insect Physiol. 55, 671-677 (2009).

54. Münch, D., Ihle, K. E., Salmela, H. \& Amdam, G. V. Vitellogenin in the honey bee brain: Atypical localization of a reproductive protein that promotes longevity. Experimental Gerontology 71, 103-108 (2015).

55. Chan, Q. W. T. et al. Honey bee protein atlas at organ-level resolution. Genome Research 23, 1951-1960 (2013).

56. Hu, H. et al. Proteome Analysis of the Hemolymph, Mushroom Body, and Antenna Provides Novel Insight into Honeybee Resistance against Varroa Infestation. J. Proteome Res. 15, 2841-2854 (2016).

57. Roskoski, R. A historical overview of protein kinases and their targeted small molecule inhibitors. Pharmacol. Res. 100, 1-23 (2015).

58. McAfee, A. et al. Toward an Upgraded Honey Bee ( Apis melliferaL.) Genome Annotation Using Proteogenomics. J. Proteome Res. 15, 411-421 (2016).

59. Mochly-Rosen, D. Localization of protein kinases by anchoring proteins: A theme in signal transduction ProQuest. Science 268, 247-251 (1995).

60. Colledge, M. \& Scott, J. D. AKAPs: from structure to function. Trends in cell biology (1999).

61. Hausken, Z. E. \& Scott, J. D. Properties of A-kinase anchoring proteins. Biochem. Soc. Trans. 24, 986-991 
(1996).

62. Edwards, A. S. \& Scott, J. D. A-kinase anchoring proteins: protein kinase A and beyond. Current Opinion in Cell Biology 12, 217-221 (2000).

63. Sanderson, J. L. \& Dell'Acqua, M. L. AKAP signaling complexes in regulation of excitatory synaptic plasticity. Neuroscientist 17, 321-336 (2011).

64. Han, J. D., Baker, N. E. \& Rubin, C. S. Molecular Characterization of a Novel A Kinase Anchor Protein from Drosophila melanogaster. J. Biol. Chem. 272, 26611-26619 (1997).

65. Lu, Y. et al. The AKAP Yu is required for olfactory long-term memory formation in Drosophila. Proc. Natl. Acad. Sci. U.S.A. 104, 13792-13797 (2007).

66. Scheunemann, L. et al. AKAPS act in a two-step mechanism of memory acquisition. J. Neurosci. 33, 1742217428 (2013).

67. Gehring, K. B., Heufelder, K., Kersting, I. \& Eisenhardt, D. Abundance of phosphorylated Apis mellifera CREB in the honeybee's mushroom body inner compact cells varies with age. J. Comp. Neurol. 524, 1165-1180 (2016).

68. Gehring, K. B. et al. Involvement of phosphorylated Apis mellifera CREB in gating a honeybee's behavioral response to an external stimulus. Learn. Mem. 23, 195-207 (2016).

69. Magalhães, A. D. et al. Trypanosoma cruzi alkaline 2-DE: Optimization and application to comparative proteome analysis of flagellate life stages. Proteome Sci 6, 24 (2008).

70. Humphries, M. A., Muller, U., Fondrk, M. K. \& Page, R. E. PKA and PKC content in the honey bee central brain differs in genotypic strains with distinct foraging behavior. J. Comp. Physiol. A Neuroethol. Sens. Neural. Behav. Physiol. 189, 555-562 (2003).

71. Lockett, G. A., Kucharski, R. \& Maleszka, R. DNA methylation changes elicited by social stimuli in the brains of worker honey bees. Genes, Brain and Behavior 11, 235-242 (2012).

72. Scholl, C., Kübert, N., Muenz, T. S. \& Rössler, W. CaMKII knockdown affects both early and late phases of olfactory long-term memory in the honeybee. Journal of Experimental Biology 218, 3788-3796 (2015).

73. Matsumoto, Y. et al. Cyclic nucleotide-gated channels, calmodulin, adenylyl cyclase, and calcium/calmodulindependent protein kinase II are required for late, but not early, long-term memory formation in the honeybee. Learn. Mem. 21, 272-286 (2014).

74. Menzel, R. The honeybee as a model for understanding the basis of cognition. Nat Rev Neurosci 13, 758-768 (2012).

75. Giurfa, M. \& Sandoz, J. C. Invertebrate learning and memory: Fifty years of olfactory conditioning of the proboscis extension response in honeybees. Learn. Mem. 19, 54-66 (2012).

76. Gala, A. et al. Changes of proteome and phosphoproteome trigger embryo-larva transition of honeybee worker (Apis mellifera ligustica). J Proteomics 78, 428-446 (2013).

77. Holtmaat, A. \& Svoboda, K. Experience-dependent structural synaptic plasticity in the mammalian brain. Nat Rev Neurosci 10, 647-658 (2009).

78. Bosch, M. \& Hayashi, Y. Structural plasticity of dendritic spines. Current Opinion in Neurobiology 22, 383-388 (2012).

79. He, J. et al. Prevalent presence of periodic actin-spectrin-based membrane skeleton in a broad range of neuronal cell types and animal species. Proceedings of the National Academy of Sciences 113, 6029-6034 (2016). 
80. Muenz, T. S. et al. Neuronal plasticity in the mushroom body calyx during adult maturation in the honeybee and possible pheromonal influences. Dev Neurobiol 75, 1368-1384 (2015).

81. Fahrbach, S. E. \& Van Nest, B. N. Synapsin-based approaches to brain plasticity in adult social insects. Current Opinion in Insect Science (2016). doi:10.1016/j.cois.2016.08.009

82. Calábria, L. K., Garcia Hernandez, L., Teixeira, R. R., Valle de Sousa, M. \& Espindola, F. S. Identification of calmodulin-binding proteins in brain of worker honeybees. Comparative Biochemistry and Physiology Part B: Biochemistry and Molecular Biology 151, 41-45 (2008).

83. Arechavaleta-Velasco, M. E. \& Alcala-Escamilla, K. PLOS ONE: Fine-Scale Linkage Mapping Reveals a Small Set of Candidate Genes Influencing Honey Bee Grooming Behavior in Response to Varroa Mites. PLoS 7, e4769; DOI: 101371/journal.pone.0047269 (2012).

84. Laemmli, U. K. Cleavage of structural proteins during the assembly of the head of bacteriophage T4. Nature 227, 680-685 (1970).

85. Conesa, A. et al. Blast2GO: a universal tool for annotation, visualization and analysis in functional genomics research. Bioinformatics 21, 3674-3676 (2005).

86. Wang, Y., Coleman-Derr, D., Chen, G. \& Gu, Y. Q. OrthoVenn: a web server for genome wide comparison and annotation of orthologous clusters across multiple species. Nucleic Acids Research 43, W78-84 (2015).

87. Kanehisa, M., Sato, Y. \& Morishima, K. BlastKOALA and GhostKOALA: KEGG Tools for Functional Characterization of Genome and Metagenome Sequences. Journal of Molecular Biology 428, 726-731 (2016). 


\section{Figures}

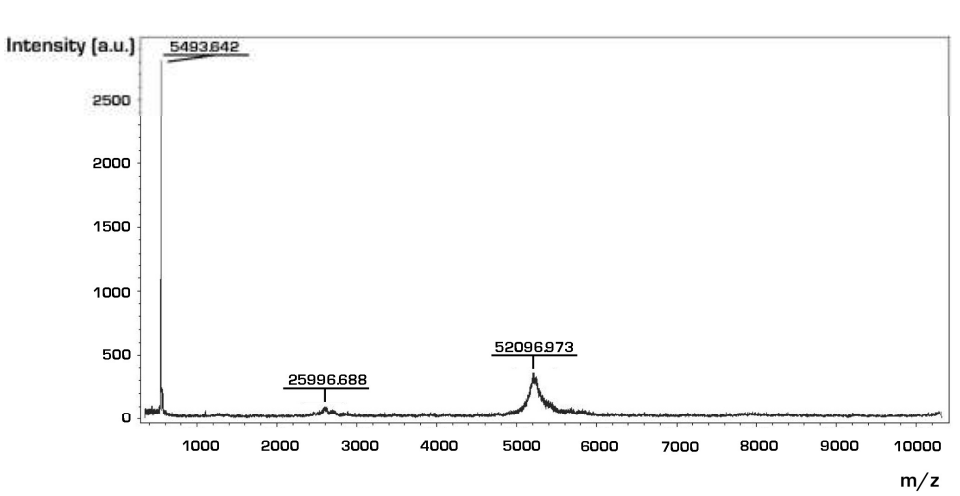

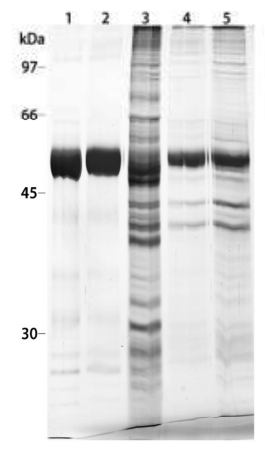

b

Fig. 1. Analysis of MRJP1 purity and affinity chromatography fractions. a) Mass spectrum of purified MRJP1. The peaks at $\mathrm{m} / \mathrm{z} 52,098.973$ and $\mathrm{m} / \mathrm{z} 25,998.688$ were assigned to singly charged and doubly charged MRJP1, respectively. The peak at $\mathrm{m} / \mathrm{z}$ at 5,493.642 was assigned to the MRJP1 binding peptide apisimin. b) SDS-PAGE profile of the affinity-separated fractions. Total protein amounts of $10 \mu \mathrm{g}$ were analyzed as purified MRJP1 (lane 1), MRJP1 uncoupled from the resin by DTT (lane 2), honey bee brain proteins not bound to imobilized MRJP1 (lane 3), complex MRJP1-binding proteins uncoupled from the resin by DTT (lanes 4 and 5, two tubes collected for protein identification by LC-MS/MS). Full length gel is shown in Supplementary Figure 12. 


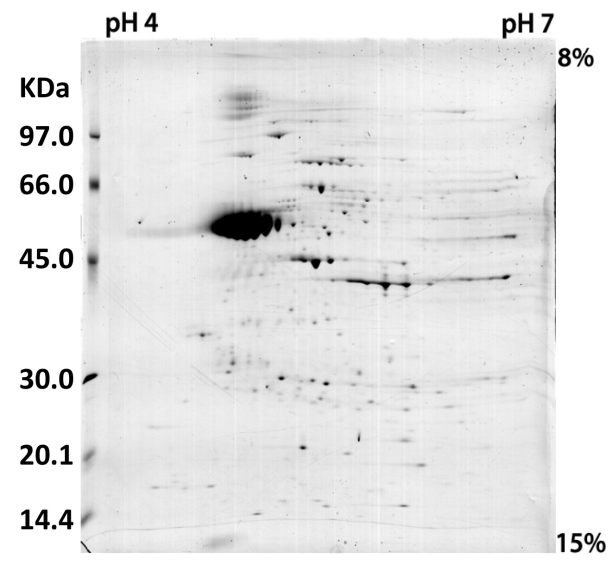

a

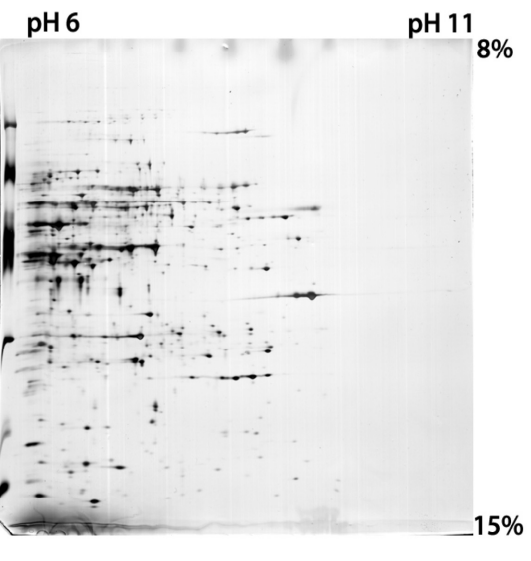

b

Fig. 2. 2DE profile of MRJP1-honey bee brain proteins interactome. The profile of MRJP1brain proteins interactome (160 $\mu \mathrm{g}$ per gel) was visualized by two dimensional electrophoresis (2DE) within $\mathrm{pH}$ ranges 4-7 and 6-11, followed by a second dimension of SDS-PAGE with gradient gels from from 8 to $15 \%$. Protein spots were silver stained. 


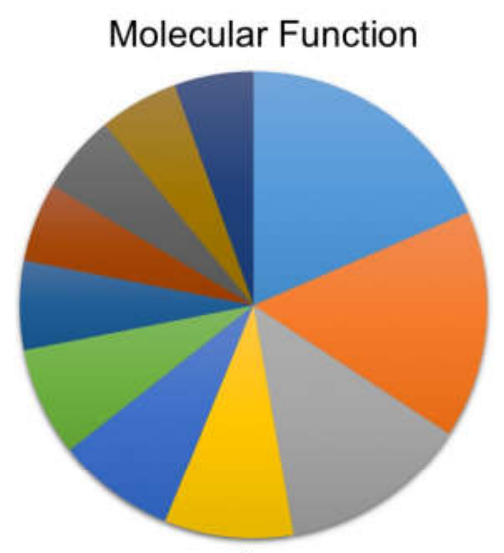

A

\section{Biological Process}

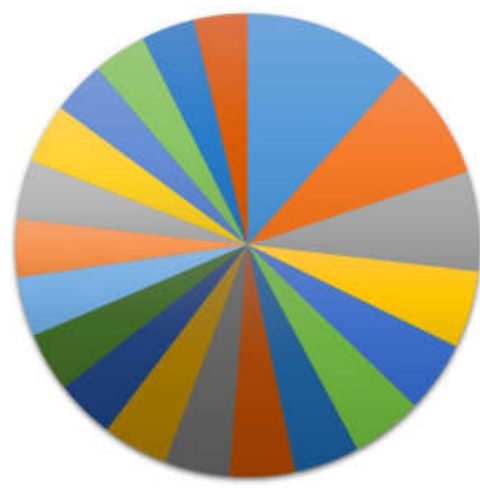

B

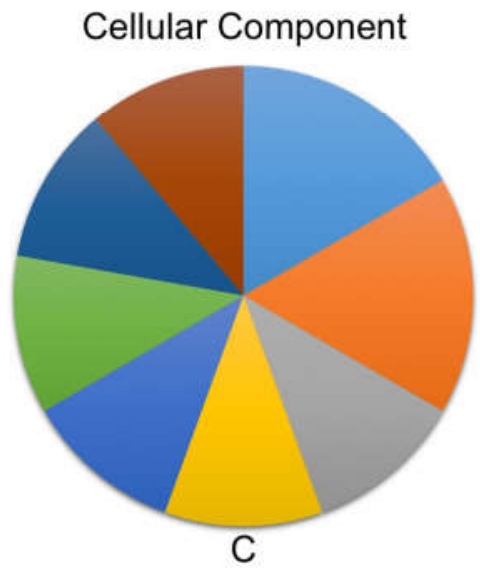

= ATP binding (27)

Oxireductase activity (23)

wetal ion binding (19)

Einase activity (13)

cofator binding (12)

wprotein binding (11)

- phosphotransferase activity, alcohol group as acceptor (9)

- Trasnporter activity (8)

- GTP binding (8)

- Nucleic acid binding (8)

- GTPase acitivity (8)

= Oxidation-reduction process (28)

= Phosphorylation (20)

= Generation of precursor metabolites and energy (17)

= Organonitrogen compound biosynthetic process (13)

- alpha-amino acid metabolic process (12)

= Cellular nitrogen compound biosynthetic process (12)

- Small molecule biosynthetic process (11)

- Single-organism trasnport (11)

- Organic substance catabolic process (11)

- Cellular macromolecule biosynthetic process (11)

- Carbohydrate metabolic process (10)

- ATP metabolic process (10)

= Response to stress (10)

= Regulation of cellular metabolic process (10)

- Cellular protein modification process (10)

=Pyruvate metabolic process (10)

= Peptide metabolic process (9)

= Regulation of primary metabolic process (9)

- Coenzyme metabolic process (9)

= Regulation of macromolecule metabolic process (9)

= Ribosome (6)

- Catalytic complex (6)

=Proton-transporting two -sector ATPase complex, catalytic domain (4)

- Intracelular membrane-bounded organelle (4)

- Proton-transportin V-type ATPase complex (4)

=xtracellular region (4)

- Polimeric cytoskeletal fiber (4)

- Microtubule cytoskeleton (4)

Fig. 3. Categorization of MRJP1-binding proteins under GO terms. FASTA sequences from the list of identified proteins were uploaded onto BLAST2GO, version 3.3.5, for sequence similarity search performed with BLASTp algorithm against a BLAST2GO non-redundant protein (nr) under default analysis values. Mapping of GO terms associated to the hits obtained with BLAST was performed to categorize proteins according to (a) molecular function, (b) biological process and (c) celullar component. 


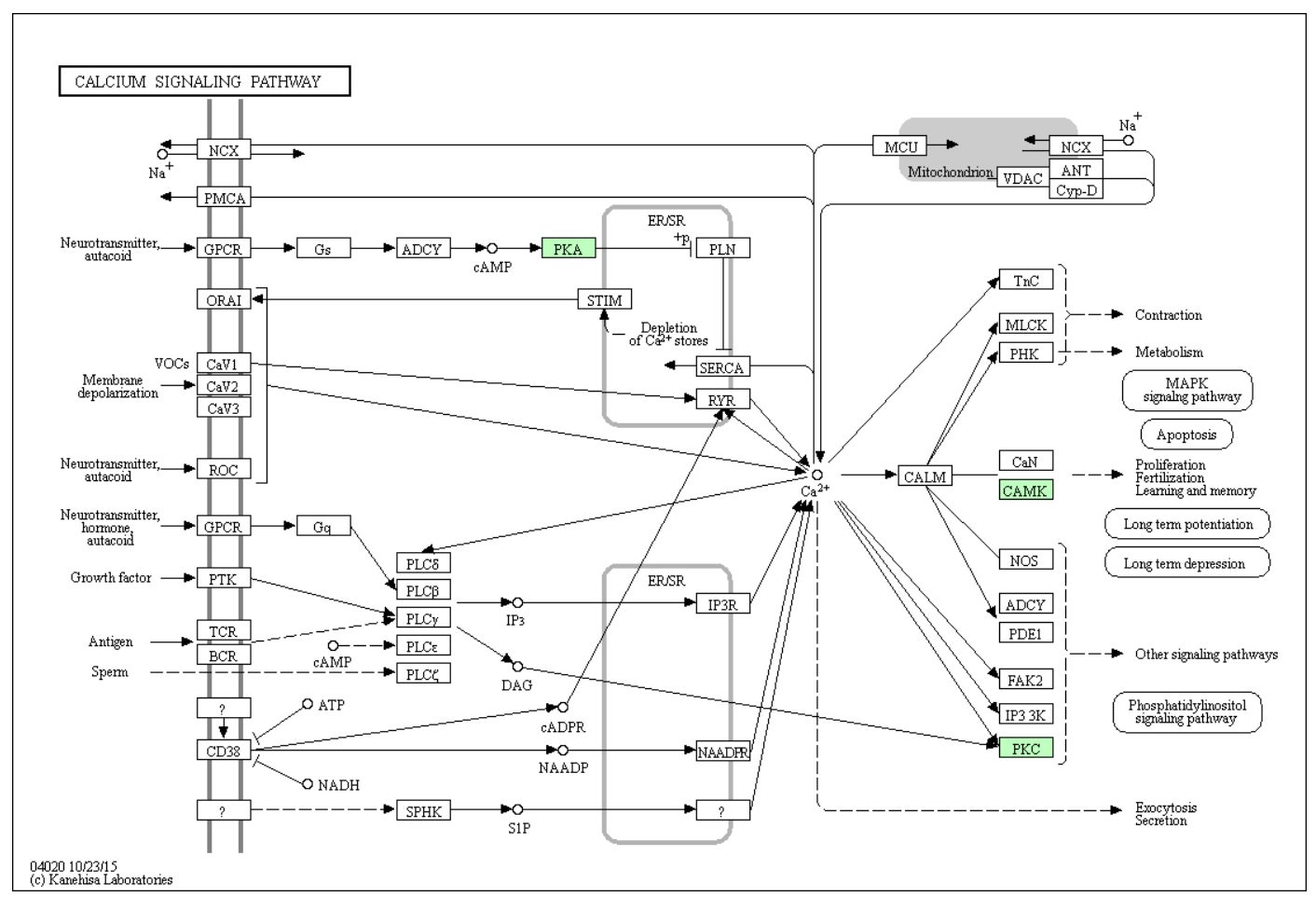

Fig. 4. Action of MRJP1-binding proteins on calcium signaling pathways. The individual proteins were place into KEGG pathways by the use of BLASTKOALA. Default search parameters were used against the "family_eukaryotes" KEGG Genes Database ( http://www.kegg.jp/kegg/kegg1.html ). 


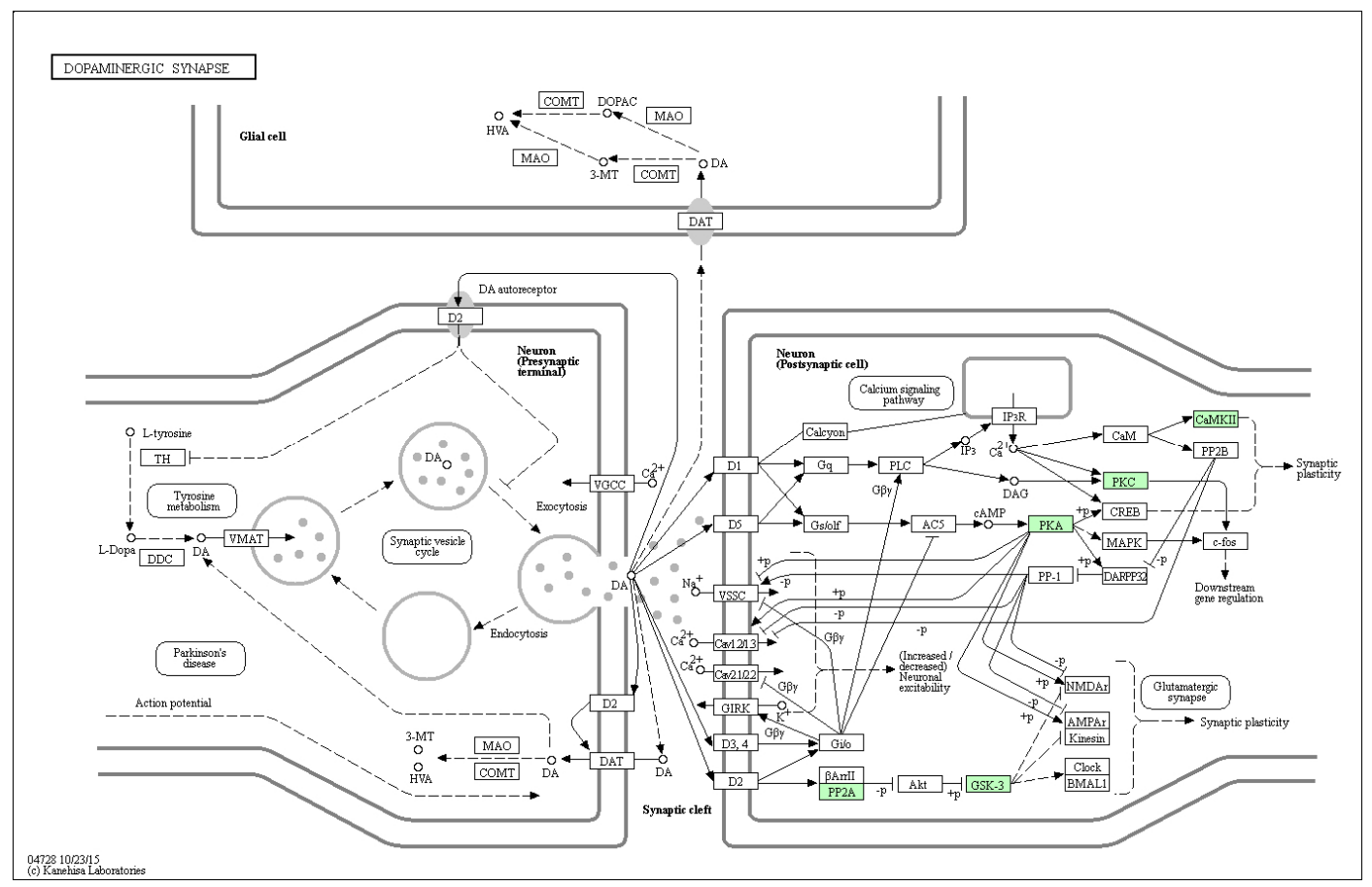

Fig. 5. Action of MRJP1-binding proteins on dopaminergic synapse pathways. The individual proteins were place into KEGG pathways by the use of BLASTKOALA. Default search parameters were used against the "family_eukaryotes" KEGG Genes Database ( http://www.kegg.jp/kegg/kegg1.html ). 


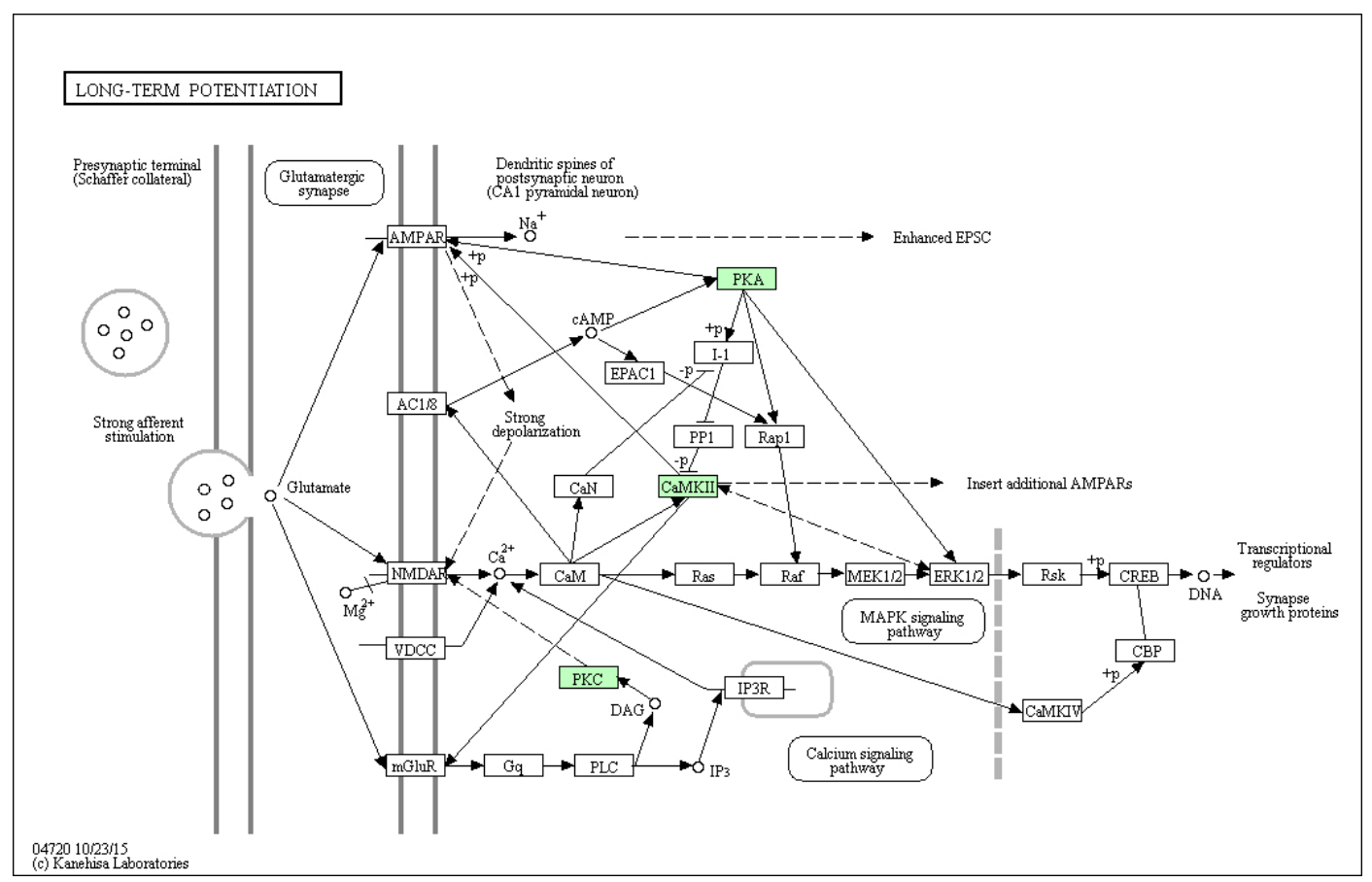

Fig. 6. Action of MRJP1-binding proteins on long-term potentiation pathways. The individual proteins were place into KEGG pathways by the use of BLASTKOALA. Default search parameters were used against the "family_eukaryotes" KEGG Genes Database ( http://www.kegg.jp/kegg/kegg1.html ).

\section{Acknowledgements}

The authors are indebted to Prof. Robert N. Miller, Department of Cell Biology, University of Brasilia, for critically reading the manuscript. The authors are grateful to excellent technical assistance from Nuno M. Domingues. Financial support came from grants 479260/2010-9, 483191/2013-2 and 309338/2013-1 from CNPq (Brazil) and 0439/11 CT-INFRA - PROINFRA 02/2010 from FINEP (Brazil) to MVS. JMS was a recipient of a CAPES PhD studentship. GCNC was a recipient of a CNPq PhD studentship and LHFDV is supported under CNPq research grant 400301/2014-8.

\section{Author contributions statement}

Honey bee head dissection, brain proteome extraction and affinity chromatography were conducted by JMS and GCNC; SDS-PAGE and 2D were run by GCNC and CAOR; top down LCMS and protein identification by LC-MS/MS were performed by LHFV and NLK; bioinformatics 
was carried out by JMS; experiments were designed by JMS, GCNC and MVS; biological data were interpreted by JMS, GCNC, LHFV, CAOR and MVS; the manuscript was written by JMS and MVS.

\section{Additional information}

The authors declare that they have no competing financial, professional or personal interests that might have influenced the work described in this manuscript. All experiments were carried out in accordance with relevant guidelines and regulations. 


\section{CONCLUSÃO GERAL DA TESE E PERSPECTIVAS}

O presente trabalho contribuiu com uma análise proteômica profunda sobre os mecanismos moleculares envolvidos no condicionamento operante em ratos e abelhas. Ademais, até o presente momento, este foi o primeiro trabalho abrangendo uma análise proteômica de auto rendimento com ênfase no proteoma cerebral da abelha $M$. quadrifasciata, possibilitando a identificação de milhares de proteínas. Foi possível identificar algumas proteínas que apresentaram diferenças em seus níveis de abundância nos animais treinados, sendo essas dependentes do tempo após de extração bem como dependente do número de sessões que os animais são submetidos. Tais resultados sugerem um forte envolvimento proteínas pertencentes ou associadas ao citoesqueleto nessa forma de aprendizagem. Além disso, pode-se concluir que a aprendizagem por condicionamento é um processo dependente não apenas da síntese, mas também da degradação proteica. Isso foi evidente principalmente quando avaliamos os resultados obtidos com o modelo de abelha. Os resultados aqui apresentados contribuem para o esclarecimento de tal processo e abrem perspectivas para novos estudos embasados na análise de modificações póstraducionais como a fosforilação, visto a identificação de cinases e fosfatases com diferentes abundâncias entre os grupos. Outra análise que pode ser realizada é a análise de ubiquitinação de proteínas, uma vez que foi observado um decréscimo da abundância de várias proteínas no treinamento com abelhas em conjunto do enriquecimento da via de proteassomo e de proteínas ubiquitina ligase. Por meio de tais estudos pode-se elucidar quais sãos as proteínas alvos dessas enzimas e em quais processos elas podem estar envolvidas. Técnicas para estudos de tais eventos podem ser utilizadas no próprio laboratório de bioquímica e química de proteínas, visto que o laboratório comporta estrutura e instrumentos para tais análise. 


\section{REFERÊNCIAS BIBLIOGRÁFICAS}

ABEL, T.; LATTAL, K. M. Molecular mechanisms of memory acquisition, consolidation and retrieval. Current Opinion in Neurobiology, v. 11, n. 2, p. $180-$ 187, 4/1/ 2001.

ABEL, T. et al. Genetic demonstration of a role for PKA in the late phase of LTP and in hippocampus-based long-term memory. Cell, v. 88, 1997.

ALONSO, M. et al. BDNF-triggered events in the rat hippocampus are required for both short-and long-term memory formation. Hippocampus, v. 12, n. 4, p. 551 560, 2002.

ALTMAN, J.; DAS, G. D. Autoradiographic and histological evidence of postnatal hippocampal neurogenesis in rats. J Comp Neurol, v. 124, n. 3, p. 319-335, 1965.

ANGGONO, V.; HUGANIR, R. L. Regulation of AMPA Receptor Trafficking and Synaptic Plasticity. Current opinion in neurobiology, v. 22, n. 3, p. 461-469, 01/02 2012.

ARDENGHI, P. et al. Late and prolonged post-training memory modulation in entorhinal and parietal cortex by drugs acting on the CAMP/protein kinase A signalling pathway. Behav Pharmacol, v. 8, n. 8, p. 745-51, Dec 1997.

BAINES, A. J.; LU, H.-C.; BENNETT, P. M. The Protein 4.1 family: Hub proteins in animals for organizing membrane proteins. Biochimica et Biophysica Acta (BBA) - Biomembranes, v. 1838, n. 2, p. 605-619, 2// 2014.

BALDWIN, A. E.; SADEGHIAN, K.; KELLEY, A. E. Appetitive instrumental learning requires coincident activation of NMDA and dopamine D1 receptors within the medial prefrontal cortex. J Neurosci, v. 22, n. 3, p. 1063-71, Feb 1 2002.

BARRON, A. B. et al. Embracing multiple definitions of learning. Trends in Neurosciences, v. 38 , n. 7, p. 405-407, 
BAYES, A. et al. Comparative study of human and mouse postsynaptic proteomes finds high compositional conservation and abundance differences for key synaptic proteins. PLoS One, v. 7, n. 10, p. e46683, 2012.

BAYÉS, À. et al. Human post-mortem synapse proteome integrity screening for proteomic studies of postsynaptic complexes. Mol Brain, v. 7, p. 88, 2014.

BAYES, A.; GRANT, S. G. Neuroproteomics: understanding the molecular organization and complexity of the brain. Nat Rev Neurosci, v. 10, n. 9, p. 63546, Sep 2009.

BAYES, A. et al. Characterization of the proteome, diseases and evolution of the human postsynaptic density. Nat Neurosci, v. 14, n. 1, p. 19-21, 2011.

BEHRENDS, A.; SCHEINER, R. Evidence for associative learning in newly emerged honey bees (Apis mellifera). Animal Cognition, v. 12, n. 2, p. 249-255, $2009 / / 2009$.

BEIßBARTH, T.; SPEED, T. P. GOstat: find statistically overrepresented Gene Ontologies within a group of genes. Bioinformatics, v. 20, n. 9, p. 1464-1465, 2004.

BENJAMINI, Y.; HOCHBERG, Y. Controlling the false discovery rate: a practical and powerful approach to multiple testing. Journal of the Royal Statistical Society B, v. 57, 1995.

BITTENCOURT, S. et al. Distribution of the protein IMPACT, an inhibitor of GCN2, in the mouse, rat, and marmoset brain. The Journal of Comparative Neurology, v. 507, n. 5, p. 1811-1830, 2008.

BRACKLEY, K. I.; GRANTHAM, J. Subunits of the chaperonin CCT interact with F-actin and influence cell shape and cytoskeletal assembly. Experimental Cell Research, v. 316, n. 4, p. 543-553, 2/15/ 2010. 
. Interactions between the actin filament capping and severing protein gelsolin and the molecular chaperone CCT: evidence for nonclassical substrate interactions. Cell Stress \& Chaperones, Dordrecht, v. 16, n. 2, p. 173-179,

BREMBS, B. Operant learning of Drosophila at the torque meter. J Vis Exp, $n$. 16, 2008.

CAMERON, H. A.; MCKAY, R. D. G. Adult neurogenesis produces a large pool of new granule cells in the dentate gyrus. The Journal of Comparative Neurology, v. 435 , n. 4, p. 406-417, 2001.

$\mathrm{CHEN}, \mathrm{Y}$. et al. Operant conditioning of rat soleus $\mathrm{H}$-reflex oppositely affects another H-reflex and changes locomotor kinematics. J Neurosci, v. 31, n. 31, p. 11370-5, Aug 3 2011. I

CHHABRA, E. S. et al. INF2 is an endoplasmic reticulum-associated formin protein. Journal of Cell Science, v. 122, n. 9, p. 1430-1440,.

CHUNG, W.-S.; ALLEN, N. J.; EROGLU, C. Astrocytes Control Synapse Formation, Function, and Elimination. Cold Spring Harbor Perspectives in Biology, v. 7, n. 9, p. a020370, 2015.

CHUNG, W.-S.; BARRES, B. A. The role of glial cells in synapse elimination. Current Opinion in Neurobiology, v. 22, n. 3, p. 438-445, 10/27 2012.

CONESA, A.; GÖTZ, S. Blast2GO: A comprehensive suite for functional analysis in plant genomics. International journal of plant genomics, v. 2008, 2008. ISSN 1687-5370.

CONESA, A. et al. Blast2GO: a universal tool for annotation, visualization and analysis in functional genomics research. Bioinformatics, v. 21, n. 18, p. 36743676, September 15, 2005

CRAFT, G. E.; CHEN, A.; NAIRN, A. C. Recent advances in quantitative neuroproteomics. Methods, v. 61, n. 3, p. 186-218, Jun 152013. 
DA SILVA MENEGASSO, A. R. et al. Profiling the proteomics in honeybee worker brains submitted to the proboscis extension reflex. Journal of Proteomics, v. 151 , p. $131-144,1 / 16 / 2017$.

DALLA, C.; SHORS, T. J. Sex differences in learning processes of classical and operant conditioning. Physiology \& Behavior, v. 97, n. 2, p. 229-238, 5/25/ 2009.

DAVID, A.; PIERRE, L. Hippocampal neuroanatomy. In: (Ed.). The hippocampus book: Oxford University Press, 2009.

DUDAI, Y. The neurobiology of consolidations, or, how stable is the engram? Annu Rev Psychol, v. 55, p. 51-86, 2004.

DUNBAR, A. B.; TAYLOR, J. R. Inhibition of protein synthesis but not $\beta$ adrenergic receptors blocks reconsolidation of a cocaine-associated cue memory. Learning \& Memory, v. 23, n. 8, p. 391-398, August 1, 2016

ESTEVEZ, M. A.; ABEL, T. Epigenetic Mechanisms of Memory Consolidation

Brain, Behavior and Epigenetics. In: PETRONIS, A. e MILL, J. (Ed.): Springer Berlin Heidelberg, 2011. p.267-285. (Epigenetics and Human Health). ISBN 978-3-642-17426-1.

ETHELL, I. M.; PASQUALE, E. B. Molecular mechanisms of dendritic spine development and remodeling. Progress in Neurobiology, v. 75, n. 3, p. 161205, 2/l 2005. ISSN 0301-0082. Disponível em: < http://www.sciencedirect.com/science/article/pii/S0301008205000146 >.

FERREIRA, E.; SHAW, D. M.; ODDO, S. Identification of learning-induced changes in protein networks in the hippocampi of a mouse model of Alzheimer/'s disease. Transl Psychiatry, v. 6, p. e849, 07/05/online 2016. Disponível em: < http://dx.doi.org/10.1038/tp.2016.114 >. 
FOUNTOULAKIS, M. et al. The rat brain hippocampus proteome. J Chromatogr B Analyt Technol Biomed Life Sci, v. 819, n. 1, p. 115-29, May 5 2005. ISSN 1570-0232 (Print)

1570-0232 (Linking). Disponivel em: < http://www.ncbi.nlm.nih.gov/pubmed/15797529 >.

FREY, U. et al. Anisomycin, an inhibitor of protein synthesis, blocks late phases of LTP phenomena in the hippocampal CA1 region in vitro. Brain research, v. 452, n. 1-2, p. 57-65, 1988/06// 1988. ISSN 0006-8993. Disponível em: < http://europepmc.org/abstract/MED/3401749

http://dx.doi.org/10.1016/0006-8993(88)90008-X >.

GIESE, K. P.; MIZUNO, K. The roles of protein kinases in learning and memory. Learning \& Memory, v. 20, n. 10, p. 540-552, October 1, 20132013. Disponível em: < http://learnmem.cshlp.org/content/20/10/540.abstract $>$.

GIL, M.; MENZEL, R.; DE MARCO, R. J. Side-specific reward memories in honeybees. Learn Mem, v. 16, n. 7, p. 426-32, Jul 2009. ISSN 1549-5485 (Electronic)

1072-0502 (Linking). Disponivel em: < http://www.ncbi.nlm.nih.gov/pubmed/19553380 >.

GIURFA, M.; SANDOZ, J.-C. Invertebrate learning and memory: Fifty years of olfactory conditioning of the proboscis extension response in honeybees. Learning \& Memory, v. 19, n. 2, p. 54-66, February 1, 2012 2012. Disponível em: $<$ http://learnmem.cshlp.org/content/19/2/54.abstract $>$.

GOMEZ-PINILLA, F. et al. BDNF and learning: Evidence that instrumental training promotes learning within the spinal cord by up-regulating BDNF expression. Neuroscience, v. 148, n. 4, p. 893-906, Sep 21 2007. ISSN 03064522 (Print)

0306-4522 (Linking). Disponivel em: < http://www.ncbi.nlm.nih.gov/pubmed/17719180 >. 
GÖTZ, S. et al. High-throughput functional annotation and data mining with the Blast2GO suite. Nucleic Acids Research, v. 36, n. 10, p. 3420-3435, June 1, 2008 2008. Disponível em: < http://nar.oxfordjournals.org/content/36/10/3420.abstract >.

GOULD, E.; GROSS, C. G. Neurogenesis in adult mammals: some progress and problems. J Neurosci, v. 22, n. 3, p. 619-23, Feb 1 2002. ISSN 1529-2401 (Electronic)

0270-6474 (Linking). Disponível em: < http://www.ncbi.nlm.nih.gov/pubmed/11826089 >.

GUREL, P. S. et al. Assembly and Turnover of Short Actin Filaments by the Formin INF2 and Profilin. The Journal of Biological Chemistry, 11200 Rockville Pike, Suite 302, Rockville, MD 20852-3110, U.S.A., v. 290, n. 37, p. 22494-22506, 06/29

06/04/received

06/26/revised 2015. ISSN 0021-9258

1083-351X Disponivel

http://www.ncbi.nlm.nih.gov/pmc/articles/PMC4566225/ >.

HAGIHARA, H. et al. Dissection of hippocampal dentate gyrus from adult mouse. J Vis Exp, n. 33, 2009. ISSN 1940-087X. Disponível em: < http://dx.doi.org/10.3791/1543 >.

HALES, J. B. et al. Hippocampus, perirhinal cortex, and complex visual discriminations in rats and humans. Learning \& Memory, v. 22, n. 2, p. 83-91, February $1, \quad 20152015 . \quad$ Disponível em: < http://learnmem.cshlp.org/content/22/2/83.abstract >.

HANLEY, J. G. NSF binds calcium to regulate its interaction with AMPA receptor subunit GluR2. Journal of neurochemistry, v. 101, n. 6, p. 1644-1650, 02/14 2007. ISSN 0022-3042

1471-4159.

Disponível

em: $<$ http://www.ncbi.nlm.nih.gov/pmc/articles/PMC1976250/ >. 
HARDT, O.; NADER, K.; WANG, Y.-T. GluA2-dependent AMPA receptor endocytosis and the decay of early and late long-term potentiation: possible mechanisms for forgetting of short- and long-term memories. Philosophical Transactions of the Royal Society B: Biological Sciences, v. 369, n. 1633, p. 20130141, 2014. ISSN 0962-8436

1471-2970.

Disponivel

em:

$<$

http://www.ncbi.nlm.nih.gov/pmc/articles/PMC3843873/ >.

HASSELMO, M. E.; EICHENBAUM, H. B. Hippocampal mechanisms for the context-dependent retrieval of episodes. Neural networks : the official journal of the International Neural Network Society, v. 18, n. 9, p. 1172-1190, 11/02 2005. ISSN 0893-6080. Disponível em: < http://www.ncbi.nlm.nih.gov/pmc/articles/PMC2253492/ >.

HEBB, D. O. The organization of behavior: A neuropsychological approach. John Wiley \& Sons, 1949.

HEKMATNEJAD, B. et al. SUMOylated aNAC Potentiates Transcriptional Repression by FIAT. Journal of Cellular Biochemistry, v. 115, n. 5, p. 866-873, 2014. ISSN 1097-4644. Disponível em: < http://dx.doi.org/10.1002/jcb.24729 >.

HERNANDEZ, P. J.; ABEL, T. The role of protein synthesis in memory consolidation: Progress amid decades of debate. Neurobiology of Learning and Memory, v. 89, n. 3, p. 293-311, 2008. ISSN 1074-7427. Disponível em: < http://www.sciencedirect.com/science/article/pii/S1074742707001621 >.

HOTULAINEN, P.; HOOGENRAAD, C. C. Actin in dendritic spines: connecting dynamics to function. The Journal of Cell Biology, v. 189, n. 4, p. 619629, 03/01/received

04/22/accepted 2010. ISSN 0021-9525

1540-8140.

Disponível

em: $<$ http://www.ncbi.nlm.nih.gov/pmc/articles/PMC2872912/ >. 
HUANG, D. W.; SHERMAN, B. T.; LEMPICKI, R. A. Bioinformatics enrichment tools: paths toward the comprehensive functional analysis of large gene lists. Nucleic Acids Research, v. 37, n. 1, p. 1-13, January 1, 20092009. Disponível em: < http://nar.oxfordjournals.org/content/37/1/1.abstract $>$.

IZQUIERDO, I. Memória. rev. e ampl. Porto Alegre: Artmed, 2011.

IZQUIERDO, I. et al. Different molecular cascades in different sites of the brain control memory consolidation. Trends in Neurosciences, v. 29, n. 9, p. 496505, 9// 2006. ISSN 0166-2236. Disponível em: < http://www.sciencedirect.com/science/article/pii/S0166223606001482 >.

IZQUIERDO, I.; MEDINA, J. H. Memory formation: the sequence of biochemical events in the hippocampus and its connection to activity in other brain structures. Neurobiol Learn Mem, v. 68, n. 3, p. 285-316, Nov 1997. ISSN 1074-7427 (Print)

1074-7427 (Linking). Disponível em: < http://www.ncbi.nlm.nih.gov/pubmed/9398590 >.

JAHOLKOWSKI, P. et al. New hippocampal neurons are not obligatory for memory formation; cyclin D2 knockout mice with no adult brain neurogenesis show learning. Learn Mem, v. 16, n. 7, p. 439-51, Jul 2009. ISSN 1549-5485 (Electronic)

1072-0502 (Linking). Disponível em: $<$ http://www.ncbi.nlm.nih.gov/pubmed/19553382 >.

JI, D.; WILSON, M. A. Coordinated memory replay in the visual cortex and hippocampus during sleep. Nat Neurosci, v. 10, n. 1, p. 100-107, 01//print 2007. ISSN 1097-6256. Disponível em: < http://dx.doi.org/10.1038/nn1825 >.

JONKMAN, S. et al. The rat prelimbic cortex mediates inhibitory response control but not the consolidation of instrumental learning. Behav Neurosci, v. 123, n. 4, p. 875-85, Aug 2009. ISSN 1939-0084 (Electronic) 
0735-7044 (Linking). Disponível em: < http://www.ncbi.nlm.nih.gov/pubmed/19634948 >.

JOZEFOWIEZ, J.; STADDON, J. E. R. 1.06 - Operant Behavior A2 - Byrne, John H. In: (Ed.). Learning and Memory: A Comprehensive Reference. Oxford: Academic Press, 2008. p.75-101. ISBN 978-0-12-370509-9.

KANDEL, E. R. The molecular biology of memory storage: a dialog between genes and synapses. Biosci Rep, v. 21, n. 5, p. 565-611, Oct 2001. ISSN 0144-8463 (Print)

0144-8463 (Linking). Disponível em: < http://www.ncbi.nlm.nih.gov/pubmed/12168768 >.

KANDEL, ERIC R.; DUDAI, Y.; MAYFORD, MARK R. The Molecular and Systems Biology of Memory. Cell, v. 157, n. 1, p. 163-186, 3/27/ 2014. ISSN 0092-8674. Disponível em: $<$ http://www.sciencedirect.com/science/article/pii/S0092867414002906 >.

KANDEL, E. R.; SCHWARTZ, J. H.; JESSELL, T. M. Principles of neural science. 4th. New York, NY ; London: McGraw-Hill, 2000. xli, 1414 p. ISBN 0838577016

0071120009 (International edition).

KANEHISA, M.; GOTO, S. KEGG: Kyoto Encyclopedia of Genes and Genomes. Nucleic Acids Research, v. 28, 2000. Disponível em: < http://dx.doi.org/10.1093/nar/28.1.27 >.

KANEHISA, M. et al. KEGG as a reference resource for gene and protein annotation. Nucleic Acids Research, v. 44, n. D1, p. D457-D462, January 4, 2016 2016. Disponível em: $<$ http://nar.oxfordjournals.org/content/44/D1/D457.abstract >.

KANEHISA, M.; SATO, Y.; MORISHIMA, K. BlastKOALA and GhostKOALA: KEGG Tools for Functional Characterization of Genome and 
Metagenome Sequences. Journal of Molecular Biology, v. 428, n. 4, p. 726-731, 2/22/ 2016. ISSN 0022-2836. Disponível em: < http://www.sciencedirect.com/science/article/pii/S002228361500649X >.

KELLY, M. P.; DEADWYLER, S. A. Acquisition of a novel behavior induces higher levels of Arc mRNA than does overtrained performance. Neuroscience, $v$. 110, n. 4, p. 617-626, 4/3/ 2002. ISSN 0306-4522. Disponível em: < http://www.sciencedirect.com/science/article/pii/S0306452201006054 >.

KIM, J. J.; DIAMOND, D. M. The stressed hippocampus, synaptic plasticity and lost memories. Nat Rev Neurosci, v. 3, n. 6, p. 453-62, Jun 2002. ISSN 1471003X (Print)

1471-003X (Linking). Disponível em: < http://www.ncbi.nlm.nih.gov/pubmed/12042880 >.

KIM, S. J.; LINDEN, D. J. Ubiquitous Plasticity and Memory Storage. Neuron, v. 56, n. 4, p. 582-592, 11/21/2007. ISSN 0896-6273. Disponível em: < http://www.sciencedirect.com/science/article/pii/S0896627307008264 >.

KLEMMER, P. et al. Proteomics, ultrastructure, and physiology of hippocampal synapses in a fragile $X$ syndrome mouse model reveal presynaptic phenotype. J Biol Chem, v. 286, n. 29, p. 25495-504, Jul 22 2011. ISSN 1083351X (Electronic)

0021-9258 (Linking). Disponível em: < http://www.ncbi.nlm.nih.gov/pubmed/21596744 >.

KOLB, B.; CIOE, J. Organization and Plasticity of the Prefrontal Cortex of the Rat

Prefrontal Cortex: From Synaptic Plasticity to Cognition. In: OTANI, S. (Ed.): Springer US, 2004. p.1-32. ISBN 978-1-4020-7949-8.

KOLB, B. et al. Age, experience and the changing brain. Neurosci Biobehav Rev, v. 22, n. 2, p. 143-59, Mar 1998. ISSN 0149-7634 (Print) 
0149-7634 (Linking). Disponível em: < http://www.ncbi.nlm.nih.gov/pubmed/9579307 >.

KOROBOVA, F.; RAMABHADRAN, V.; HIGGS, H. N. An Actin-Dependent Step in Mitochondrial Fission Mediated by the ER-Associated Formin INF2. Science (New York, N.Y.), v. 339, n. 6118, p. 10.1126/science.1228360, 2013. ISSN 0036-8075

1095-9203.

Disponível

em: $<$ http://www.ncbi.nlm.nih.gov/pmc/articles/PMC3843506/ >.

KRUG, M.; LÖSSNER, B.; OTT, T. Anisomycin blocks the late phase of long-term potentiation in the dentate gyrus of freely moving rats. Brain research bulletin, v. 13, n. 1, p. 39-42, 1984. ISSN 0361-9230.

KUCUKDERELI, $\mathrm{H}$. et al. Control of excitatory CNS synaptogenesis by astrocyte-secreted proteins Hevin and SPARC. Proceedings of the National Academy of Sciences of the United States of America, v. 108, n. 32, p. E440E449, 07/25 2011. ISSN 0027-8424

1091-6490.

Disponível em: http://www.ncbi.nlm.nih.gov/pmc/articles/PMC3156217/ >.

LECHNER, H. A.; SQUIRE, L. R.; BYRNE, J. H. 100 years of consolidation-remembering Müller and Pilzecker. Learning \& Memory, v. 6, n. 2, p. 77-87, 1999. ISSN 1072-0502.

LEUNER, B.; GOULD, E. Structural plasticity and hippocampal function. Annu Rev Psychol, v. 61, p. 111-40, C1-3, 2010. ISSN 1545-2085 (Electronic) 0066-4308 (Linking). Disponível em: < http://www.ncbi.nlm.nih.gov/pubmed/19575621 >.

LEVY, R.; LEVITAN, D.; SUSSWEIN, A. J. New learning while consolidating memory during sleep is actively blocked by a protein synthesis dependent process. eLife, v. 5, p. e17769, 2016/12/06 2016. ISSN 2050-084X. Disponível em: < https://dx.doi.org/10.7554/eLife.17769 >. 
LI, K.; KLEMMER, P.; SMIT, A. Interaction proteomics of synapse protein complexes. Analytical and Bioanalytical Chemistry, v. 397, n. 8, p. 3195-3202, 2010. ISSN 1618-2642. Disponível em: < http://dx.doi.org/10.1007/s00216-010$3658-z>$.

LI, Q. et al. A multidimensional approach to an in-depth proteomics analysis of transcriptional regulators in neuroblastoma cells. J Neurosci Methods, v. 216, n. 2, p. 118-27, Jun 15 2013. ISSN 1872-678X (Electronic)

0165-0270 (Linking). Disponivel em: < http://www.ncbi.nlm.nih.gov/pubmed/23558336 >.

LIHOREAU, M.; LATTY, T.; CHITTKA, L. An Exploration of the Social Brain Hypothesis in Insects. Frontiers in Physiology, v. 3, n. 442, $2012-$ November-27 2012. ISSN 1664-042X. Disponível em: < http://journal.frontiersin.org/article/10.3389/fphys.2012.00442 >.

LOCATELLI, F.; ROMANO, A. Differential activity profile of cAMPdependent protein kinase isoforms during long-term memory consolidation in the crab Chasmagnathus. Neurobiology of learning and memory, v. 83 , n. 3, p. 232242, 2005. ISSN 1074-7427.

LORENZETTI, F. D.; BAXTER, D. A.; BYRNE, J. H. Molecular Mechanisms Underlying a Cellular Analog of Operant Reward Learning. Neuron, v. 59, n. 5, p. $815-828$, 2008. ISSN 0896-6273. Disponível em: < http://www.sciencedirect.com/science/article/pii/S0896627308005928 >.

MALENKA, R. C.; NICOLL, R. A. Long-term potentiation--a decade of progress? Science, v. 285, n. 5435, p. 1870-1874, 1999. ISSN 0036-8075.

MALLICK, P.; KUSTER, B. Proteomics: a pragmatic perspective. Nat Biotech, v. 28, n. 7, p. 695-709, 07//print 2010. ISSN 1087-0156. Disponível em: < http://dx.doi.org/10.1038/nbt.1658 >. 
MATSUMOTO, Y. et al. Revisiting olfactory classical conditioning of the proboscis extension response in honey bees: A step toward standardized procedures. Journal of Neuroscience Methods, v. 211, n. 1, p. 159-167, 10/15/ 2012. ISSN 0165-0270. Disponível em: < http://www.sciencedirect.com/science/article/pii/S0165027012003299 >.

MAYFORD, M.; SIEGELBAUM, S. A.; KANDEL, E. R. Synapses and Memory Storage. Cold Spring Harbor Perspectives in Biology, v. 4, n. 6, p. a005751, 2012. ISSN 1943-0264. Disponível em: < http://www.ncbi.nlm.nih.gov/pmc/articles/PMC3367555/ >.

MCGAUGH, J. L. Memory--a century of consolidation. Science, v. 287, n. 5451, p. 248-51, Jan 14 2000. ISSN 0036-8075 (Print)

0036-8075 (Linking). Disponível em: <
http://www.ncbi.nlm.nih.gov/pubmed/10634773 >.

MEISSNER, F.; MANN, M. Quantitative shotgun proteomics: considerations for a high-quality workflow in immunology. Nat Immunol, v. 15, n. 2, p. 112-117, 02//print 2014. ISSN 1529-2908. Disponível em: < http://dx.doi.org/10.1038/ni.2781 >.

MENZEL, R.; BENJAMIN, P. R. Beyond the cellular alphabet of learning and memory in invertebrates. Invertebrate learning and memory (ed. Menzel R, Benjamin PR), p. 3-8, 2013.

MENZEL, R.; LEBOULLE, G.; EISENHARDT, D. Small brains, bright minds. Cell, v. 124, n. 2, p. 237-9, Jan 27 2006. ISSN 0092-8674 (Print) 0092-8674 (Linking). Disponível em: < http://www.ncbi.nlm.nih.gov/pubmed/16439194 >.

MONTAROLO, P. G. et al. A critical period for macromolecular synthesis in long-term heterosynaptic facilitation in Aplysia. Science, v. 234, 1986. 
MOZZACHIODI, R. et al. Changes in neuronal excitability serve as a mechanism of long-term memory for operant conditioning. Nat Neurosci, v. 11, n. 10, p. 1146-1148, 2008. ISSN 1097-6256. Disponível em: < http://dx.doi.org/10.1038/nn.2184 >.

MURAKOSHI, H.; YASUDA, R. Postsynaptic signaling during plasticity of dendritic spines. Trends in Neurosciences, v. 35, n. 2, p. 135-143, 01/03 2012. ISSN 0166-2236

1878-108X.

Disponível

em:

$<$ http://www.ncbi.nlm.nih.gov/pmc/articles/PMC3306839/ >.

NADER, K.; HARDT, O. A single standard for memory: the case for reconsolidation. Nat Rev Neurosci, v. 10, n. 3, p. 224-234, 03//print 2009. ISSN 1471-003X. Disponível em: < http://dx.doi.org/10.1038/nrn2590 >.

NESVIZHSKII, A. I.; AEBERSOLD, R. Interpretation of shotgun proteomic data: the protein inference problem. Mol Cell Proteomics, v. 4, 2005. Disponível em: < http://dx.doi.org/10.1074/mcp.R500012-MCP200 >.

NUSSER, Z. Alterations in the expression of GABAA receptor subunits in cerebellar granule cells after the disruption of the [alpha]6 subunit gene. Eur. J. Neurosci., v. 11, p. 1685-1697, // 1999. Disponível em: < http://dx.doi.org/10.1046/j.1460-9568.1999.00581.x >.

OKUDA, S. et al. KEGG Atlas mapping for global analysis of metabolic pathways. Nucleic Acids Research, v. 36, n. Web Server issue, p. W423-W426, $05 / 13$

02/09/received

04/03/revised

04/26/accepted 2008. ISSN 0305-1048

1362-4962. Disponível

em: $\quad<$

http://www.ncbi.nlm.nih.gov/pmc/articles/PMC2447737/ >. 
OSBORNE, J. K.; ZAGANJOR, E.; COBB, M. H. Signal control through Raf: in sickness and in health. Cell Research, v. 22, n. 1, p. 14-22, 12/06 2012. ISSN 1001-0602

1748-7838.

Disponível

em:

$<$ http://www.ncbi.nlm.nih.gov/pmc/articles/PMC3351917/ >.

OTA, K. T. et al. Synaptic Plasticity and NO-cGMP-PKG Signaling Regulate Pre- and Postsynaptic Alterations at Rat Lateral Amygdala Synapses Following Fear Conditioning. PLOS ONE, v. 5, n. 6, p. e11236, 2010. Disponível em: < http://dx.doi.org/10.1371\%2Fjournal.pone.0011236>.

PAOLICELLI, R. C. et al. Synaptic Pruning by Microglia Is Necessary for Normal Brain Development. Science, v. 333, n. 6048, p. 1456-1458, 2011.

PATIL, S. S. et al. Differences in hippocampal protein levels between C57BI/6J, PWD/PhJ, and Apodemus sylvaticus are paralleled by differences in spatial memory. Hippocampus, v. 21, n. 7, p. 714-23, Jul 2011. ISSN 1098-1063 (Electronic)

1050-9631 (Linking). Disponível em: < http://www.ncbi.nlm.nih.gov/pubmed/20740491 >.

PAUL E, G. Protein synthesis inhibition and memory: Formation vs amnesia. Neurobiology of Learning and Memory, v. 89, n. 3, p. 201-211, 2008. ISSN 1074-7427. Disponível em: < http://www.sciencedirect.com/science/article/pii/S1074742707001669 >.

PIENAAR, I. S.; DANIELS, W. M.; GOTZ, J. Neuroproteomics as a promising tool in Parkinson's disease research. J Neural Transm, v. 115, n. 10, p. 1413-30, Oct 2008. ISSN 0300-9564 (Print)

0300-9564 (Linking). Disponível em: < http://www.ncbi.nlm.nih.gov/pubmed/18523721 >.

POPOV, V. et al. Mitochondria form a filamentous reticular network in hippocampal dendrites but are present as discrete bodies in axons: A three- 
dimensional ultrastructural study. The Journal of Comparative Neurology, v. 492, n. 1, p. 50-65, 2005. ISSN 1096-9861. Disponível em: < http://dx.doi.org/10.1002/cne.20682 >.

QUILLFELDT, J. A. Behavioral Methods to Study Learning and Memory in Rats. In: ANDERSEN, M. L. e TUFIK, S. (Ed.). Rodent Model as Tools in Ethical Biomedical Research. Cham: Springer International Publishing, 2016. p.271311. ISBN 978-3-319-11578-8.

QUILLFELDT, J. A. et al. Different Brain Areas Are Involved in Memory Expression at Different Times from Training. Neurobiology of Learning and Memory, v. 66, n. 2, p. 97-101, 9// 1996. ISSN 1074-7427. Disponível em: < http://www.sciencedirect.com/science/article/pii/S1074742796900507 >.

RAMABHADRAN, V. et al. Splice variant-specific cellular function of the formin INF2 in maintenance of Golgi architecture. Molecular Biology of the Cell, v. 22 , n. 24 , p. $4822-4833,05 / 27 /$ received

10/06/revised

10/06/accepted 2011. ISSN 1059-1524

1939-4586. Disponivel em: < http://www.ncbi.nlm.nih.gov/pmc/articles/PMC3237625/ >.

RAPANELLI, M.; FRICK, L. R.; ZANUTTO, B. S. Differential gene expression in the rat hippocampus during learning of an operant conditioning task. Neuroscience, v. 163, n. 4, p. 1031-1038, 2009. ISSN 0306-4522. Disponível em:

http://www.sciencedirect.com/science/article/pii/S0306452209012111 >.

RAPANELLI, M.; FRICK, L. R.; ZANUTTO, B. S. Modulation of endothelial and neuronal nitric oxide synthases during learning of an operant conditioning task. Journal of neurochemistry, v. 113, n. 3, p. 725-734, 2010. ISSN 1471-4159.

RAPANELLI, M.; FRICK, L. R.; ZANUTTO, B. S. Learning an operant conditioning task differentially induces gliogenesis in the medial prefrontal cortex 
and neurogenesis in the hippocampus. PLoS One, v. 6, n. 2, p. e14713, 2011. ISSN 1932-6203 (Electronic)

1932-6203 (Linking). Disponível em: < http://www.ncbi.nlm.nih.gov/pubmed/21364751 >.

RAPANELLI, M. et al. Plasticity in the rat prefrontal cortex: linking gene expression and an operant learning with a computational theory. PLoS One, v. 5, n. 1, p. e8656, 2010. ISSN 1932-6203 (Electronic)

1932-6203 (Linking). Disponível em: < http://www.ncbi.nlm.nih.gov/pubmed/20111591 >.

REUL, J. M. et al. Epigenetic mechanisms in the dentate gyrus act as a molecular switch in hippocampus-associated memory formation. Epigenetics, $v$. 4, n. 7, p. 434-9, Oct 1 2009. ISSN 1559-2308 (Electronic)

1559-2294 (Linking). Disponível em: < http://www.ncbi.nlm.nih.gov/pubmed/19829071 >.

REYMANN, K. G.; FREY, J. U. The late maintenance of hippocampal LTP: requirements, phases,'synaptic tagging','late-associativity'and implications. Neuropharmacology, v. 52, n. 1, p. 24-40, 2007. ISSN 0028-3908.

ROGOWSKA-WRZESINSKA, A. et al. 2D gels still have a niche in proteomics. Journal of Proteomics, v. 88, n. 0, p. 4-13, 8/2/ 2013. ISSN 18743919. Disponível em: < http://www.sciencedirect.com/science/article/pii/S1874391913000389 >.

ROSENEGGER, D.; LUKOWIAK, K. The participation of NMDA receptors, PKC, and MAPK in the formation of memory following operant conditioning in Lymnaea. Mol Brain, v. 3, p. 24, 2010. ISSN 1756-6606 (Electronic)

1756-6606 (Linking). Disponível em: < http://www.ncbi.nlm.nih.gov/pubmed/20807415 >.

ROSSATO, J. I. et al. Dopamine controls persistence of long-term memory storage. Science, v. 325, n. 5943, p. 1017-1020, 2009. ISSN 0036-8075. 
SANTAMARIA, P. G.; NEBREDA, A. R. Deconstructing ERK Signaling in Tumorigenesis. Molecular Cell, v. 38, n. 1, p. 3-5, ISSN 1097-2765. Disponível em: < http://dx.doi.org/10.1016/j.molcel.2010.03.012 >. Acesso em: 2017/02/23.

SATOH, Y. et al. ERK2 Contributes to the Control of Social Behaviors in Mice. The Journal of Neuroscience, v. 31, n. 33, p. 11953-11967, 2011.

SCHAFE, G. E. et al. Activation of ERK/MAP kinase in the amygdala is required for memory consolidation of pavlovian fear conditioning. Journal of Neuroscience, v. 20, n. 21, p. 8177-8187, 2000. ISSN 0270-6474.

SCHAFER, D. P. et al. Microglia Sculpt Postnatal Neural Circuits in an Activity and Complement-Dependent Manner. Neuron, v. 74, n. 4, p. 691-705, 2012. ISSN 0896-6273

1097-4199.

Disponível

em:

$<$ http://www.ncbi.nlm.nih.gov/pmc/articles/PMC3528177/ >.

SCHMIDT-HIEBER, C.; JONAS, P.; BISCHOFBERGER, J. Enhanced synaptic plasticity in newly generated granule cells of the adult hippocampus. Nature, v. 429, n. 6988, p. 184-187, 05/13/print 2004. ISSN 0028-0836. Disponível em: < http://dx.doi.org/10.1038/nature02553 >.

SCHMIDT, A.; FORNE, I.; IMHOF, A. Bioinformatic analysis of proteomics data. BMC Systems Biology, v. 8, n. Suppl 2, p. S3-S3, 03/13 2014. ISSN 17520509. Disponível em: < http://www.ncbi.nlm.nih.gov/pmc/articles/PMC4108846/ $>$.

SCHWÄMMLE, V.; JENSEN, O. N. A simple and fast method to determine the parameters for fuzzy c-means cluster analysis. Bioinformatics, v. 26, n. 22, p. 2841-2848, November 15, 2010 2010. Disponível em: < http://bioinformatics.oxfordjournals.org/content/26/22/2841.abstract >. 
SHENG, G. Hypothalamic huntingtin-associated protein 1 as a mediator of feeding behavior. Nature Med., v. 12, p. 526-533, // 2006. Disponível em: < http://dx.doi.org/10.1038/nm1382 >.

SMITH-ROE, S. L.; KELLEY, A. E. Coincident activation of NMDA and dopamine D1 receptors within the nucleus accumbens core is required for appetitive instrumental learning. J Neurosci, v. 20, n. 20, p. 7737-42, Oct 152000. ISSN 1529-2401 (Electronic)

0270-6474 (Linking). Disponivel em: < http://www.ncbi.nlm.nih.gov/pubmed/11027236 >.

SMITH, H. L.; LI, W.; CHEETHAM, M. E. Molecular chaperones and neuronal proteostasis. Seminars in cell \& developmental biology, v. 40, p. $142-$ 152, 03/12 2015. ISSN 1084-9521

1096-3634.

Disponível

em: $<$

http://www.ncbi.nlm.nih.gov/pmc/articles/PMC4471145/ >.

SPENCE, E. F. et al. The Arp2/3 Complex Is Essential for Distinct Stages of Spine Synapse Maturation, Including Synapse Unsilencing. The Journal of Neuroscience, v. 36, n. 37, p. 9696-9709, 2016.

SPENCE, E. F.; SODERLING, S. H. Actin Out: Regulation of the Synaptic Cytoskeleton. Journal of Biological Chemistry, v. 290, n. 48, p. 28613-28622, November 27, 20152015.2 Disponível em: < http://www.jbc.org/content/290/48/28613.abstract >.

SQUIRE, L. R. Memory and the hippocampus: a synthesis from findings with rats, monkeys, and humans. Psychol Rev, v. 99, n. 2, p. 195-231, Apr 1992. ISSN 0033-295X (Print)

0033-295X (Linking). Disponível em: < http://www.ncbi.nlm.nih.gov/pubmed/1594723 >. 
SQUIRE, L. R. Memory systems of the brain: a brief history and current perspective. Neurobiol Learn Mem, v. 82, n. 3, p. 171-7, 2004. ISSN 1074-7427. Disponível em: < http://dx.doi.org/10.1016/j.nlm.2004.06.005 >.

SQUIRE, L. R.; STARK, C. E. L.; CLARK, R. E. The medial temporal lobe. Annu Rev Neurosci, v. 27, p. 279-306, 2004. ISSN 0147-006X. Disponível em: < http://dx.doi.org/10.1146/annurev.neuro.27.070203.144130 >.

STEPAN, J.; DINE, J.; EDER, M. Functional optical probing of the hippocampal trisynaptic circuit in vitro: network dynamics, filter properties, and polysynaptic induction of CA1 LTP. Frontiers in Neuroscience, v. 9, p. 160, 05/06 01/15/received

04/19/accepted 2015. ISSN 1662-4548

1662-453X. Disponivel em: $<$ http://www.ncbi.nlm.nih.gov/pmc/articles/PMC4422028/ >.

STERNLICHT, $\mathrm{H}$. et al. The t-complex polypeptide 1 complex is a chaperonin for tubulin and actin in vivo. Proceedings of the National Academy of Sciences of the United States of America, v. 90, n. 20, p. 9422-9426, 1993. ISSN 0027-8424

1091-6490.

Disponível

em:

$<$ http://www.ncbi.nlm.nih.gov/pmc/articles/PMC47580/ >.

SUPEK, F. et al. REVIGO Summarizes and Visualizes Long Lists of Gene Ontology Terms. PLOS ONE, v. 6, n. 7, p. e21800, 2011. Disponível em: < http://dx.doi.org/10.1371\%2Fjournal.pone.0021800 >.

SUSUKI, K.; OTANI, Y.; RASBAND, M. N. Submembranous cytoskeletons stabilize nodes of Ranvier. Experimental Neurology, v. 283, Part B, p. 446-451, 9// 2016. ISSN 0014-4886. Disponível em: < http://www.sciencedirect.com/science/article/pii/S0014488615301254 >. 
SVANSTRÖM, A.; GRANTHAM, J. The molecular chaperone CCT modulates the activity of the actin filament severing and capping protein gelsolin in vitro. Cell Stress \& Chaperones, Dordrecht, v. 21, n. 1, p. 55-62, 09/12

07/06/received

08/26/revised

08/31/accepted 2016. ISSN 1355-8145

1466-1268.

Disponível

em:

$<$

http://www.ncbi.nlm.nih.gov/pmc/articles/PMC4679748/ >.

SWEATT, J. D. Neural plasticity and behavior - sixty years of conceptual advances. Journal of Neurochemistry, v. 139, p. 179-199, 2016. ISSN 14714159. Disponível em: < http://dx.doi.org/10.1111/jnc.13580 >.

SWIERGIEL, A. H.; ZHOU, Y.; DUNN, A. J. Effects of chronic footshock, restraint and corticotropin-releasing factor on freezing, ultrasonic vocalization and forced swim behavior in rats. Behav Brain Res, v. 183, n. 2, p. 178-87, Nov 2 2007. ISSN 0166-4328 (Print)

0166-4328 (Linking). Disponivel em: < http://www.ncbi.nlm.nih.gov/pubmed/17645963 >.

SZABÓ, E. C.; MANGUINHAS, R.; FONSECA, R. The interplay between neuronal activity and actin dynamics mimic the setting of an LTD synaptic tag. Scientific Reports, v. 6, p. 33685, 09/21

04/27/received

08/31/accepted 2016. ISSN 2045-2322. Disponível em: < http://www.ncbi.nlm.nih.gov/pmc/articles/PMC5030642/ >.

SZAPIRO, G. et al. The role of NMDA glutamate receptors, PKA, MAPK, and CAMKII in the hippocampus in extinction of conditioned fear. Hippocampus, v. 13, n. 1, p. 53-58, 2003. ISSN 1098-1063. Disponível em: < http://dx.doi.org/10.1002/hipo.10043 >.

TAKAHASHI, $H$. et al. Learning-stage-dependent, field-specific, map plasticity in the rat auditory cortex during appetitive operant conditioning. 
Neuroscience, v. 199 , n. 0, p. 243-258, 2011. ISSN 0306-4522. Disponível em: < http://www.sciencedirect.com/science/article/pii/S0306452211011316 >.

TAKEDA, K. Classical conditioned response in the honey bee. Journal of Insect Physiology, v. 6, n. 3, p. 168-179, 7// 1961. ISSN 0022-1910. Disponível em: < http://www.sciencedirect.com/science/article/pii/0022191061900609 >.

TEDJAKUMALA, S. R.; GIURFA, M. Rules and mechanisms of punishment learning in honey bees: the aversive conditioning of the sting extension response. The Journal of Experimental Biology, v. 216, n. 16, p. 29852997, 2013.

TRINH, M. A.; KLANN, E. Translational Control by elF2a Kinases in Longlasting Synaptic Plasticity and Long-term Memory. Neurobiology of learning and memory, v. 105, p. 93-99, 05/22 2013. ISSN 1074-7427

1095-9564. Disponível em: < http://www.ncbi.nlm.nih.gov/pmc/articles/PMC3769507/ >.

WALENSKY, L. D. et al. Neurobehavioral deficits in mice lacking the erythrocyte membrane cytoskeletal protein 4.1. Curr Biol, v. 8, 1998. Disponível em: < http://dx.doi.org/10.1016/S0960-9822(07)00536-2 >.

WANG, H.; HU, Y.; TSIEN, J. Z. Molecular and systems mechanisms of memory consolidation and storage. Prog Neurobiol, v. 79, n. 3, p. 123-35, Jun 2006. ISSN 0301-0082 (Print)

0301-0082 (Linking). Disponível em: < http://www.ncbi.nlm.nih.gov/pubmed/16891050 >.

WAYMAN, G. A. et al. Analysis of CaM-kinase signaling in cells. Cell calcium, v. 50, n. 1, p. 1-8, 2011. ISSN 0143-4160.

WEITZDORFER, R. et al. Changes of hippocampal signaling protein levels during postnatal brain development in the rat. Hippocampus, v. 18, n. 8, p. 807-13, 2008. ISSN 1098-1063 (Electronic) 
1050-9631 (Linking). Disponível em: < http://www.ncbi.nlm.nih.gov/pubmed/18493952 >.

WHITLOCK, J. R. et al. Learning Induces Long-Term Potentiation in the Hippocampus. Science, v. 313, n. 5790, p. 1093-1097, 2006.

WISNIEWSKI, J. et al. Universal sample preparation method for proteome analysis. Nat Methods, v. 6, p. 359 - 362, 2009.

WITHERS, G. S.; FAHRBACH, S. E.; ROBINSON, G. E. Selective neuroanatomical plasticity and division of labour in the honeybee. Nature, v. 364, n. 6434, p. 238-240, 07/15/print 1993 . Disponível em: < http://dx.doi.org/10.1038/364238a0 >.

WITTHÖFT, W. Absolute anzahl und verteilung der zellen im him der honigbiene. Zeitschrift für Morphologie der Tiere, v. 61, n. 1, p. 160-184, 1967. ISSN 1432-234X. Disponível em: < http://dx.doi.org/10.1007/BF00298776 >.

XIE, C. et al. KOBAS 2.0: a web server for annotation and identification of enriched pathways and diseases. Nucleic Acids Research, v. 39, n. suppl_2, p. W316-W322, 2011. ISSN 0305-1048. Disponível em: < http://dx.doi.org/10.1093/nar/gkr483 >.

YILMAZ, Ş. et al. A pipeline for differential proteomics in unsequenced species. Journal of Proteome Research, 2016/04/18 2016. ISSN 1535-3893. Disponível em: < http://dx.doi.org/10.1021/acs.jproteome.6b00140 >.

ZHANG, Y. et al. Protein Analysis by Shotgun/Bottom-up Proteomics. Chemical Reviews, v. 113, n. 4, p. 2343-2394, 2013/04/10 2013. ISSN 00092665. Disponível em: < http://dx.doi.org/10.1021/cr3003533 >. 